\title{
Pathological consequences of chronic olfactory inflammation on neurite morphology of olfactory bulb projection neurons
}

\section{Brandon Joseph LaFever}

Penn State College of Medicine https://orcid.org/0000-0002-8766-1260

\section{Yuka Imamura Kawasawa}

Penn State College of Medicine

Ayako Ito

Penn State College of Medicine

Fumiaki Imamura ( $\nabla$ fui1@psu.edu )

Penn State College of Medicine https://orcid.org/0000-0003-1410-3126

\section{Research}

Keywords: Chronic rhinosinusitis, chronic olfactory inflammation, olfactory system, projection neurons, neurite, lipopolysaccharide

Posted Date: November 22nd, 2021

DOI: https://doi.org/10.21203/rs.3.rs-1054067/v1

License: (c) (i) This work is licensed under a Creative Commons Attribution 4.0 International License. Read Full License

Version of Record: A version of this preprint was published at Brain, Behavior, \&amp; Immunity - Health on March 1st, 2022. See the published version at https://doi.org/10.1016/j.bbih.2022.100451. 


\section{TITLE PAGE}

2

3 Title

4 Pathological consequences of chronic olfactory inflammation on neurite morphology of olfactory

5 bulb projection neurons

6

7 Authors

8 Brandon J. LaFever, BS ${ }^{a}$, Yuka Imamura Kawasawa, $\mathrm{PhD}^{\mathrm{a}, \mathrm{b}, \mathrm{c}}$, Ayako Ito, $\mathrm{PhD}^{\mathrm{a}}$, and Fumiaki

9 Imamura, $\mathrm{PhD}^{\mathrm{a}}$

10

\section{Author affiliation}

12 aDepartment of Pharmacology, Penn State College of Medicine, 500 University Dr., Hershey,

13 Pennsylvania 17033, USA

14 bepartment of Biochemistry and Molecular Biology, Penn State College of Medicine, 500

15 University Dr., Hershey, Pennsylvania 17033, USA

16 'Institute for Personalized Medicine, Penn State College of Medicine, 500 University Dr., Hershey,

17 Pennsylvania 17033, USA

19 Corresponding Author

20 Fumiaki Imamura, PhD

21 Department of Pharmacology,

22 Penn State College of Medicine

23500 University Drive

24 Hershey, PA 17033, USA

25 Email: fui1@psu.edu

26 Tel: +1-717-531-5734

27 
Background: Chronic olfactory inflammation (COI) in conditions such as chronic rhinosinusitis significantly impairs the functional and anatomical components of the olfactory system. COI

32 induced by intranasal administration of lipopolysaccharide (LPS) results in atrophy, gliosis, and 33 pro-inflammatory cytokine production in the OB. Although chronic rhinosinusitis patients have 34 smaller olfactory bulbs (OBs), the consequences of olfactory inflammation on OB neurons are 35 largely unknown.

36 Methods: In this study, we investigated the neurological consequence of COI on OB projection 37 neurons, mitral cells (MCs) and tufted cells (TCs). To induce COI, we performed unilateral 38 intranasal administration of LPS to mice for 4 and 10 weeks. Effects of COI on the OB were examined using RNA-sequencing approaches and immunohistochemical analyses. Results: We found that repeated LPS administration upregulated immune-related biological pathways in the OB after 4 weeks. We also determined that the length of TC lateral dendrites in

42 the OB significantly decreased after 10 weeks of COI. The axon initial segment of TCs decreased 43 in number and in length after 10 weeks of COI. The lateral dendrites and axon initial segments of 44 MCs, however, were largely unaffected. In addition, dendritic arborization and axon initial segment 45 reconstruction both took place following a 10-week recovery period.

46 Conclusion: Our findings suggests that olfactory inflammation specifically affects TCs and their 47 integrated circuitry, whereas MCs are potentially protected from this condition. This data demonstrates unique characteristics of the OBs ability to undergo neuroplastic changes in response to stress. 


\section{KEY MESSAGES}

52 - Tufted cells undergo neurite dysregulation in response to chronic olfactory inflammation, 53 whereas mitral cells are largely unaffected.

54 - Tufted cells experience complete recovery from neurite dysregulation following a period 55 of ceased inflammation.

56

\section{KEY WORDS}

58 Chronic rhinosinusitis; chronic olfactory inflammation; olfactory system; projection neurons;

59 neurite; lipopolysaccharide

60 
Individuals are exposed to chemicals and environmental agents on a daily basis, some of which are capable of entering the body and inducing an immune response. Bacteria, viruses, and allergens such as dust, mold, or pollen are common agents that can enter the nasal cavity and induce inflammation of the olfactory mucosa, mucous membranes lining the olfactory epithelium $(\mathrm{OE})$, and the paranasal sinuses ${ }^{1,2}$. This inflammatory state is the foundation to the disease known as rhinosinusitis ${ }^{3}$. Rhinosinusitis is one of the most common medical conditions in the world ${ }^{4}$, currently affecting about $12.5 \%$ of individuals in the United States alone ${ }^{5}$. Symptoms of rhinosinusitis can include thick nasal mucus, stuffy nose and congestion, facial pain, headache, cough, fever, and hyposmia/anosmia ${ }^{6-8}$. Rhinosinusitis can be an acute or chronic disease ${ }^{9,10}$, yet when the condition lasts longer than 12 weeks it is considered chronic rhinosinusitis (CRS) and is typically due to a bacterial infection $4,8,11,12$.

Although immune responses are an essential first line of defense for the body against invading pathogens, chronic inflammation can act as a significant stressor on an organ or system and may result in damage of the affected tissue ${ }^{13-15}$. Although airflow obstruction within the nasal cavity has been linked to hyposmia, clinical studies have demonstrated that the immune response induced during CRS can severely damage the olfactory mucosa and olfactory epithelium, another major contributor to the loss of smell ${ }^{16-19}$. Patients with CRS also exhibit a decrease in the volumetric size of their olfactory bulbs $(\mathrm{OBs})^{20,21}$. Nonetheless, the extent to which the CRSinduced inflammatory responses affect the central nervous system (CNS) including the OB is currently not well understood.

Preclinical research using rodents has established that intranasal (i.n.) administration of various chemical entities can induce inflammation of the olfactory epithelium in the form of immune cell activation, infiltration, and pro-inflammatory cytokine release resulting in apoptosis of olfactory sensory neurons ${ }^{22-28}$. Our previous studies have also demonstrated that i.n. administration of lipopolysaccharide (LPS) has severe implications on the CNS including OB gliosis and atrophy ${ }^{23}$, 29, 30. More specifically, beginning as early as 3 weeks of i.n. LPS administrations, a significant upregulation of microglial and astrocytic activity as well as the presence of pro-inflammatory cytokines can be detected in the superficial OB layers including the olfactory nerve layer (ONL), glomerular layer (GL), and the superficial external plexiform layer (sEPL). Interestingly, after 10 
95 in which the layers are significantly thinner than in controls ${ }^{29}, 30$. In this study, and in conjunction

96 with our previous studies, we administered LPS into the mouse nostril repetitively over the course

97 of 4 and 10 weeks to induce a state of chronic inflammation of the olfactory epithelium (or chronic

98 olfactory inflammation, $\mathrm{COI}$ ). We report that $\mathrm{COI}$ induces a decrease in the activity of projection

99 neurons residing in the EPL (tufted cells, TCs), as well as dendritic retraction and axonal instability

100 of the same neurons. Mitral cells (MCs) residing in the mitral cell layer (MCL), however, appear

101 to be almost entirely unaffected. Finally, we report that the COI-induced TC impairments return to

102 homeostasis following a recovery period. These results provide further evidence that the OB

103 consists of highly plastic components capable of undergoing severe stress.

104 


\section{METHODS}

\section{Animals}

In this study, we used eight-week-old C57BL/6J (stock \#000664) and YFP knockin (stock \#006148; C57BL/6J background) mice purchased from The Jackson Laboratory, as well as Pcdh21-CreER knockin (BRC \#RBRC02410; C57BL/6J background) mice purchased from Riken BRC. Pcdh21-CreER x YFP mice were created by crossing Pcdh21-CreER-positive mice with YFP homozygotes to create Cre-positive/YFP heterozygotes (+/Het mice; this was the only genotype used for this mouse line in this study). Among the $+/$ Het mice, a yellow fluorescent protein (YFP) is specifically expressed in MC/TCs in the OBs following tamoxifen injections. All mice were deeply anesthetized with isoflurane and intranasally administered $10 \mu \mathrm{L}$ of LPS from Escherichia coli (Sigma; product \#L2880; lot \#025M4040V) in physiologic saline $(1 \mathrm{mg} / \mathrm{ml}$; Sigma). LPS administrations took place three times per week for 4 or 10 weeks and were carried out unilaterally to the left naris of each mouse, with the right side serving as an internal control. For analyses of recovery, one group of eight-week-old $+/$ Het mice $(n=3)$ underwent unilateral 10week LPS administrations as discussed previously $23,29,30$ and were subsequently housed for 10 weeks with no additional treatment.

Three days prior to being sacrificed for immunohistochemical analyses, mice were intraperitoneally injected with tamoxifen $(30 \mathrm{mg} / \mathrm{kg})$. The dose for tamoxifen was selected after multiple trials at different doses in order to observe optimal YFP expression in fewer OB projection neurons allowing us to trace individual neuron apical and lateral dendrites (data not shown). For histologic preparation, mice were anesthetized with ketamine $(100 \mathrm{mg} / \mathrm{kg})$ and xylazine (10 $\mathrm{mg} / \mathrm{kg}$ ) and transcardially perfused with PBS, followed by $4 \%$ (wt/vol) paraformaldehyde in PBS. Heads were removed and placed in the same fixative at $4^{\circ} \mathrm{C}$ overnight. The rostral half of the calvaria (anterior to the bregma) and the nasal bone were then placed in $0.45 \mathrm{~mol} / \mathrm{L}$ EDTA in PBS at $4^{\circ} \mathrm{C}$ for 2 days for decalcification, cryoprotected with $30 \%$ sucrose (wt/vol) at $4^{\circ} \mathrm{C}$ overnight, embedded in OCT compound (Sakura Finetek USA, Torrance, Calif), and maintained at $-80^{\circ} \mathrm{C}$ until use. All protocols were approved by and all methods were performed in accordance with the guidelines of the Institutional Animal Care and Use Committee of Penn State College of Medicine.

\section{RNA sequencing analysis}

RNA Extraction: OBs were microdissected from fixed and cryopreserved whole mouse brains. Approximately $5 \mathrm{mg}$ of frozen tissue was incubated with proteinase $\mathrm{K}(500 \mu \mathrm{g} / \mathrm{ml})$ in $500 \mu \mathrm{l}$ of 10 
$\mathrm{mM} \mathrm{NaCl}, 500 \mathrm{mM}$ Tris (pH 8.0), $20 \mathrm{mM}$ EDTA, and 1\% SDS at $55^{\circ} \mathrm{C}$ for 3 hours until the tissue was completely dissolved ${ }^{31}$. The acid phenol-chloroform method was applied for RNA extraction using the Direct-zol ${ }^{\mathrm{TM}}$ RNA Micro prep Kit (Zymo Research). RNA quality and quantity were determined by RNA Pico BioAnalyzer (Agilent technologies). RNA-sequencing and Analysis: The cDNA libraries were prepared using the QuantSeq 3'mRNASeq Library Prep Kit FWD for Illumina (Lexogen) as per the manufacturer's instructions. Briefly, total RNA was reverse transcribed using oligo (dT) primers. The second cDNA strand was synthesized by random priming, in which DNA polymerase is efficiently stopped when reaching the next hybridized random primer allowing only the fragment closest to the 3' end being captured for later indexed adapter ligation and PCR amplification. The processed libraries were assessed for their size distribution and concentration using the BioAnalyzer High Sensitivity DNA Kit (Agilent Technologies). The libraries were pooled and diluted to $3 \mathrm{nM}$ using $10 \mathrm{mM} \mathrm{Tris-HCl}, \mathrm{pH} 8.5$, and then denatured using the Illumina protocol. The denatured libraries were loaded onto an S1 flow cell on an Illumina NovaSeq 6000 (Illumina) and run for 53-101 cycles according to the manufacturer's instructions. After the quality and polyA trimming by BBDuk and alignment by HISAT2 (version 2.1.0) ${ }^{32}$, read counts were calculated using HTSeq ${ }^{33}$ by supplementing Ensembl gene annotation (GRCm38.78). DESeq2 $R$ package ${ }^{34}$ was used to determine differentially expressed genes by taking into account a paired design where each mouse individual was compared between ipsilateral and contralateral. Significance was defined to be those with adjusted $p$-value < 0.1 calculated by the Benjamini-Hochberg method to control the false discovery rate (FDR). The ggplot2 $\mathrm{R}$ package ${ }^{35}$ was used for generating a heatmap. The list of differentially expressed genes was analyzed with Ingenuity Pathway Analysis (IPA). Fastq files and raw read counts generated during this study are available at GEO (GSE185945).

\section{Immunostaining}

Olfactory tissues were coronally cut on a cryostat into $20 \mu \mathrm{m}$ slices, mounted on slide glasses, dried and stored at $-80^{\circ} \mathrm{C}$ until use. The sections were rehydrated with TBST $(10 \mathrm{mmol} / \mathrm{L}$ Tris$\mathrm{HCl}[\mathrm{pH} 7.4]$ and $100 \mathrm{mmol} / \mathrm{L} \mathrm{NaCl}$ with $0.3 \%$ Triton-X100 [vol/vol]), blocked with blocking buffer (5\% normal donkey serum [vol/vol] in TBST) at room temperature for one hour, and incubated with primary antibodies diluted in blocking buffer overnight at $4^{\circ} \mathrm{C}$. The antibodies and dilutions used in the present study are as follows: mouse anti-Ankyrin G IgG2a (NeuroMab, catalog \#75146, 1:500), chicken anti-green fluorescent protein (GFP; Abcam, catalog \#ab13970, 1:1000) which also recognizes YFP, mouse anti-Calretinin (NeuroMarkers, catalog \#MA5-14540, 1:400), Alexa Fluoro 488 mouse anti-Tbx21 (Biolegend, catalog \#644830, 1:300), rabbit anti-Phospho- 
S6 Ribosomal Protein (PS6; Cell Signaling Technology, catalog \#4854S, 1:1000), rabbit antiParvalbumin (Millipore Sigma, catalog \#MAB1572, 1:300), and rabbit anti-Somatostatin (ImmunoStar, catalog \#20067, 1:300). For double immunostaining with fluorescence, Alexa Fluoro 488-conjugated or 555-conjugated donkey antispecies IgGs (Thermo Fisher Scientific) were used as secondary antibodies (1:300) and incubated on tissue sections at room temperature for one hour. Nuclei were counterstained with 4',6-diamidino-2-phenylindole (DAPI). The sections were coverslipped with fluorescence mounting medium (Dako Agilent) and imaged using the Zeiss Axio Imager M2 fluorescent microscope with an automated motorized XY stage. All images were acquired using the same excitation light intensity, exposure time, and numerical aperture of the objective lens.

\section{Image analyses and morphometry}

Five OB sections were stained from each mouse brain with calretinin and DAPI and divided into each OB sublayer (including the superficial and deep EPL) to measure their area. Cells that were positive for DAPI, Tbx21, and YFP in the MCL and EPL were defined as MCs and TCs, respectively, and were subsequently counted to determine the numbers in their respective layers. The area of the superficial and deep (s/d)EPL were measured separately by using Photoshop software. The lengths of YFP-positive (YFP+) dendrites were measured in the SEPL and dEPL separately by manual tracing in the FIJI/Image J software using the ROI Manager tool with the freehand line tracer. The primary method of normalizing the dendrite data was to divide the total length of dendrites per $\mathrm{OB}$ (in $\mu \mathrm{m}$ ) by the number of YFP+ somata in that $\mathrm{OB}$ (final units in $\mu \mathrm{m} / \mathrm{cell})$. Similarly, we also normalized this data with respect to dendrite density by converting the sEPL and dEPL areas to square millimeters $\left(\mathrm{mm}^{2}\right)$ and divided the total length of dendrites (in $\mu \mathrm{m}$ ) in each layer of each $\mathrm{OB}$ section by the respective area in $\mathrm{mm}^{2}$ (resulting units of $\mu \mathrm{m} / \mathrm{mm}^{2}$ ). Axon initial segments (AISes) were measured in a region defined by a rectangle with an area of $650 \times 450 \mu \mathrm{m}^{2}$ in both the medial and lateral portion of the OB. AlSes were defined by positive Ankyrin G staining and all AISes in the region were counted and measured in length $(\mu \mathrm{m})$, and were analyzed via manual tracing in the FIJI/ImageJ software using the ROI Manager tool with the freehand line tracer.

\section{Experimental design and statistical analysis}

Comparisons of the relative OB sizes and AIS length/count among contralateral and ipsilateral OBs were statistically analyzed by one-way analysis of variance followed by Tukey's HSD posthoc tests for multiple comparisons. Comparisons of dendrite length among contralateral and 
207 ipsilateral OBs were statistically analyzed by paired t-tests due to differences in inherent cre208 recombination and subsequent expression of YFP. A p-value $\leq 0.05$ indicated a significant 209 difference. Statistical analyses were performed using Prism software (GraphPad Software, Inc.). 210 Values are reported as means \pm SEM.

211 


\section{RESULTS}

\section{Upregulation of interferon-y-driven inflammatory pathways following 4-week COI}

We first aimed to examine gene expression signatures affected by early stage COI. To induce COI, LPS administrations took place three times per week for 4 weeks and were carried out unilaterally to the left naris of each mouse, with the right side serving as an internal control. The OB ipsilateral to the side of the injected naris is referred to as ipsilateral (ipsi), and the opposite OB (control) as contralateral (contra). Differential gene expression analysis was performed between the ipsilateral and contralateral OB from mice administered LPS $(n=3)$. We identified 47 genes upregulated and 18 downregulated in the ipsilateral OBs compared to contralateral OBs (Fig. 1A). To understand the functional relevance of these clusters, we performed functional annotation analysis for these genes using Ingenuity Pathway Analysis (IPA, Qiagen). The Core Analysis highlighted the most significantly enriched and activated Canonical Pathway as "Neuroinflammation Signaling Pathway" $(-\log (p-v a l u e)=5.95, z$-score $=2.646$, Fig. 1B). Molecules directly involved in this pathway include B2M, CCL5, CYBB, HLA-A, HLA-DQA1, HLADQB1, HLA-DRB5, and RAC2.

Next, we examined the upstream regulator in the IPA Core Analysis and identified interferon- $Y$ $($ IFN-Y) as the most significant upstream regulator with the largest z-score (p-value $=5.04 \mathrm{E}-20$, $z$-score $=4.749$, Supplementary Table 1$)$. Although the expression level of IFN-Y itself is not altered, the significant number of related downstream molecules including B2M, Bst2, C1QA, C1QB, C4A/C4B, CCL5, CD74, CTSS, Cxc19, CYBB, GBP2, GFAP, HLA-A, HLA-DQA1, HLADQB1, HLA-DRB5, Ifi47, IFITM3, Igtp, ligp1, IRF1, IRF8, LGALS3BP, PARP14, PENK, RAC2, TAP1, and TAPBP are upregulated. The Mechanistic Network (Fig. 1C), a method to predict signaling cascades that connect other significantly represented upstream regulators to elicit the observed gene expression changes, demonstrated that IFN- $\gamma$ may orchestrate with other cytokines such as TNF- $\alpha$ and $\mathrm{IL}-1 \beta$ and regulate cascades of intracellular signaling to lead to activations of multiple transcription regulators such as IRF1, NF-kB complex, CREBBP, RELA, IRF8, STAT1, and STAT3. NR3C1, on the other hand, is downregulated and its inhibition is predicted to be mediated by TNF- $\alpha$.

Finally, we summarize our findings by IPA's Graphical Summary (Fig. 1D) to provide an overview of the major biological themes in the IPA analysis by selecting the most significant entities identified in the Core Analysis such as Canonical Pathways, Upstream Regulators, and Disease 
and Biological Functions, further representing how they relate to each other. The Graphical

247 Summary demonstrates how upregulated/activated (shown in orange) and

248 downregulated/inhibited (shown in blue) genes, pathways, or diseases interact with each other.

249 In addition to the activation of Neuroinflammation Signaling Pathway observed in the Canonical

250 Pathway analysis (Fig. 1B) and IFN-Y which was depicted in the Upstream Regulator analysis

251 (Fig. 1C), we revealed that many pathways associated with immune responses and leukocyte

252 activities are activated, while infectious status is predicted to be inhibited.

\section{Reduction of tufted cell lateral dendrites following 10 -week COI}

255 The presence of proinflammatory cytokines such as IFN- $\gamma$ and TNF- $\alpha$ are capable of causing dendritic atrophy, retraction, and loss of synapses in primary neuronal cultures ${ }^{36}$. It is important to note that LPS-induced COI does not cause the death of OB projection neurons (MCs/TCs) at any point up to the 24 -week time point ${ }^{23}, 29,30$. Therefore, we aimed to explore the potential phenomenon of dendritic retraction of MC/TCs following our COI paradigm.

The distribution of projection neuron somata and lateral dendrites is unique based on cell type. TC somata are located in the EPL and extend their lateral dendrites throughout the SEPL, whereas $\mathrm{MC}$ somata exist in the MCL and extend their lateral dendrites in the $\mathrm{dEPL}^{37}$. In order to observe changes to the somata and dendritic morphology of MCs/TCs in the OB, we used Pcdh21-CreER $x$ YFP (+/Het) transgenic mice unilaterally administered with LPS (i.n.) for 10 weeks. Protocadherin-21 (Pcdh21) is a member of the protocadherin homophilic cell-adhesion protein family uniquely expressed in MCs/TCs in the mouse $\mathrm{OB}^{38}$. On the final LPS-administration day, the mice were treated with tamoxifen (i.p., $30 \mathrm{mg} / \mathrm{kg}$ ) to activate CreER for the YFP expression from the ROSA site and sacrificed 3 days after the injection.

As expected, the overall shape of the ipsilateral $O B$ appears to be atrophied and narrower compared to the contralateral OB (Fig. 2A). Cell bodies and dendrites expressing YFP were observed in the GL, EPL, and MCL of both OBs (Fig. 2B, C). There were no differences in the total number of TCs, YFP+ cells in the EPL, counted from 5 coronal OB sections (contra., 72.00 \pm 17.58 vs ipsi., $72.67 \pm 21.39$ ). The number of MCs, YFP+ cells in the MCL, was smaller than that of TCs but not significantly different comparing the contralateral to the ipsilateral OBs (contra., $23.67 \pm 12.86$ vs ipsi., $29.00 \pm 16.92$ ). This data suggests that the +/Het transgenic model preferentially labels TCs over MCs in the OB, and LPS treatment does not influence the expression of YFP in OB projection neurons. 
Next, we analyzed the YFP+ dendrites in the EPL. In the contralateral OB, the total length of

282 YFP+ dendrites counted from 5 coronal sections was significantly greater in the sEPL than in the 283 dEPL (Fig. 2B; $15217 \pm 1332 \mu \mathrm{m}$ vs $7421 \pm 1905 \mu \mathrm{m}$, respectively; $\mathrm{p}=0.0014$ ). However, the 284 length of YFP+ dendrites in the ipsilateral OB was not statistically different between sEPL and 285 dEPL (Fig. $2 C ; 10095 \pm 1470 \mu \mathrm{m}$ vs $7327 \pm 1588 \mu \mathrm{m}$, respectively; $p=0.2210$ ). The total length of 286 YFP+ dendrites in the SEPL was significantly reduced in the ipsilateral OB compared to that of 287 contralateral OBs $(p=0.0178)$. However, the densities of YFP+ dendrites were not significantly 288 different in the $\operatorname{sEPL}(p=0.7458)$ nor in the dEPL $(p=0.9751)$ between contralateral and ipsilateral 289 OBs, which is consistent with the area reduction of the sEPL but not dEPL in the ipsilateral OB ${ }^{29}$, 29030.

291

In order to normalize the effects of $\mathrm{COI}$ on the dendrites of MCs and TCs, we calculated ratios of YFP+ dendrites (length in $\mu \mathrm{m})$ to YFP+ cell bodies measured in each OB ( $\mu \mathrm{m} / \mathrm{cell})$. This allows us to normalize for variability in our data that may exist due to animal differences in CreER expression. Upon analysis, we observed a significant reduction of dendrites in the sEPL (Fig. 2D; contra., $223.1 \pm 74.70 \mu \mathrm{m} /$ cell vs ipsi., $152.4 \pm 69.77 \mu \mathrm{m} /$ cell; $\mathrm{p}=0.0073$ ). However, we did not observe any changes to dendrite density in the dEPL (Fig. 2E; contra., $382.5 \pm 190.6 \mu \mathrm{m} /$ cell vs ipsi., $345.2 \pm 244.4 \mu \mathrm{m} /$ cell; $p=0.3594$ ). These results suggest that the overall length of $\mathrm{TC}$, but not $\mathrm{MC}$, dendrites has been reduced.

\section{Alterations in the axon initial segment of tufted cells following 10 -week $\mathrm{COI}$}

Our findings of decreased TC dendrites have led us to believe that there may be further physiological impairments to TCs following COI. The AIS is the site of a neuron that separates its somatodendritic and axonal compartments, and is primarily responsible for maintaining the neuron's polarity and initiating action potentials ${ }^{39}$. One of the most essential components of the AIS is the cytoskeletal-associated protein, Ankyrin-G (AnkG) ${ }^{40}$. Previous studies have shown that shorter or fewer AISes measured by AnkG are indicative of impairments to the neurons physiology, such as a decrease in excitability ${ }^{39,41,42}$. We first co-stained OB sections with AnkG and Tbx21, an OB projection neuron-specific marker, and confirmed that the vast majority of AnkG+ AISes present in the EPL and MCL are derived from TCs and MCs, respectively

311 (Supplementary Fig. 1). 
We, then, measured the length of each individual AIS, as well as the number in each OB. Since our previous studies primarily investigated the response of LPS-treatment on the medial and lateral OBs, we chose to focus on these regions as well. Through this analysis, we observed a significant reduction in the number of AISes in the ipsilateral OB EPL (Fig. 3A, B). Our data demonstrated that fewer AISes were present in the lateral EPL of the ipsilateral OB (Fig. 3B2). The number of AlSes in the lateral OB EPL decreased from $165.6 \pm 47.45$ AlSes in the contralateral $\mathrm{OB}$ to $94.20 \pm 29.24$ in the ipsilateral $\mathrm{OB}$ (Fig. 3F histogram; $\mathrm{p}=0.0175$ ). This phenomenon, however, was not found in the medial OB EPL (Fig. 3E histogram; contra., $165.4 \pm$ 26.47 vs ipsi., $130.8 \pm 24.81 ; p=0.3829$ ). For both $O B s$, there were no differences in the number of MCL AISes counted, regardless of laterality (Fig. 3C, D histograms; medial contra., $119.2 \pm$ 12.76; lateral contra., $122.6 \pm 23.09$; medial ipsi., $120.2 \pm 16.25$; lateral ipsi., $120.6 \pm 24.17$ ).

We further analyzed the length of the AISes that were present in each OB. Since TCs reside solely in the EPL and MCs in the MCL, we have classified the AISes measured in the EPL as belonging primarily to TCs and AISes in the MCL as those of MCs. It was determined that the TC AISes in the lateral OB significantly decreased in their length (Fig. 3F; contra., $12.05 \pm 1.079 \mu \mathrm{m}$ vs ipsi., $9.399 \pm 1.100 \mu \mathrm{m} ; \mathrm{p}=0.0009$ ). This phenomenon was not found for the TC AISes in the medial OB (Fig. 3E; contra., $14.84 \pm 0.6815 \mu \mathrm{m}$ vs ipsi., $13.58 \pm 0.3369 \mu \mathrm{m} ; \mathrm{p}=0.1370$ ). Although there was no change in the number of MC AISes in the medial OB, it did appear that the AISes present in the medial region of the OB significantly decreased in length (Fig. 3C; contra., $21.88 \pm$ $4.978 \mu \mathrm{m}$ vs ipsi., $19.49 \pm 4.964 \mu \mathrm{m} ; \mathrm{p}=0.0006$ ). However, the length of MC AISes in the lateral OB did not appear to shorten (Fig. 3D; contra., $15.84 \pm 0.7814 \mu \mathrm{m}$ vs ipsi., $16.29 \pm 0.8635 \mu \mathrm{m}$; $p=0.7684$ ). Collectively, these results suggest that $\mathrm{COI}$ has the most significant effect on TCs morphologically and physiologically in the lateral OB.

\section{Reduction in tufted cell activity following 10-week COI}

To examine the alterations in cellular activity of the OB projection neuros, we stained OBs with an antibody against phoso-S6 ribosomal protein (pS6), one of neuronal activity markers ${ }^{43}$. A recent study demonstrated that pS6 is an exceptional activity marker for OB projection neurons, and that naris occlusion is capable of significantly reducing the expression of pS6 among projection neurons on the ipsilateral $\mathrm{OB}^{41}$. It is also worth noting that the vast majority of pS6expressing projection neuron somata were double-positive for Tbx21 (Supplementary Fig. 2). Upon immunohistochemical analysis of mice that underwent the 10-week unilateral $\mathrm{COI}$ paradigm, we observed robust pS6 staining throughout the entire MCL and EPL of the 
contralateral OB (Fig. 4). In contrast, we observed fewer pS6-positive projection neuron somata throughout the EPL in the ipsilateral $\mathrm{OB}$. The $\mathrm{MCL}$, however, did not appear to have any reduction in pS6 signal (Fig. 4B, C). These findings further suggest that functional impairments may be occurring to TCs rather than MCs throughout the ipsilateral OB.

\section{No apparent loss of OB interneurons following 10-week COI}

Olfactory information is not only processed by $O B$ projection neurons, but requires substantial communication with a variety of $\mathrm{OB}$ interneurons. Based on their location in the $\mathrm{OB}$, interneurons play a major role in fine-tuning of olfactory information before it even reaches the cortex. OB interneurons can also be further differentiated by their immunoreactivity ${ }^{37}$. For example, the parvalbumin-positive $(\mathrm{PV}+)$ and somatostatin-positive (SST+) interneurons are found in the EPL and are distributed primarily throughout the SEPL and $\mathrm{dEPL}$, respectively ${ }^{37,44-46}$. Here, we investigated whether the effects of $\mathrm{COI}$ on TCs would extend to interneurons residing throughout the sEPL and dEPL. Figure 5 shows PV+ and SST+ interneurons in the sEPL and dEPL of the contralateral and ipsilateral OBs following the 10-week $\mathrm{CO}$ paradigm. To quantify the effects of $\mathrm{COI}$ on these interneurons, we counted the numbers from 5 coronal sections ( $n=5$ mice). Consistent with previous literature, there were more PV+ interneurons in the SEPL than in the $\mathrm{dEPL}$ of the contralateral $\mathrm{OB}(333.0 \pm 29.04 \text { vs } 256.0 \pm 30.55 \text {, respectively; } \mathrm{p}=0.0037)^{40}$. However, the number of PV+ interneurons in each EPL sublayer of the ipsilateral $O B$ was not significantly different from that of the contralateral OB (Fig. 5A, B; sEPL: contra., $333.0 \pm 29.04$ vs ipsi., $298.8 \pm 33.91$, p=0.2874; dEPL: contra., $274.0 \pm 22.15$ vs ipsi., $256.0 \pm 30.55$, p=0.7660). Similarly, as SST+ interneurons are not present in the SEPL ${ }^{47}$, we counted only from the dEPL. No differences were observed in the number of SST+ interneurons following 10-week COI (Fig. 5C, D; contra., $167.4 \pm 16.83$ vs ipsi., $169.4 \pm 12.64$; $p=0.3859$ ). Collectively, this data suggests that there is no change in the number of $\mathrm{PV}+$ or SST+ interneurons in the OB following the 10week COI paradigm.

\section{Remodeling of tufted cell lateral dendrites after recovery period following 10 -week $\mathrm{COI}$}

Our previous studies demonstrated that a 10-week period of no LPS treatment following the 10week $\mathrm{CO}$ paradigm resulted in a recovery of the $\mathrm{OB}$ atrophy and depletion of inflammatory responses ${ }^{30}$. Therefore, we sought to investigate if the recovery phenomenon would extend to the OB on a cellular level. For this experiment, we used male $+/$ Het mice $(n=3)$ treated with LPS for 10 weeks followed by a 10 -week recover period of no treatment. We first investigated if TC lateral dendrites recover from their reduction caused by $\mathrm{COI}$. 
382 Consistent with our previous studies, the overall shape of the ipsilateral OB appears to undergo 383 a complete recovery ${ }^{29,30}$. We counted the total number of YFP+ cells in the EPL of the 384 contralateral and ipsilateral OBs and observed more YFP+ TC soma in the ipsilateral OB 385 compared to the contralateral (contra., $64.00 \pm 15.52$ vs ipsi., $79.00 \pm 14.42 ; p=0.0131$ ). The 386 number of YFP+ MCs, however, was not significantly different (contra., $16.00 \pm 6.083$ vs ipsi., $38717.33 \pm 1.528 ; p=0.6667$ ). To compensate the difference in the numbers of labeled YFP+ cells, 388 the total number of YFP+ dendrites in the SEPL and dEPL were divided by the total number of 389 YFP+ TCs and MCs, respectively. Surprisingly, even after this normalization, we still observed a 390 slightly significant increase of dendrites in the ipsilateral sEPL compared to contralateral (Fig. 6D; 391 contra., $202.1 \pm 41.38 \mu \mathrm{m} /$ cell vs ipsi., $222.8 \pm 37.70 \mu \mathrm{m} /$ cell; $p=0.0357$ ). We did not observe any 392 changes to dendrite length in the dEPL (Fig. 6E; contra., $294.0 \pm 88.64 \mu \mathrm{m} /$ cell vs ipsi., $340.6 \pm$ $393101.2 \mu \mathrm{m} / \mathrm{cell} ; \mathrm{p}=0.1139)$. Thus, our results suggest that the overall length of TC dendrites has 394 not only recovered, but the TCs may have more dendrites in the ipsilateral OB following the 10395 week recovery period.

Stabilization of tufted cell activity and axon initial segment integrity after recovery period following 10-week COI

Lastly, we investigated the effect of a recovery period on the integrity of the AIS of MCs and TCs following COI. We performed the same analysis as previously stated, and observed no significant differences between the ipsilateral and contralateral OBs in either the length or number of AISes for both MCs and TCs (Fig. 7). These results indicate that no apparent "over-recovery" phenomenon occurs with respect to TC AIS integrity. Combined with our previous findings, these results suggest that the TC AISes in the lateral OB that are damaged following COI are capable of returning back to appropriate lengths, essentially re-stabilizing, allowing for a restoration in the transfer of OB information. Consistent with this observation, there was no apparent reduction of the pS6 expression in the EPL of the ipsilateral OB in mice who underwent the 10-week COI paradigm followed by a 10-week recovery period of no treatment (Fig. 8). These results suggest that a functional recovery of TCs occurs after a sufficient period without exposure to LPS. 
In this study, we found that COI induced by i.n. administration of LPS causes dendritic retraction and axonal instability of TCs, but not MCs, in the mouse OB. The superficial OB layers (GL, ONL, SEPL) are the primary region of $\mathrm{OB}$ atrophy and inflammation at 10 weeks of LPS administrations ${ }^{29,30}$. Our results suggest that the reduction of dendrites that was observed in the ipsilateral $\mathrm{OB}$ is primarily attributed to a reduction in the SEPL. Similarly, the shortening and loss of AISes takes place primarily in the lateral EPL of the ipsilateral OB, a region that has been proven to be most susceptible to $\mathrm{COI}$ at this time point.

The signaling cascades downstream of proinflammatory cytokines such as IFN- $\gamma$ and TNF- $\alpha$ has been demonstrated to occur in the OB as early as at 4 weeks of i.n. LPS administrations. These cytokines are capable of inducing the retraction of neuronal dendrites and synaptic degradation in primary neuronal cultures ${ }^{36}$. We anticipate that a similar phenomenon is taking place in our current paradigm in which the presence of proinflammatory cytokines and activated glial cells among the superficial $O B$ layers induce neuronal stress and subsequent structural dysregulation. Our previous study, however, demonstrated that cessation of $\mathrm{COI}$ results in a reduction of immune responses in the $\mathrm{OB}$. This suggests that anti-inflammatory mechanisms may take place following the absence of persistent inflammation. Microglia and astrocytes are well established to engage in both pro- and anti-inflammatory activities ${ }^{48-50}$. Our research thus far has established that signaling cascades activated by cytokines such as TNF- $\alpha$, IFN- $\gamma$, IL-1 $1 \beta$, and IL-10 are significantly

432 upregulated in the OB following COI. Although the former three are pro-inflammatory, IL-10 is an 433 anti-inflammatory cytokine released by astrocytes which may act to maintain (or restore) neuronal 434 homeostasis ${ }^{51,52}$. The release of IL-10 and other neuroprotective agents may be a necessary step 435 in evading, or recovering from, potential TC degeneration. Similarly, astrocytes and microglia are 436 capable of mediating and amplifying axonal and dendrite growth through mechanisms including 437 the release of fibroblast growth factor and purinergic signaling, respectively ${ }^{53-56}$. The present study 438 demonstrating a recovery effect of the observed TC dendritic retraction may be attributed to 439 similar neuroprotective mechanisms via glial cell activity.

441 Our findings of reduced TC AIS number and length is highly suggestive of functional impairments 442 to TC-integrated neural circuits. AISes are responsible for action potential initiation and 443 maintenance of neuronal polarity ${ }^{39,57}$. The actual assembly of the AIS is coordinated primarily by 444 AnkG, a cytoskeletal-associated protein ${ }^{40,58}$. It remains unknown whether the mechanisms of AIS 
445

446

447

448

449

450

451

452

453

454

455

456

457

458

459

460

461

462

463

464

465

466

467

468

469

470

471

472

473

474

475

476

477

maintenance and AIS assembly (or reassembly) as controlled by AnkG are related ${ }^{59}$. However, we speculate that the ability of TCs to reconstruct their AISes in the recovery period following COI is possibly also coordinated by AnkG-mediated mechanisms. Nonetheless, dysfunctional AISes induced by diminished AnkG integrity will likely contribute to a decrease in excitability and signal transmission to a neuron's downstream targets ${ }^{60}$. It is also interesting to note that AnkG is necessary to maintain the structural and functional segregation of a neurons axon from its dendrites ${ }^{61}$. These implications suggest a potential biological connection between axon destabilization and dendritic retraction in our COI paradigm.

All of our sensory systems are comprised of first-, second-, and third-order neurons which uniquely relay sensory information to the CNS at each level. Therefore, it is plausible to assert that damage to the neural components at any of these levels will impair sensory processing in the CNS. Multiple clinical studies reported cortical atrophy and altered brain activity in response to spinal cord injury ${ }^{62-64}$. Similarly, clinical studies investigating the role of diabetic retinopathy on CNS have found remapping and impairments of the primary visual cortex following disease onset ${ }^{65-67}$. This phenomenon, however, has yet to be thoroughly investigated with respect to the olfactory system. COI causes ablation to the first-order neurons of the olfactory system, olfactory sensory neurons, which can occur after only one day of i.n. LPS administration ${ }^{23}$, and this phenotype will persist for the duration of $\mathrm{CO}$. Our current findings which model $\mathrm{CRS}$ suggest that olfactory information processing and transmission at the level of the second-order neurons (specifically, TCs) may be disrupted due to structural and functional pathophysiology. While the olfactory second-order neurons (MCs/TCs) share a multitude of features, they differ in two distinct ways, anatomically; (1) somata location within the $\mathrm{OB}$, and (2) neurite projection patterns. MCs project their axons to most structures within the olfactory cortex $(\mathrm{OC})$, whereas TC axons are more localized to targets including the anterior olfactory nucleus, olfactory tubercle, and anterior piriform cortex ${ }^{68-71}$. When drawing comparisons to other sensory systems, this information leads us to speculate that the differences in axonal projection patterns of MCs and TCs may also be a component of the olfactory system impacted by the pathophysiological nature of COI. More specifically, the third-order neurons of the olfactory system residing in the TC-targeted OC regions may also be impacted by $\mathrm{COI}$ in the form of cortical atrophy or even immune responses. Further studies are needed to address whether these OC regions are also susceptible to the neuropathological effects of $\mathrm{COI}$. 


\section{CONCLUSIONS}

In conclusion, the findings presented in this report demonstrate that TCs undergo significant neurite dysregulation following $\mathrm{COI}$ primarily in the forms of lateral dendrite retraction and AIS shortening, whereas MCs, as well as PV+ and SST+ interneurons, are largely unaffected. Our study also suggests that the mechanisms underlying neurite dysregulation are induced through common pathways involving the pro-inflammatory cytokine, IFN-y. Furthermore, the pathological responses of TCs to COI was shown to recover following a period without olfactory inflammation. In summary, this study provides a strong foundation for investigating the cellular and molecular mechanisms responsible for regulating the reversible changes occurring in TC-integrated $\mathrm{OB}$ neural circuits. Overall, we have revealed some of the major consequences of inflammation on the homeostatic functioning of olfactory bulb projection neurons, as well as unveiled a novel pathway of neuroinflammation from the periphery to the CNS. Developing a deeper understanding of the biological mechanisms underlying CRS and the consequences of inflammation-induced hyposmia is a vital next step to the overarching goal of enhancing human health.

\section{ABBREVIATIONS}

AIS: axon initial segment; AnkG: Ankyrin G; CNS: central nervous system; COI: chronic olfactory inflammation; CRS: chronic rhinosinusitis; dEPL: deep external plexiform layer; EPL: external plexiform layer; GL: glomerular layer; i.n.: intranasal; IFN-ү: interferon-ү; LPS: lipopolysaccharide; MC: mitral cell; MCL: mitral cell layer; OB: olfactory bulb; OC: olfactory cortex; OE: olfactory epithelium; ONL: olfactory nerve layer; Pcdh21: protocadherin-21; pS6: phoso-S6 ribosomal protein; PV: parvalbumin; sEPL: superficial external plexiform layer; SST: somatostatin; TC: tufted cell; YFP: yellow fluorescent protein. 
511 Not applicable.

512

\section{Availability of data and material}

514 The datasets analyzed during the current study are available from the corresponding author upon

515 reasonable request.

516

517

518

519

520

521

522

523

524

525

526

527

528

529

530

\section{Ethics approval and consent to participate}

All protocols were approved by and all methods were performed in accordance with the guidelines of the Institutional Animal Care and Use Committee of Penn State College of Medicine.

\section{Consent for publication}$$
\text { reasonable request. }
$$

\section{Competing interests}

The authors declare no competing interests.

\section{Funding Source}

The present study was supported by NIH grant R01DC016307 (FI).

\section{Authors contributions}

B.J.L. and F.I. designed research; B.J.L., Y.I., and A.I. performed research; B.J.L., Y.K., and F.I. analyzed data; B.J.L., Y.K., and F.I. wrote the paper.

\section{Acknowledgement}

28 This work was supported by NIH grant R01DC016307 (F.I.). We thank Dr. Andras Hajnal for 29 critical reading of this manuscript. 
532 Figure 1: Differentially expressed genes in the OB following 4-week COI.

533 (A) Heatmap of differentially expressed genes. (B) Most significant Canonical Pathways of 534 differentially expressed genes. (C) Mechanistic Network of the most significantly activated

535 Upstream Regulator, IFN-y. (D) Graphical summary of differentially expressed genes illustrated 536 with their subcellular localizations. Each entity has passed a fisher's exact test p-value cut-off of 5370.05 and absolute z-score cut-off of 2 or greater. In panels (B-D), orange represents upregulated 538 genes or activated pathways, where blue represents downregulated genes or inhibited pathways.

539 Details for shapes of nodes and colors or patterns of lines can be found in the IPA's website (https://qiagen.secure.force.com/KnowledgeBase/articles/Basic_Technical_Q_A/Legend).

Figure 2. Reduction of tufted cell lateral dendrites following 10-week COI. (A) Coronal section of the OBs stained for YFP, calretinin, and DAPI. Calretinin is used to delineate between the superficial and deep EPL, where the lateral dendrites of TCs and MCs exist, respectively. (B) Enlarged view of the medial (B1) and lateral (B2) contralateral OB. (C) Enlarged view of the medial (C1) and lateral (C2) ipsilateral OB. The Pcdh21-CreER x YFP transgenic mouse model (+/Het) preferentially labels TCs and their lateral dendrites compared to MCs. (D, E) Graphs show the densities of lateral dendrites for TCs (D) and MCs (E) in $\mu \mathrm{m}$ of dendrites per cell. Dendrite densities of TC lateral dendrites decreased significantly in the ipsilateral $\mathrm{OB}$ compared to contralateral. There were no changes in the densities of MC lateral dendrites. Individual data are plotted, and the means are shown as bars. Data in D and E were analyzed with a paired t-test: ${ }^{* *} p<0.01$ compared to contralateral OB (control). Scale bars, 500 $\mu \mathrm{m}(\mathrm{A})$, and $100 \mu \mathrm{m}(\mathrm{B}, \mathrm{C})$.

Figure 3. Reduction and shortening of tufted cell axon initial segments following 10 -week 556 COl.

557 (A, B) Coronal sections of the OBs stained for Ankyrin G and DAPI. Axon initial segments of TCs 558 and MCs exist in the EPL and MCL, respectively. (A) Enlarged views of the medial (A1) and lateral 559 (A2) contralateral OB. (B) Enlarged views of the medial (B1) and lateral (B2) contralateral OB. (C560 F) Histograms show the frequency of axon initial segments at various lengths from five coronal 561 OB sections for each mouse $(n=5)$. Graphs show differences in the average length of AIS length 562 comparing the contralateral to ipsilateral OB. Data are shown as mean \pm SEM. There were no 563 differences in the number of MC AISes counted in either the medial (C; histogram) or lateral OBs 564 (D; histogram). MC AISes in the medial OB appeared to have shortened in length (C; graph), 
whereas those in the lateral OB did not change in length (D; graph). There were no differences in the number of TC AISes counted in medial OB (E; histogram). The TC AISes in the lateral OB were the only AISes to significantly decrease in number (F; histogram). TC AISes in the medial OB did not change in length (E; graph), whereas those in the lateral OB significantly decreased (F; graph). Data in C-F were analyzed by one-way analysis of variance followed by Tukey's HSD post-hoc tests for multiple comparisons: ${ }^{*} p<0.05,{ }^{* *} p<0.001$ compared to contralateral OB (control). Scale bars, $100 \mu \mathrm{m}$.

\section{Figure 4. Reduced cellular activity of the OB following 10-week COI.}

(A) Coronal sections of the OB stained with pS6 and DAPI. TCs express less pS6 in the ipsilateral OB compared to the contralateral OB following 10-week COI, whereas MCs are unaffected. (B) Enlarged view of the medial (B1) and lateral (B2) contralateral OB. (C) Enlarged view of the medial (C1) and lateral (C2) ipsilateral OB. Scale bars, $500 \mu \mathrm{m}(\mathrm{A})$, and $100 \mu \mathrm{m}(\mathrm{B}, \mathrm{C})$.

\section{Figure 5. No changes in the number of $\mathrm{OB}$ interneurons following 10-week COI.}

(A, B) Coronal sections of the OBs stained for PV and DAPI. More PV+ interneurons exist in the sEPL than in the dEPL of the untreated OB. However, the number of PV+ interneurons in each EPL sublayer of the ipsilateral OB was not significantly different from that of the contralateral OB. (C, D) Coronal sections of the OBs stained for SST and DAPI. There were no differences in the number of SST+ interneurons in the dEPL between the contralateral and ipsilateral OBs. Data in C-F were analyzed by one-way analysis of variance followed by Tukey's HSD post-hoc tests for multiple comparisons. Scale bars, $100 \mu \mathrm{m}$.

\section{Figure 6. 10-week recovery period restores tufted cell lateral dendrites following 10-week} col.

(A) Coronal section of the OBs stained for YFP, calretinin, and DAPI. Calretinin is used to delineate between the superficial and deep EPL, where the lateral dendrites of TCs and MCs exist, respectively. (B) Enlarged view of the medial (B1) and lateral (B2) contralateral OB. (C) Enlarged view of the medial (C1) and lateral (C2) ipsilateral OB. (D, E) Graphs show the densities of lateral dendrites for TCs (D) and MCs (E) in $\mu \mathrm{m}$ of dendrites per cell. Dendrite densities of TC lateral dendrites were greater in the ipsilateral $\mathrm{OB}$ compared to contralateral. There were no changes in the densities of MC lateral dendrites. Individual data are plotted, and the means are shown as bars. Data in $D$ and $E$ were analyzed with a paired t-test: ${ }^{*} p<0.05$ compared to contralateral OB (control). Scale bars, $500 \mu \mathrm{m}(\mathrm{A})$, and $100 \mu \mathrm{m}(\mathrm{B}, \mathrm{C})$. 
Figure 7. 10-week recovery period restores tufted cell axon initial segments following 10week COI.

602 (A, B) Coronal sections of the OBs stained for Ankyrin G and DAPI. Axon initial segments of TCs 603 and MCs exist in the EPL and MCL, respectively. (A) Enlarged views of the medial (A1) and lateral 604 (A2) contralateral OB. (B) Enlarged views of the medial (B1) and lateral (B2) contralateral OB. (C605 F) Histograms show the frequency of axon initial segments at various lengths from five coronal 606 OB sections for each mouse $(n=5)$. Graphs show differences in the average length of AIS length 607 comparing the contralateral to ipsilateral OB. Data are shown as mean \pm SEM. There were no 608 differences in the number of MC AISes counted in either the medial (C; histogram) or lateral (D; 609 histogram) OBs. No differences were observed in the lengths of MC AISes in either the medial 610 (C; graph) nor lateral (D; graph) OBs. There were also no differences in the number of TC AISes counted in medial (E; histogram) or lateral (F; histogram) OBs. TC AISes in the medial OB did not change in length (E; graph), nor did those in the lateral OB (F; graph). Data in C-F were analyzed by one-way analysis of variance followed by Tukey's HSD post-hoc tests for multiple comparisons. Scale bars, $100 \mu \mathrm{m}$.

615

Figure 8. 10-week recovery period restores cellular activity of the OB following 10-week col.

618 (A) Coronal sections of the OB stained with pS6 and DAPI. The expression of pS6 among TCs has recovered in the ipsilateral $\mathrm{OB}$ after the 10-week recovery period following 10-week COI. (B)

620 Enlarged view of the medial (B1) and lateral (B2) contralateral OB. (C) Enlarged view of the medial 621 (C1) and lateral (C2) ipsilateral OB. Scale bars, $500 \mu \mathrm{m}(A)$, and $100 \mu \mathrm{m}(B, C)$.

\section{Supplementary Figure 1.}

624 Labelling of the AIS using AnkG preferentially occurs in conjunction with somata expressing 625 Tbx21 both in the MCL and EPL in untreated mice.

\section{Supplementary Figure 2.}

628 Using pS6 as a marker for OB projection neuron cellular activity was demonstrated to occur in conjunction with somata expressing Tbx21 both in the MCL and EPL in untreated mice. 


\section{REFERENCES}

1. Peters AT, Spector S, Hsu J, Hamilos DL, Baroody FM, Chandra RK, et al. Diagnosis and management of rhinosinusitis: a practice parameter update. Ann Allergy Asthma Immunol 2014; 113:347-85.

2. Ahmad N, Zacharek MA. Allergic rhinitis and rhinosinusitis. Otolaryngol Clin North Am 2008; 41:267-81, v.

3. Patel RM, Pinto JM. Olfaction: anatomy, physiology, and disease. Clin Anat 2014; 27:5460.

4. Rosenfeld RM, Piccirillo JF, Chandrasekhar SS, Brook I, Kumar KA, Kramper M, et al. Clinical practice guideline (update): Adult Sinusitis Executive Summary. Otolaryngol Head Neck Surg 2015; 152:598-609.

5. Hamilos DL. Chronic rhinosinusitis: epidemiology and medical management. J Allergy Clin Immunol 2011; 128:693-707; quiz 8-9.

6. Dalton P. Olfaction and anosmia in rhinosinusitis.

7. Doty RL, Mishra A. Olfaction and its alteration by nasal obstruction, rhinitis, and rhinosinusitis. Laryngoscope 2001; 111:409-23.

8. Meltzer EO, Hamilos DL, Hadley JA, Lanza DC, Marple BF, Nicklas RA, et al. Rhinosinusitis: Establishing definitions for clinical research and patient care. Otolaryngol Head Neck Surg 2004; 131:S1-62.

9. Gudis DA, Soler ZM. Chronic Rhinosinusitis-Related Smell Loss: Medical And Surgical Treatment Efficacy. Current otorhinolaryngology reports 2016; 4:142-7.

10. Sánchez-Vallecillo MV, Fraire ME, Baena-Cagnani C, Zernotti ME. Olfactory dysfunction in patients with chronic rhinosinusitis. International journal of otolaryngology 2012; 2012:327206-.

11. Gwaltney JM, Jr. Acute Community-Acquired Sinusitis. Clinical Infectious Diseases 1996; 23:1209-25.

12. Benninger MS, Ferguson BJ, Hadley JA, Hamilos DL, Jacobs M, Kennedy DW, et al. Adult chronic rhinosinusitis: definitions, diagnosis, epidemiology, and pathophysiology. Otolaryngol Head Neck Surg 2003; 129:S1-32.

13. DiSabato DJ, Quan N, Godbout JP. Neuroinflammation: the devil is in the details. Journal of neurochemistry 2016; 139 Suppl 2:136-53.

14. Kotas Maya E, Medzhitov R. Homeostasis, Inflammation, and Disease Susceptibility. Cell 2015; 160:816-27. 
15. Skaper SD, Facci L, Zusso M, Giusti P. An Inflammation-Centric View of Neurological Disease: Beyond the Neuron. Frontiers in Cellular Neuroscience 2018; 12:72.

16. Kern RC. Chronic sinusitis and anosmia: pathologic changes in the olfactory mucosa. Laryngoscope 2000; 110:1071-7.

17. Lanza DC, Kennedy DW. Adult rhinosinusitis defined. Otolaryngol Head Neck Surg 1997; 117:S1-7.

18. Wolfensberger M, Hummel T. Anti-inflammatory and surgical therapy of olfactory disorders related to sino-nasal disease. Chem Senses 2002; 27:617-22.

19. Yee KK, Pribitkin EA, Cowart BJ, Rosen D, Feng P, Rawson NE. Analysis of the olfactory mucosa in chronic rhinosinusitis. Ann N Y Acad Sci 2009; 1170:590-5.

20. Alarabawy RA, Eltomey MA, Shehata EM. Volumetric study of the olfactory bulb in patients with chronic rhinonasal sinusitis using MRI. The Egyptian Journal of Radiology and Nuclear Medicine 2016; 47:487-91.

21. Rombaux P, Potier H, Bertrand B, Duprez T, Hummel T. Olfactory bulb volume in patients with sinonasal disease. Am J Rhinol 2008; 22:598-601.

22. Epstein VA, Bryce PJ, Conley DB, Kern RC, Robinson AM. Intranasal Aspergillus fumigatus exposure induces eosinophilic inflammation and olfactory sensory neuron cell death in mice. Otolaryngol Head Neck Surg 2008; 138:334-9.

23. Hasegawa-Ishii S, Shimada A, Imamura F. Lipopolysaccharide-initiated persistent rhinitis causes gliosis and synaptic loss in the olfactory bulb. Sci Rep 2017; 7:11605.

24. Islam Z, Harkema JR, Pestka JJ. Satratoxin G from the black mold Stachybotrys chartarum evokes olfactory sensory neuron loss and inflammation in the murine nose and brain. Environ Health Perspect 2006; 114:1099-107.

25. Islam Z, Amuzie CJ, Harkema JR, Pestka JJ. Neurotoxicity and Inflammation in the Nasal Airways of Mice Exposed to the Macrocyclic Trichothecene Mycotoxin Roridin A: Kinetics and Potentiation by Bacterial Lipopolysaccharide Coexposure. Toxicological Sciences 2007; 98:526-41.

26. Kanaya K, Kondo K, Suzukawa K, Sakamoto T, Kikuta S, Okada K, et al. Innate immune responses and neuroepithelial degeneration and regeneration in the mouse olfactory mucosa induced by intranasal administration of Poly(I:C). Cell Tissue Res 2014; 357:27999.

27. Lindsay R, Slaughter T, Britton-Webb J, Mog SR, Conran R, Tadros M, et al. Development of a murine model of chronic rhinosinusitis. Otolaryngol Head Neck Surg 2006; 134:72430; discussion 31-2. 
28. Yagi S, Tsukatani T, Yata T, Tsukioka F, Miwa T, Furukawa M. Lipopolysaccharideinduced apoptosis of olfactory receptor neurons in rats. Acta Otolaryngol 2007; 127:74853.

29. Hasegawa-Ishii S, Shimada A, Imamura F. Neuroplastic changes in the olfactory bulb associated with nasal inflammation in mice. J Allergy Clin Immunol 2019; 143:978-89.e3.

30. Hasegawa-Ishii S, Imamura F, Nagayama S, Murata M, Shimada A. Differential Effects of Nasal Inflammation and Odor Deprivation on Layer-Specific Degeneration of the Mouse Olfactory Bulb. eNeuro 2020; 7.

31. Körbler T, Grsković M, Dominis M, Antica M. A simple method for RNA isolation from formalin-fixed and paraffin-embedded lymphatic tissues. Exp Mol Pathol 2003; 74:336-40.

32. Kim D, Langmead B, Salzberg SL. HISAT: a fast spliced aligner with low memory requirements. Nat Methods 2015; 12:357-60.

33. Anders S, Pyl PT, Huber W. HTSeq--a Python framework to work with high-throughput sequencing data. Bioinformatics 2015; 31:166-9.

34. Love Ml, Huber W, Anders S. Moderated estimation of fold change and dispersion for RNA-seq data with DESeq2. Genome Biol 2014; 15:550.

35. Wickham H. ggplot2: Elegant Graphics for Data Analysis. Springer-Verlag New York, 2016.

36. Kim IJ, Beck HN, Lein PJ, Higgins D. Interferon gamma induces retrograde dendritic retraction and inhibits synapse formation. J Neurosci 2002; 22:4530-9.

37. Nagayama S, Homma R, Imamura F. Neuronal organization of olfactory bulb circuits. Front Neural Circuits 2014; 8:98.

38. Nagai $\mathrm{Y}$, Sano H, Yokoi M. Transgenic expression of Cre recombinase in mitral/tufted cells of the olfactory bulb. genesis $2005 ; 43: 12-6$.

39. Ogawa $\mathrm{Y}$, Rasband $\mathrm{MN}$. The functional organization and assembly of the axon initial segment. Curr Opin Neurobiol 2008; 18:307-13.

40. Alshammari MA, Alshammari TK, Laezza F. Improved Methods for Fluorescence Microscopy Detection of Macromolecules at the Axon Initial Segment. Front Cell Neurosci 2016; 10:5.

41. Galliano E, Hahn C, Browne LP, P RV, Tufo C, Crespo A, et al. Brief Sensory Deprivation Triggers Cell Type-Specific Structural and Functional Plasticity in Olfactory Bulb Neurons. J Neurosci 2021; 41:2135-51.

42. Yamada R, Kuba H. Structural and Functional Plasticity at the Axon Initial Segment. Front Cell Neurosci 2016; 10:250. 
43. Knight ZA, Tan K, Birsoy K, Schmidt S, Garrison JL, Wysocki RW, et al. Molecular profiling of activated neurons by phosphorylated ribosome capture. Cell 2012; 151:1126-37.

44. Liu G, Froudarakis E, Patel JM, Kochukov MY, Pekarek B, Hunt PJ, et al. Target specific functions of EPL interneurons in olfactory circuits. Nature Communications 2019; 10:3369.

45. Miyamichi K, Shlomai-Fuchs Y, Shu M, Weissbourd Brandon C, Luo L, Mizrahi A. Dissecting Local Circuits: Parvalbumin Interneurons Underlie Broad Feedback Control of Olfactory Bulb Output. Neuron 2013; 80:1232-45.

46. Lepousez G, Csaba Z, Bernard V, Loudes C, Videau C, Lacombe J, et al. Somatostatin interneurons delineate the inner part of the external plexiform layer in the mouse main olfactory bulb. J Comp Neurol 2010; 518:1976-94.

47. Lepousez G, Csaba Z, Bernard V, Loudes C, Videau C, Lacombe J, et al. Somatostatin interneurons delineate the inner part of the external plexiform layer in the mouse main olfactory bulb. Journal of Comparative Neurology 2010; 518:1976-94.

48. Pozzo ED, Tremolanti C, Costa B, Giacomelli C, Milenkovic VM, Bader S, et al. Microglial Pro-Inflammatory and Anti-Inflammatory Phenotypes Are Modulated by Translocator Protein Activation. Int J Mol Sci 2019; 20.

49. Shinozaki Y, Shibata K, Yoshida K, Shigetomi E, Gachet C, Ikenaka K, et al. Transformation of Astrocytes to a Neuroprotective Phenotype by Microglia via P2Y(1) Receptor Downregulation. Cell Rep 2017; 19:1151-64.

50. Becerra-Calixto A, Cardona-Gómez GP. The Role of Astrocytes in Neuroprotection after Brain Stroke: Potential in Cell Therapy. Front Mol Neurosci 2017; 10:88.

51. Mizuno T, Sawada M, Marunouchi T, Suzumura A. Production of interleukin-10 by mouse glial cells in culture. Biochem Biophys Res Commun 1994; 205:1907-15.

52. Rasley A, Tranguch SL, Rati DM, Marriott I. Murine glia express the immunosuppressive cytokine, interleukin-10, following exposure to Borrelia burgdorferi or Neisseria meningitidis. Glia 2006; 53:583-92.

53. Le R, Esquenazi S. Astrocytes mediate cerebral cortical neuronal axon and dendrite growth, in part, by release of fibroblast growth factor. Neurol Res 2002; 24:81-92.

54. Chen C, Jiang Z, Fu X, Yu D, Huang H, Tasker JG. Astrocytes Amplify Neuronal Dendritic Volume Transmission Stimulated by Norepinephrine. Cell Rep 2019; 29:4349-61.e4.

55. Eyo UB, Gu N, De S, Dong H, Richardson JR, Wu LJ. Modulation of microglial process convergence toward neuronal dendrites by extracellular calcium. J Neurosci 2015; 35:2417-22. 
56. Eyo UB, Haruwaka K, Mo M, Campos-Salazar AB, Wang L, Speros XSt, et al. Microglia provide structural resolution to injured dendrites after severe seizures. Cell Rep 2021; 35:109080.

57. Hedstrom KL, Ogawa Y, Rasband MN. AnkyrinG is required for maintenance of the axon initial segment and neuronal polarity. J Cell Biol 2008; 183:635-40.

58. Jenkins SM, Bennett $\mathrm{V}$. Ankyrin-G coordinates assembly of the spectrin-based membrane skeleton, voltage-gated sodium channels, and L1 CAMs at Purkinje neuron initial segments. J Cell Biol 2001; 155:739-46.

59. Le Bras B, Fréal A, Czarnecki A, Legendre P, Bullier E, Komada M, et al. In vivo assembly of the axon initial segment in motor neurons. Brain Struct Funct 2014; 219:1433-50.

60. Jacques L, Morris CE, Longtin A, Joos B. Action potential initiation in damaged axon initial segment. BMC Neuroscience 2014.

61. Sobotzik JM, Sie JM, Politi C, Del Turco D, Bennett V, Deller T, et al. AnkyrinG is required to maintain axo-dendritic polarity in vivo. Proc Natl Acad Sci U S A 2009; 106:17564-9.

62. Aguilar J, Humanes-Valera D, Alonso-Calviño E, Yague JG, Moxon KA, Oliviero A, et al. Spinal cord injury immediately changes the state of the brain. The Journal of neuroscience : the official journal of the Society for Neuroscience 2010; 30:7528-37.

63. Curt A, Bruehlmeier M, Leenders KL, Roelcke U, Dietz V. Differential Effect of Spinal Cord Injury and Functional Impairment on Human Brain Activation. Journal of Neurotrauma 2002; 19:43-51.

64. Karunakaran KD, He J, Zhao J, Cui J-L, Zang Y-F, Zhang Z, et al. Differences in Cortical Gray Matter Atrophy of Paraplegia and Tetraplegia after Complete Spinal Cord Injury. Journal of Neurotrauma 2018; 36:2045-51.

65. Ferreira FS, Pereira JMS, Reis A, Sanches M, Duarte JV, Gomes L, et al. Early visual cortical structural changes in diabetic patients without diabetic retinopathy. Graefe's Archive for Clinical and Experimental Ophthalmology 2017; 255:2113-8.

66. Ferreira S, Pereira AC, Quendera B, Reis A, Silva ED, Castelo-Branco M. Primary visual cortical remapping in patients with inherited peripheral retinal degeneration. Neurolmage: Clinical 2017; 13:428-38.

67. Murphy MC, Conner IP, Teng CY, Lawrence JD, Safiullah Z, Wang B, et al. Retinal Structures and Visual Cortex Activity are Impaired Prior to Clinical Vision Loss in Glaucoma. Scientific reports 2016; 6:31464-. 
68. Chon U, LaFever BJ, Nguyen U, Kim Y, Imamura F. Topographically distinct projection patterns of early- and late-generated projection neurons in the mouse olfactory bulb. eneuro 2020:ENEURO.0369-20.2020.

69. Igarashi KM, leki N, An M, Yamaguchi Y, Nagayama S, Kobayakawa K, et al. Parallel mitral and tufted cell pathways route distinct odor information to different targets in the olfactory cortex. J Neurosci 2012; 32:7970-85.

70. Mori K, Sakano H. How is the olfactory map formed and interpreted in the mammalian brain? Annu Rev Neurosci 2011; 34:467-99.

71. Orona E, Rainer EC, Scott JW. Dendritic and axonal organization of mitral and tufted cells in the rat olfactory bulb. J Comp Neurol 1984; 226:346-56. 


\section{$\mathbf{A}$}
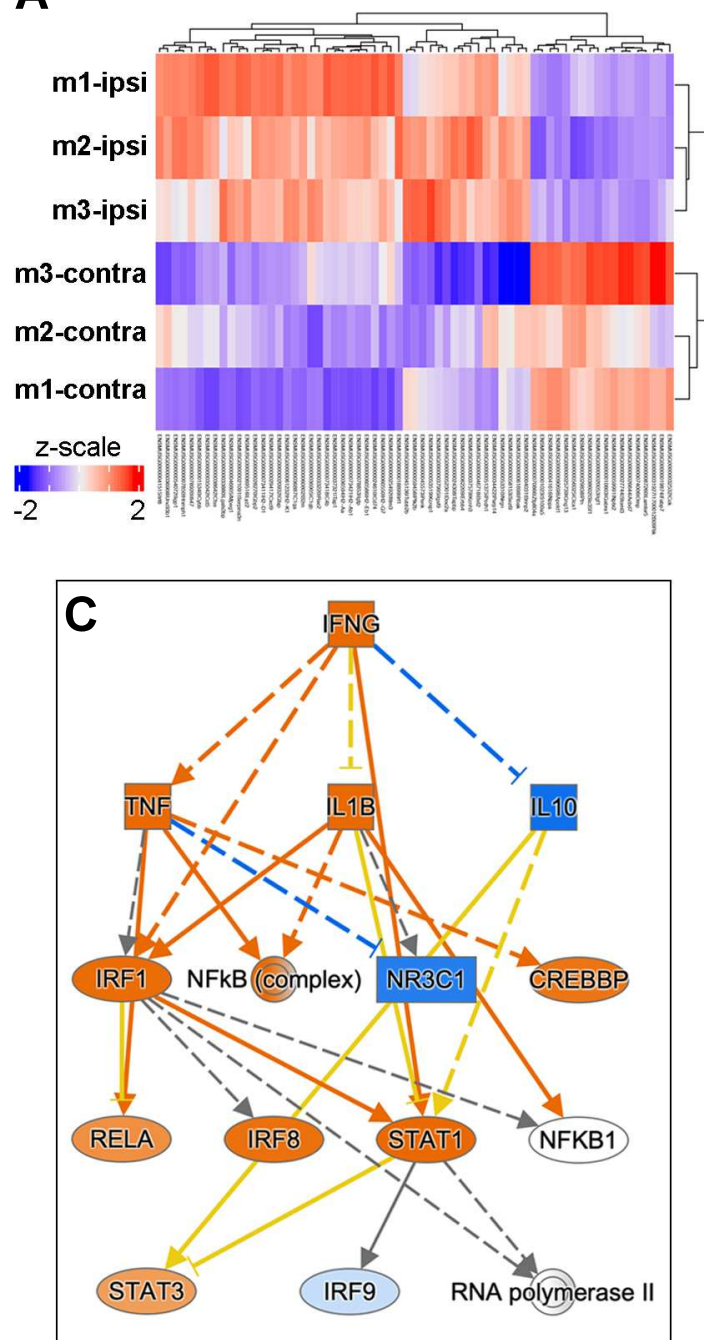

IPA canonical pathway analysis

\begin{tabular}{|c|c|c|}
\hline Ingenuity Canonical Pathways & -log(p-value) & z-score \\
\hline Neuroinflammation Signaling Pathway & 5.95 & 2.646 \\
\hline Th1 Pathway & 4.87 & 1.342 \\
\hline Production of Nitric Oxide and Reactive Oxygen Species in Macrophages & 3.94 & 2 \\
\hline Dendritic Cell Maturation & 2.46 & 2.449 \\
\hline Systemic Lupus Erythematosus In T Cell Signaling Pathway & 2.29 & 2.449 \\
\hline PKC Signaling in T Lymphocytes & 1.9 & 2.236 \\
\hline Role of NFAT in Regulation of the Immune Response & 1.8 & 2 \\
\hline T Cell Receptor Signaling & 1.73 & 2.236 \\
\hline Calcium-induced T Lymphocyte Apoptosis & 1.55 & 2 \\
\hline ICOS-ICOSL Signaling in T Helper Cells & 1.42 & 2 \\
\hline PD-1, PD-L1 cancer immunotherapy pathway & 5.16 & -2.236 \\
\hline
\end{tabular}

\section{D}

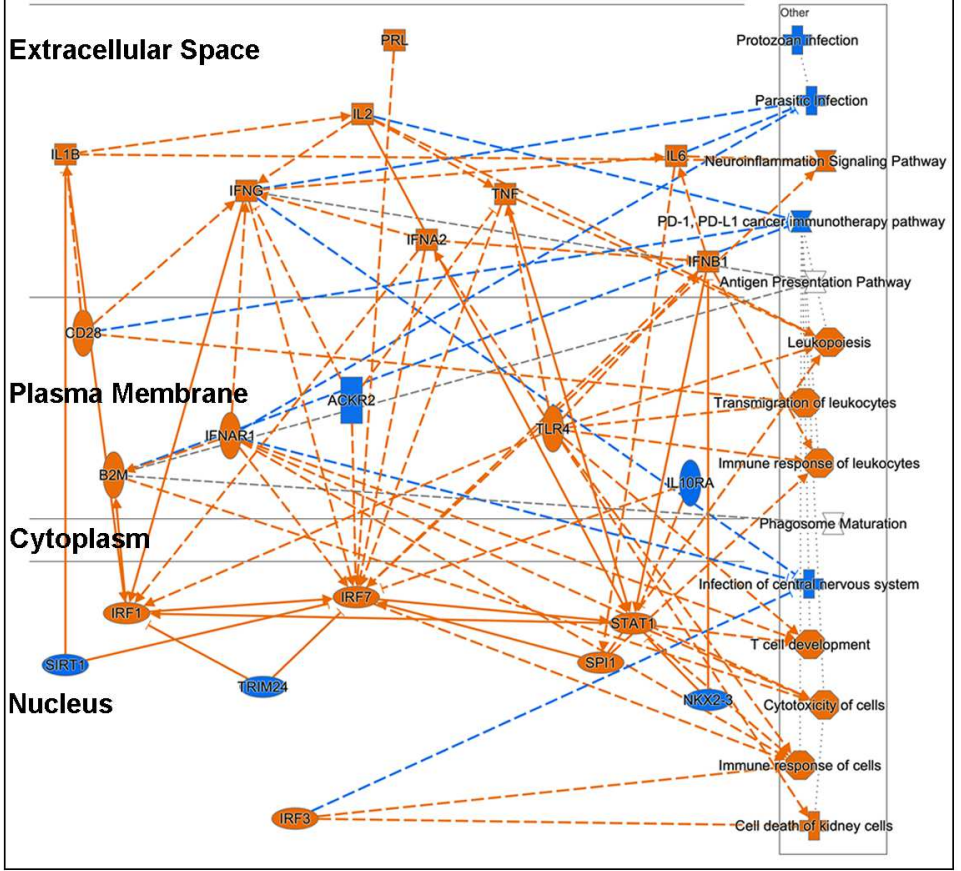

Figure 1: Differentially expressed genes in the OB following 4-week COI.

(A) Heatmap of differentially expressed genes. (B) Most significant Canonical Pathways of differentially expressed genes. (C) Mechanistic Network of the most significantly activated Upstream Regulator, IFN-y. (D) Graphical summary of differentially expressed genes illustrated with their subcellular localizations. Each entity has passed a fisher's exact test p-value cut-off of 0.05 and absolute z-score cut-off of 2 or greater. In panels (B-D), orange represents upregulated genes or activated pathways, where blue represents downregulated genes or inhibited pathways. Details for shapes of nodes and colors or patterns of lines can be found in the IPA's website (https://qiagen.secure.force.com/KnowledgeBase/articles/Basic_Technical_Q_A/Legend). 


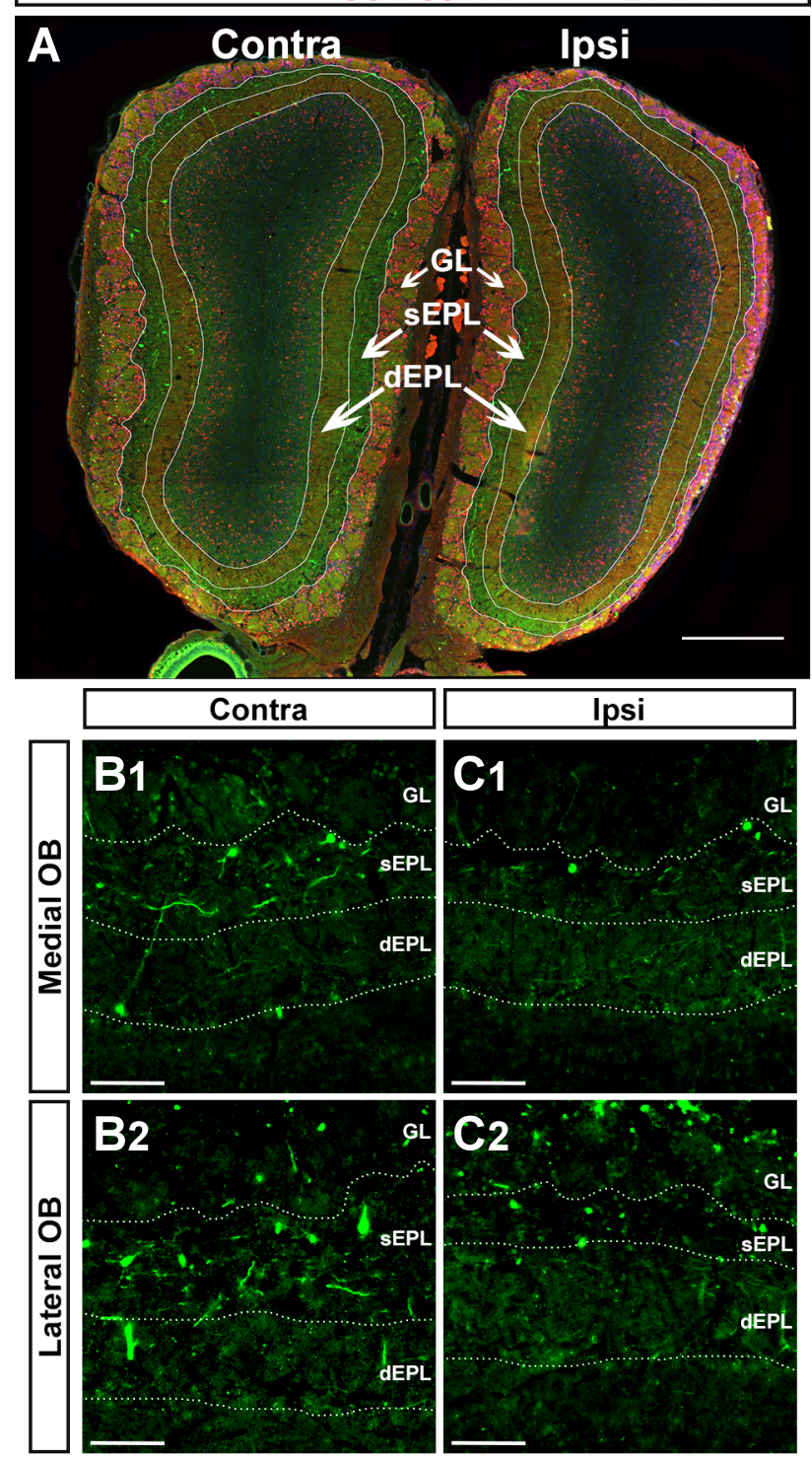

D
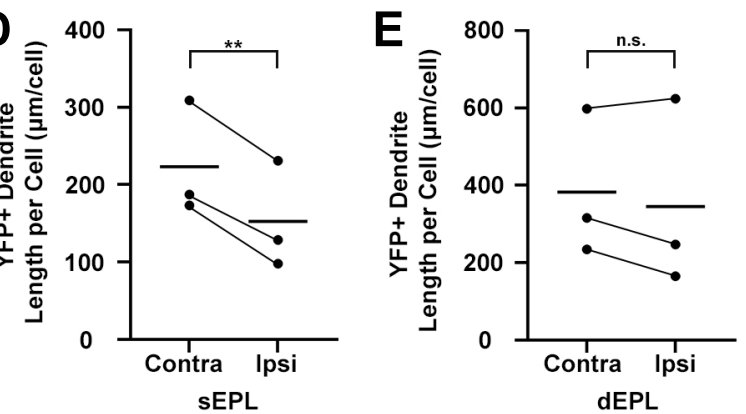

Figure 2. Reduction of tufted cell lateral dendrites following 10-week COI.

(A) Coronal section of the OBs stained for YFP, calretinin, and DAPI. Calretinin is used to delineate between the superficial and deep EPL, where the lateral dendrites of TCs and MCs exist, respectively. (B) Enlarged view of the medial (B1) and lateral (B2) contralateral $\mathrm{OB}$. (C) Enlarged view of the medial $(\mathrm{C} 1)$ and lateral (C2) ipsilateral OB. The Pcdh21-CreER x YFP transgenic mouse model (+/Het) preferentially labels TCs and their lateral dendrites compared to MCs. (D, E) Graphs show the densities of lateral dendrites for TCs (D) and MCs (E) in $\mu \mathrm{m}$ of dendrites per cell. Dendrite densities of TC lateral dendrites decreased significantly in the ipsilateral OB compared to contralateral. There were no changes in the densities of MC lateral dendrites. Individual data are plotted, and the means are shown as bars. Data in D and $E$ were analyzed with a paired t-test: ${ }^{* *} p<0.01$ compared to contralateral $O B$ (control). Scale bars, $500 \mu \mathrm{m}(\mathrm{A})$, and $100 \mu \mathrm{m}(\mathrm{B}, \mathrm{C})$ 


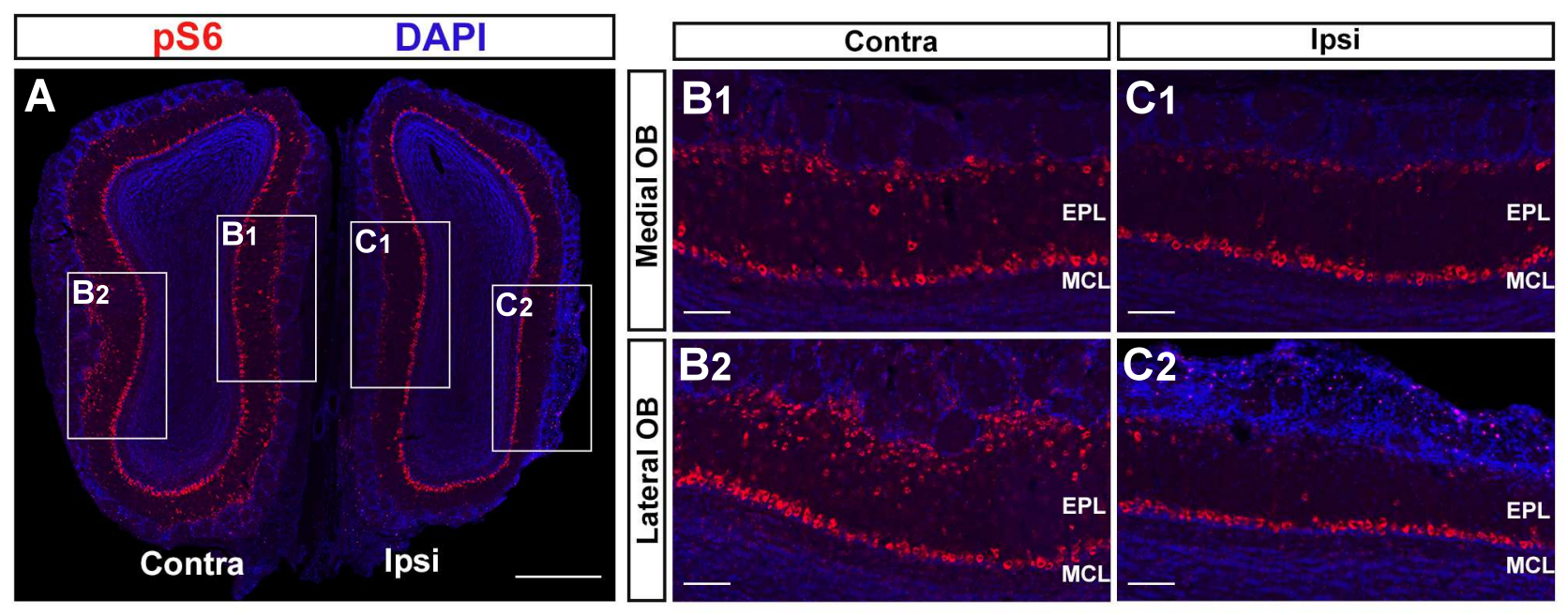

Figure 4. Reduced cellular activity of the OB following 10-week COI.

(A) Coronal sections of the OB stained with pS6 and DAPI. TCs express less pS6 in the ipsilateral OB compared to the contralateral OB following 10-week COI, whereas MCs are unaffected. (B) Enlarged view of the medial (B1) and lateral (B2) contralateral OB. (C) Enlarged view of the medial $(C 1)$ and lateral $(C 2)$ ipsilateral OB. Scale bars, $500 \mu \mathrm{m}(A)$, and $100 \mu \mathrm{m}(B, C)$ 


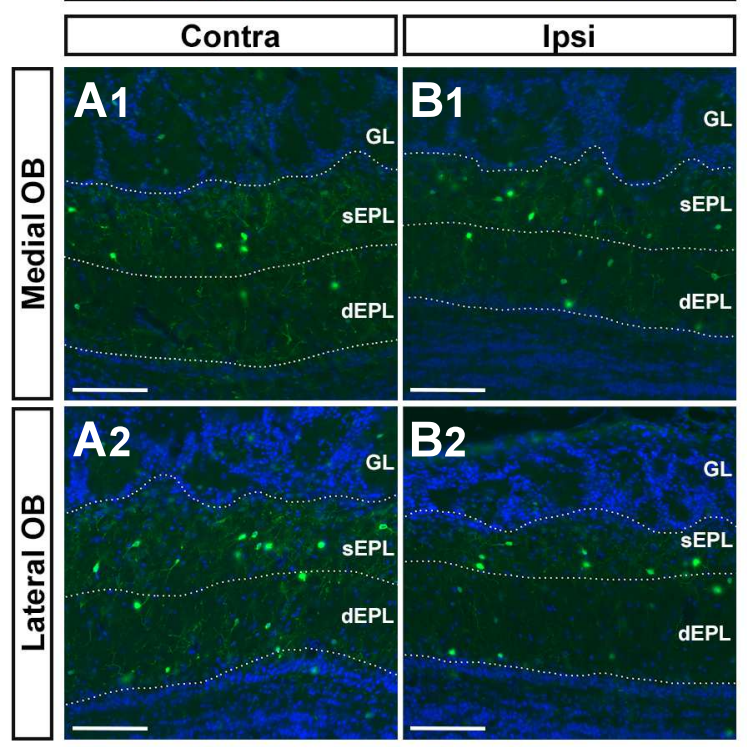

Somatostatin

\section{DAPI}

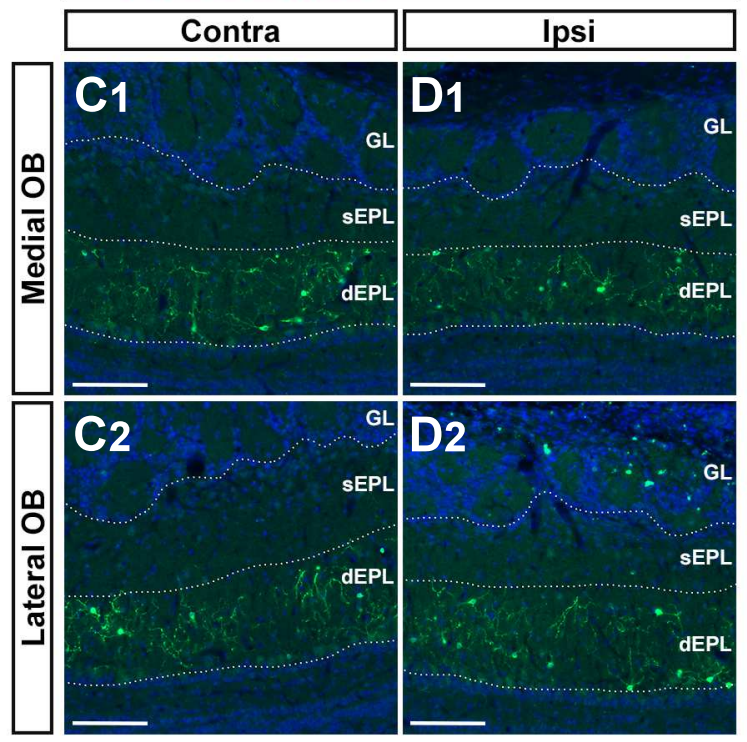

Figure 5. No changes in the number of $O B$ interneurons following 10-week COI.

(A, B) Coronal sections of the OBs stained for PV and DAPI. More PV+ interneurons exist in the sEPL than in the dEPL of the untreated $\mathrm{OB}$. However, the number of $\mathrm{PV}+$ interneurons in each EPL sublayer of the ipsilateral OB was not significantly different from that of the contralateral OB. (C, D) Coronal sections of the OBs stained for SST and DAPI. There were no differences in the number of SST+ interneurons in the dEPL between the contralateral and ipsilateral OBs. Data in C-F were analyzed by one-way analysis of variance followed by Tukey's HSD post-hoc tests for multiple comparisons. Scale bars, $100 \mu \mathrm{m}$. 

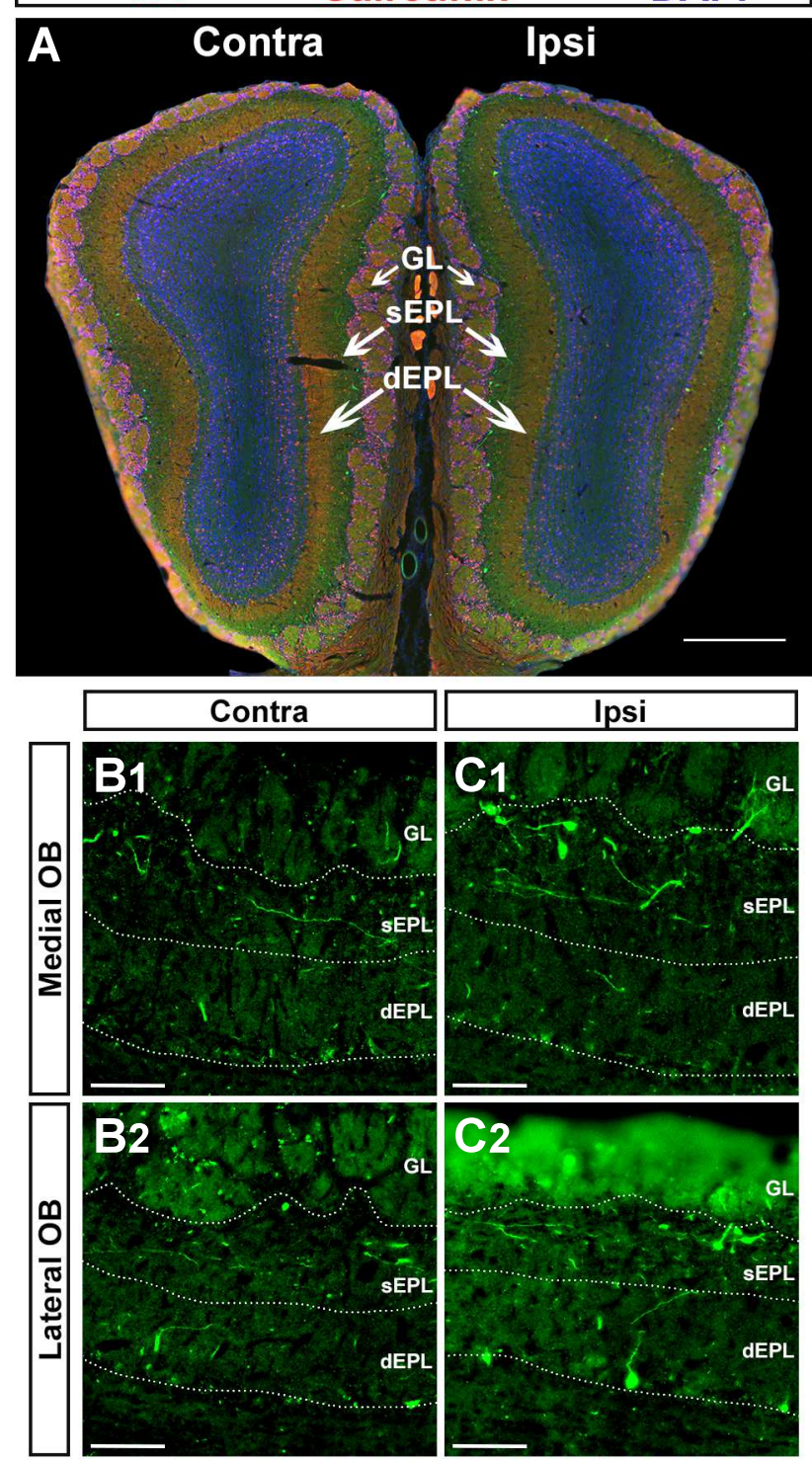

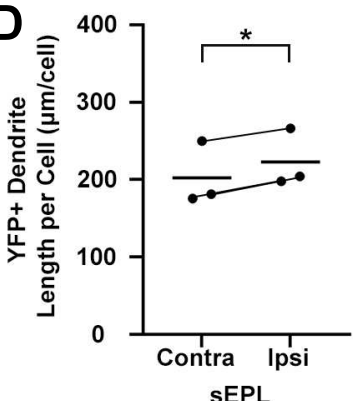

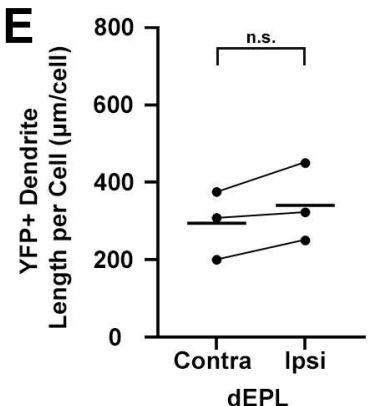

Figure 6. 10-week recovery period restores tufted cell lateral dendrites following 10-week COI.

(A) Coronal section of the OBs stained for YFP, calretinin, and DAPI. Calretinin is used to delineate between the superficial and deep EPL, where the lateral dendrites of TCs and MCs exist, respectively. (B) Enlarged view of the medial (B1) and lateral (B2) contralateral OB. (C) Enlarged view of the medial (C1) and lateral (C2) ipsilateral OB. (D, E) Graphs show the densities of lateral dendrites for TCs (D) and MCs (E) in $\mu \mathrm{m}$ of dendrites per cell. Dendrite densities of TC lateral dendrites were greater in the ipsilateral OB compared to contralateral. There were no changes in the densities of MC lateral dendrites. Individual data are plotted, and the means are shown as bars. Data in $D$ and $E$ were analyzed with a paired t-test: ${ }^{*} p<0.05$ compared to contralateral OB (control). Scale bars, $500 \mu \mathrm{m}(\mathrm{A})$, and $100 \mu \mathrm{m}(\mathrm{B}, \mathrm{C})$. 

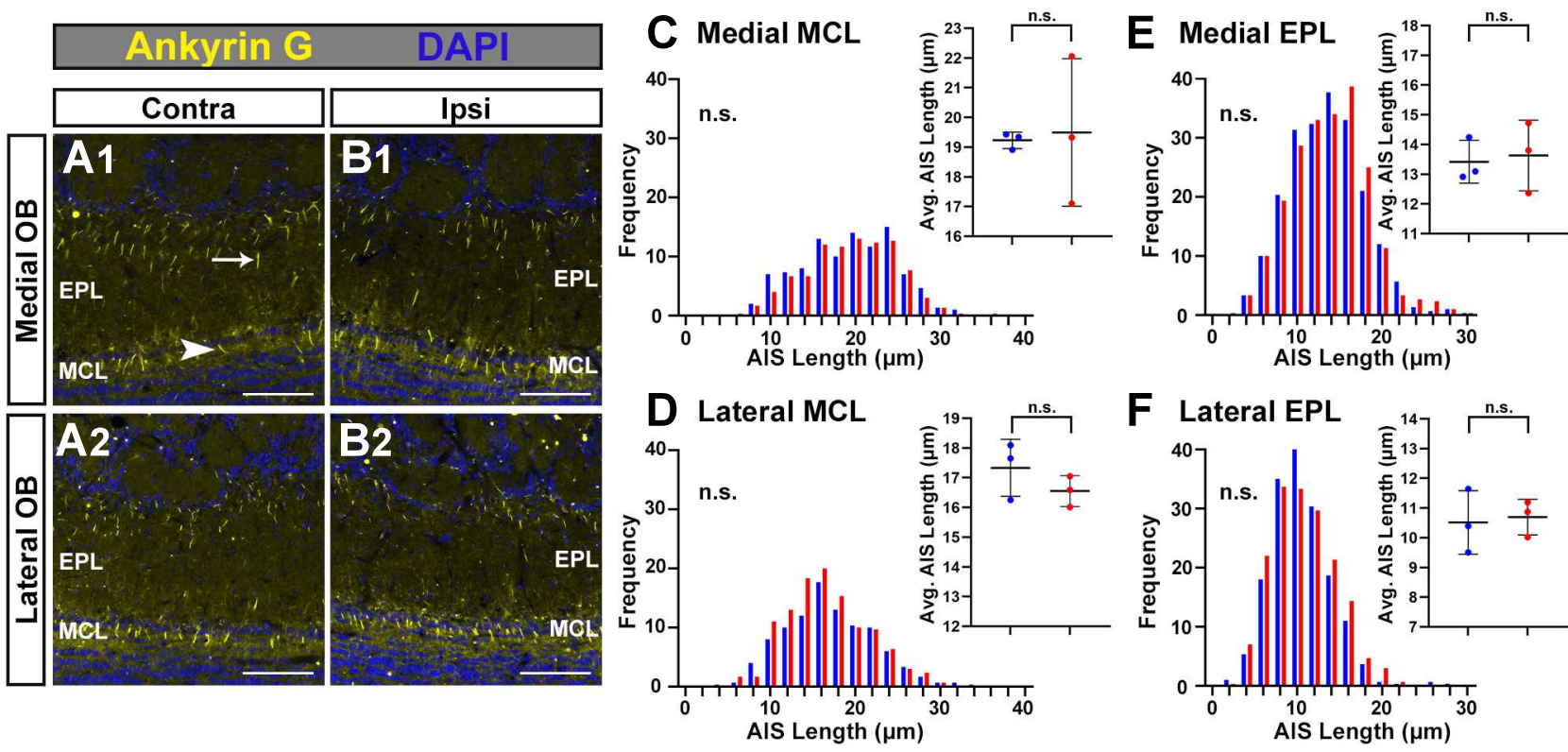

Figure 7. 10-week recovery period restores tufted cell axon initial segments following 10-week COI.

(A, B) Coronal sections of the OBs stained for Ankyrin G and DAPI. Axon initial segments of TCs and MCs exist in the EPL and MCL, respectively. (A) Enlarged views of the medial (A1) and lateral (A2) contralateral OB. (B) Enlarged views of the medial (B1) and lateral (B2) contralateral $\mathrm{OB}$. (C-F) Histograms show the frequency of axon initial segments at various lengths from five coronal $O B$ sections for each mouse $(n=5)$. Graphs show differences in the average length of AIS length comparing the contralateral to ipsilateral OB. Data are shown as mean \pm SEM. There were no differences in the number of MC AISes counted in either the medial (C; histogram) or lateral (D; histogram) OBs. No differences were observed in the lengths of MC AISes in either the medial (C; graph) nor lateral (D; graph) OBs. There were also no differences in the number of TC AISes counted in medial (E; histogram) or lateral (F; histogram) OBs. TC AISes in the medial OB did not change in length ( $\mathrm{E}$; graph), nor did those in the lateral OB ( $F$; graph). Data in C-F were analyzed by one-way analysis of variance followed by Tukey's HSD post-hoc tests for multiple comparisons. Scale bars, $100 \mu \mathrm{m}$. 


\section{AnkG

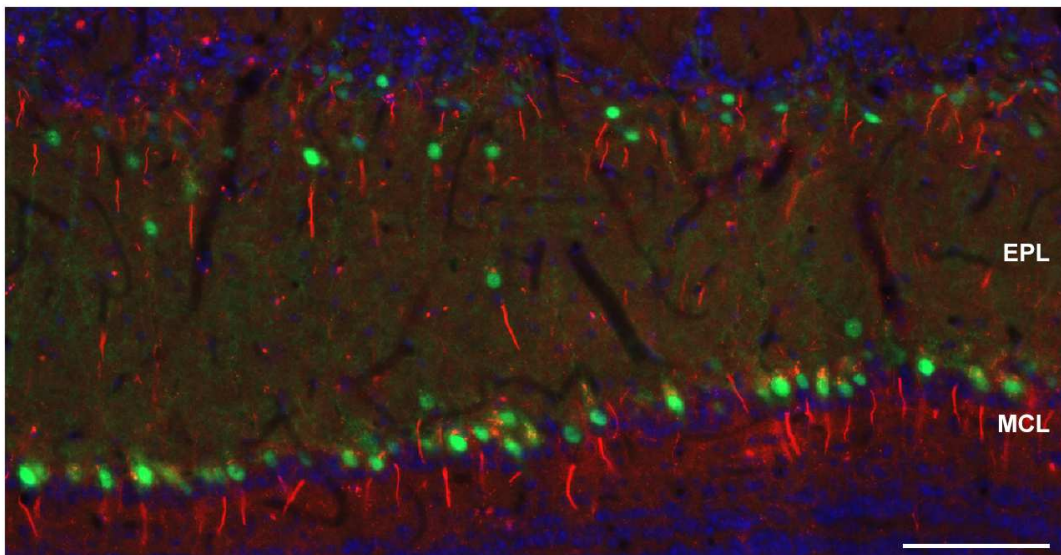

Supplementary Figure 1.

Labelling of the AIS using AnkG preferentially occurs in conjunction with somata expressing Tbx21 both in the MCL and EPL in untreated mice. 


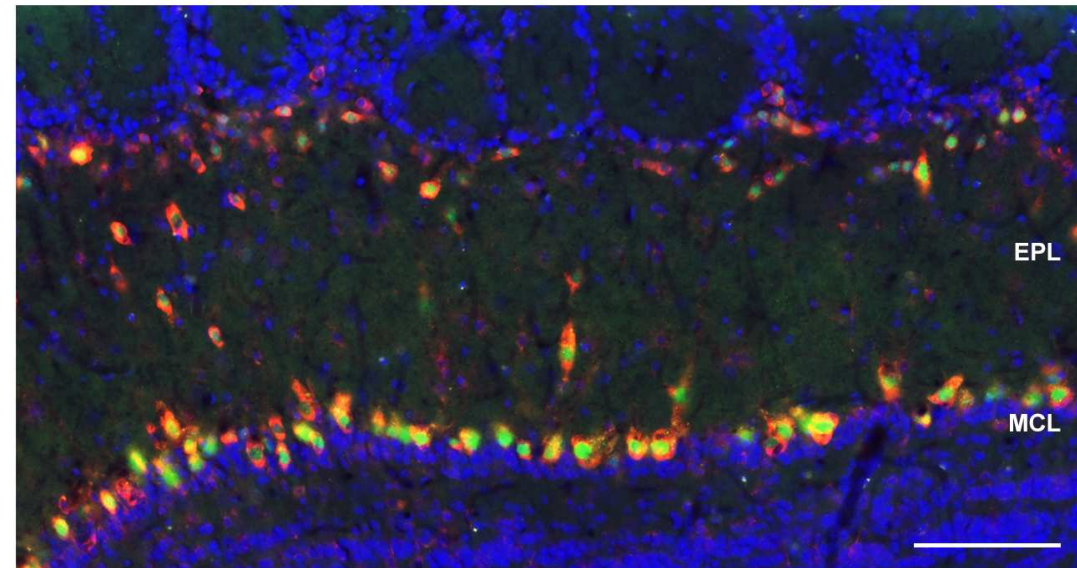

Supplementary Figure 2.

Using pS6 as a marker for OB projection neuron cellular activity was demonstrated to occur in conjunction with somata expressing Tbx21 both in the MCL and EPL in untreated mice. 
Supplementary Table1: Upstream Regulator

\begin{tabular}{|c|c|c|c|c|c|c|c|c|}
\hline Upstream Regulator & Expr Fold Change & Molecule Type & \begin{tabular}{|l|} 
Predicted Activation State \\
\end{tabular} & Activation z-score & Flags & p-value of overlap & Target Molecules in Dataset & Mechanistic Network \\
\hline KDM1A & 0.088 & enzyme & & & & $2.9 \mathrm{E}-21$ & $\begin{array}{l}\text { Bst2,C1QB,C4A/C4B,CCL5,CD74,CTSS,CYBB,,GBP2,GFAP,HLA-A,HLA- } \\
\text { DQA1,HLA-DQB1,HLA- } \\
\text { DRB5,IFITM3,Igtp,LGALS3BP,LYZ,MPEG1,PARP14,TAP1 }\end{array}$ & \\
\hline IFNG & & cytokine & Activated & 4.749 & & $5.04 \mathrm{E}-20$ & 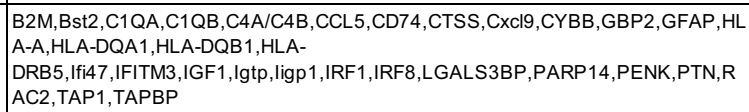 & $34(15)$ \\
\hline STAT1 & 1.108 & transcription regulator & Activated & 2.826 & bias & $9.4 \mathrm{E}-20$ & \begin{tabular}{|l|} 
B2M,C4A/C4B,CCL5,CTSS,Cxc19,GBP2,HLA-DQA1,HLA- \\
DRB5, Ifi47,IFITM3,IGF1,Igtp,ligp1,IRF1,IRF8,NPPA,PTN,SERPINA3,TAP1
\end{tabular} & $34(15)$ \\
\hline Ifnar & & group & Activated & 3.576 & bias & $3.16 \mathrm{E}-19$ & $\begin{array}{l}\text { B2M,Bst2,CCL5,CD74,Cxc19,GBP2,HLA- } \\
\text { A,IFITM3,IRF1,IRF8,TAP1,TAPBP,UNC93B1 }\end{array}$ & $35(17)$ \\
\hline MAPT & -0.014 & other & & & & $7.02 \mathrm{E}-18$ & $\begin{array}{l}\text { C1QB,C4A/C4B,CD74,CTSS,CYBB,GBP2,GFAP,HLA-A,HLA-DQA1,HLA- } \\
\text { DQB1, HLA- } \\
\text { DRB5,IFITM3,Igtp,LGALS3BP,LYZ,MPEG1,PARP14,PENK,TAP1,TUBB2B }\end{array}$ & $36(11)$ \\
\hline DYSF & 0.984 & other & & & & 1.45E-15 & $\begin{array}{l}\text { B2M,C1QB,CD74,CTSS,HLA-A,HLA-DQA1,HLA-DQB1,HLA- } \\
\text { DRB5,LYZ,MPEG1,SERPINA3 }\end{array}$ & \\
\hline SIRT1 & 0.155 & transcription regulator & Inhibited & -3.45 & & $2.18 \mathrm{E}-14$ & $\begin{array}{l}\text { CCL5,CD74,GNG13,HLA-A,HLA-DQA1,HLA-DQB1,HLA- } \\
\text { DRB5,Ifi47,IFITM3,,IGF1,Igtp,ligp1,LGALS3BP,PARP14,PTN,TAP1 }\end{array}$ & $35(10)$ \\
\hline ZBTB10 & -0.096 & other & Activated & 3.317 & bias & $4.19 \mathrm{E}-13$ & B2M,Bst2,CCL5,Cxc19,CYBB, Ifi47,IFITM3, Igtp, ligp 1,IRF1, UNC93B1 & \\
\hline Interferon alpha & & group & Activated & 3.537 & bias & $8.51 \mathrm{E}-13$ & $\begin{array}{l}\text { B2M,Bst2, CCL5,Cx19,GBP2,HLA- } \\
\text { A,Ifi47,IFITM3, ligp1,IRF1,IRF8,PARP14,TAP1, TAPBP, UNC93B1 }\end{array}$ & $26(12)$ \\
\hline STAT3 & 0.016 & transcription regulator & & 0.931 & & $1.15 E-12$ & $\begin{array}{l}\text { CCL5,CD74,Cxc19,GBP2,GFAP,HLA-A,HLA-DQA1,HLA- } \\
\text { DRB5,IFITM3,Igtp,IRF1,LYZ,NPPA,OMP,PTN,SERPINA3,TAP1 }\end{array}$ & $32(13)$ \\
\hline IL4 & & cytokine & & -1.331 & bias & $1.25 \mathrm{E}-12$ & $\begin{array}{l}\text { APOLD1,Bst2,CCL5,CD74,Cxc19,CYBB,GBP2,HLA-DQA1,HLA-DQB1,HLA- } \\
\text { DRB5, IFITM3,IGF1,Igtp,ligp1,IRF1,IRF8,LGALS3BP,MPEG1,Nrgn,OMP,TAPBP }\end{array}$ & $38(14)$ \\
\hline IRF1 & 2.122 & transcription regulator & Activated & 2.23 & bias & $2.96 \mathrm{E}-12$ & B2M,CCL5,CTSS,Cxc19,CYBB,GBP2,Ifi47,,IFITM3,IRF1,TAP1,TAPBP & $34(15)$ \\
\hline SNCA & 0.514 & enzyme & Activated & 3.138 & & $3.06 \mathrm{E}-12$ & $\begin{array}{l}\text { Bst2,CD74,CYBB,FABP7,GBP2,GFAP,HLA-DQA1,HLA- } \\
\text { DRB5,Ifi47,IGF1,IRF1,NPTX2,Nrgn }\end{array}$ & $34(9)$ \\
\hline QKI & 0.205 & other & & 1.941 & & $4.35 \mathrm{E}-12$ & CTSS,FABP7,GFAP,HLA-DQA1,HLA-DQB1,HNRNPH1,TAP1,TUBB2B & \\
\hline IL27 & & cytokine & Activated & 2.609 & & $6.28 \mathrm{E}-12$ & B2M,CCL5,CD74,Cxc19,GBP2,HLA-A,HLA-DQA1,HLA-DQB1,IRF1,TAP1 & $34(16)$ \\
\hline ELAVL1 & 0.759 & other & Activated & 2.985 & bias & $7.53 \mathrm{E}-12$ & B2M,Bst2,CTSS,Cxc19,HLA-A,HLA-DRB5,IFITM3,ligp1,IRF1,LGALS3BP,MPEG1 & \\
\hline PIK3CG & 2.644 & kinase & Inhibited & -2.813 & & $1.03 \mathrm{E}-11$ & B2M,CD74,Cxc19,GBP2,HLA-A,Igtp,ligp 1,IRF1,TAP1 & $34(14)$ \\
\hline JAK $1 / 2$ & & group & Activated & 2.828 & bias & $1.54 \mathrm{E}-11$ & Bst2,CD74,GBP2,HLA-DQA1,HLA-DRB5,Iffi47,IRF1,Nrgn & \\
\hline STAT6 & 1.324 & transcription regulator & Inhibited & -2.487 & & $1.68 \mathrm{E}-11$ & $\begin{array}{l}\text { APOLD1,Bst2,CCL5,Clca3a1/CIca3a2,CTSS,CYBB, GBP2,IFITM3,IGF1, Igtp, ligp1 } \\
\text {,IRF1,LGALS3BP,MPEG1 }\end{array}$ & \\
\hline TRIM24 & 0.301 & transcription regulator & Inhibited & -2.343 & bias & $1.85 \mathrm{E}-11$ & Bst2,CCL5,GBP2,Ifi47,Igtp,ligp1,IRF1,LGALS3BP,TAP1 & $28(8)$ \\
\hline G protein alphai & & group & Activated & 2.795 & bias & $2.42 \mathrm{E}-11$ & Bst2,C4A/C4B,GBP2,HLA-A,IFITM3,Igtp,ligp1,TAP1 & \\
\hline lipopolysaccharide & & chemical drug & Activated & 4.2 & & $3.94 \mathrm{E}-11$ & $\begin{array}{l}\text { C1QA, CCL5,CD74,Cxc19,CYBB,,GBP2, GFAP,HLA-A,HLA-DQA1,HLA-DQB1, HLA- } \\
\text { DRB5,Ifi47,IGF1, Igtp,ligp1, IRF1,IRF8, LGALS3BP, LYZ,NPPPA,PARP14,PENK,SE } \\
\text { RPINA3, TAP1, TAPBP }\end{array}$ & $34(16)$ \\
\hline IRF9 & 0.37 & transcription regulator & & -0.277 & & $7.35 \mathrm{E}-11$ & Cxc19, Ifi47,IFITM3, ligp1,IRF1,IRF8,NPPA & $29(10)$ \\
\hline SLC9A3 & & ion channel & & & & $8.16 \mathrm{E}-11$ & B2M,CCL5,CD74,Ifi47,Igtp,IRF8 & \\
\hline inosine & & $\begin{array}{l}\text { chemical - endogenous } \\
\text { mammalian }\end{array}$ & Activated & 2.646 & bias & $8.48 \mathrm{E}-11$ & C1QA,C1QB,C4A/C4B,GFAP,IFITM3,IRF1,LGALS3BP & \\
\hline IRF3 & 0.052 & transcription regulator & Activated & 3.1 & bias & $1.96 \mathrm{E}-10$ & B2M,Bst2,CCL5,Cxc19,Ifi47,IFITM3,Igtp,IRF1,PARP14,TAP1 & $31(13)$ \\
\hline IL6 & & cytokine & Activated & 2.93 & & $2.12 \mathrm{E}-10$ & $\begin{array}{l}\text { CCLL5,CD74,CXC19,CYBB,GBP2,GFAP,HLA-A,HLA-DQA1,HLA- } \\
\text { DRB5,IFITM3,IGF1,IRF1,LYZ,PENK,SERPINA3,TAP1 }\end{array}$ & $34(15)$ \\
\hline poly rl:rC-RNA & & biologic drug & Activated & 3.648 & bias & $2.86 \mathrm{E}-10$ & $\begin{array}{l}\text { B2M,Bst2,CCL5,CD74,Cxc19,GBP2,HLA- } \\
\text { A,IFITM3,IGF1,Igtp,ligp1,IRF1,LYZ,PARP14,TAP1 }\end{array}$ & $31(17)$ \\
\hline TLR4 & 1.494 & transmembrane receptor & Activated & 2.149 & bias & $5.38 \mathrm{E}-10$ & CCL5,Cxcl9, GBP2, GFAP, HLA-DQA1,Ifi47,,IFITM3, Igtp, Iigp1,IRF1,IRF8,NPPA & $31(12)$ \\
\hline CIITA & & \begin{tabular}{|l|} 
transcription regulator \\
\end{tabular} & Activated & 2.435 & & $1.03 \mathrm{E}-09$ & B2M,CD74,HLA-A,HLA-DQA1,HLA-DQB1, HLA-DRB5 & \\
\hline IL1B & 0.77 & cytokine & Activated & 2.654 & & $1.5 \mathrm{E}-09$ & $\begin{array}{l}\text { B2M,CCL5,CD74,CTSS,Cx19,CYBB,GBP2,HLA- } \\
\text { A,Ifi47,IFITM3,IGF1,IRF1,IRF8,NPPA,PENK,RAC2,SERPINA3 }\end{array}$ & $30(15)$ \\
\hline Immunoglobulin & & complex & & 0.858 & & $3.02 \mathrm{E}-09$ & $\begin{array}{l}\text { B2M,CCL5,CD74,CXC19,GFAP,HLA-A,HLA- } \\
\text { DQB1,IFITM3,IRF1,IRF8,LGALS3BP,PARP14,PENK,RAC2,SERPINA3 }\end{array}$ & $34(18)$ \\
\hline NRAS & 0.378 & enzyme & Inhibited & -2.63 & & $4.29 \mathrm{E}-09$ & B2M,CCL5,CYBB, GBP2, HLA-A, ligp1,NPPA, PENK, TAP1 & $27(11)$ \\
\hline NFAT5 & 0.301 & transcription regulator & & 0.933 & & $6.13 \mathrm{E}-09$ & CD74,Cxcl9,CYBB,HLA-DQA1,HLA-DQB1,HLA-DRB5,ligp1,IRF1 & \\
\hline $\operatorname{Irgm1}$ & 1.289 & other & Inhibited & -2.588 & bias & $7.97 \mathrm{E}-09$ & B2M,CCL5,Cxcl9,GBP2,IFITM3,ligp1,IRF1 & $33(17)$ \\
\hline
\end{tabular}




\begin{tabular}{|c|c|c|c|c|c|c|c|c|}
\hline dexamethasone & & chemical drug & & -1.963 & & $8.72 \mathrm{E}-09$ & $\begin{array}{l}\text { B2M,C1QB,CCL5,CD74,Clca3a1/CIca3a2,Cxc19,CYBB,,GBP2,HLA-A,HLA- } \\
\text { DQB1,HLA- } \\
\text { DRB5,HNRNPH1,IFITM3,IGF1,IRF1,IRF8,LGALS3BP,MPEG1,NPPA,PARP14,PE } \\
\text { NK,PTN,SERPINA3 }\end{array}$ & $37(17)$ \\
\hline $\mathrm{EBI3}$ & 0.996 & cytokine & Activated & 2.425 & bias & $1.05 \mathrm{E}-08$ & B2M,GBP2,HLA-A,HLA-DQA1,IRF1,TAP1 & $26(8)$ \\
\hline B2M & 1.931 & transmembrane receptor & Activated & 2.2 & bias & $1.32 \mathrm{E}-08$ & HLA-A,HLA-DQA1, HLA-DQB1, HLA-DRB5,TAPBP & \\
\hline IFNA2 & & cytokine & Activated & 2.79 & bias & $1.91 \mathrm{E}-08$ & B2M,CCL5,GBP2, HLA-A,IFITM3,IRF1,LGALS3BP,NPTX2,TAP1 & $27(11)$ \\
\hline IRF7 & 3.615 & transcription regulator & Activated & 2.777 & bias & $2.16 \mathrm{E}-08$ & CCL5, Ifi47, IFITM3, Igtp, IRF1,IRF8, PARP14,TAP1 & $25(9)$ \\
\hline APP & 0.006 & other & Activated & 3.073 & & $2.34 \mathrm{E}-08$ & $\begin{array}{l}\text { C4A/C4B,CCL5,CD74,CXc19,CYBB, GBP2, GFAP, Ifi47, IGF1, Igtp,IRF1,Nrgn, PARP } \\
\text { 14,PENK,TUBB2B }\end{array}$ & $33(16)$ \\
\hline POR & 0.265 & enzyme & & -1.912 & & $2.81 \mathrm{E}-08$ & CD74,GBP2,HLA-A,HLA-DQA1,HLA-DQB1,HLA-DRB5,SERPINA3,TUBB2B & \\
\hline PARP1 & -0.331 & enzyme & & 0.749 & & $3.27 \mathrm{E}-08$ & CCL5, Cxcl9, GBP2,IGF1, Igtp, Iigp 1, LGALS3BP & $32(9)$ \\
\hline IFN Beta & & group & & 1.404 & bias & $3.34 \mathrm{E}-08$ & Bst2,CCL5,CD74,Cxc19,CYBB,HLA-A,IRF1,TAPBP & $34(17)$ \\
\hline Ifn & & group & Activated & 2.588 & bias & $3.67 \mathrm{E}-08$ & B2M,HLA-A,IFITM3,IGF1,IRF1,IRF8,TAP1 & $31(9)$ \\
\hline E. coli B4 lipopolysaccharide & & chemical toxicant & Activated & 2.183 & bias & $6.34 \mathrm{E}-08$ & C1QB,CCL5,Clca3a1/CIca3a2,GBP2,HLA-A, IFITM3, Igtp, ,igp1, TAP1 & $14(3)$ \\
\hline IRF2 & 0.249 & transcription regulator & & & & $6.66 \mathrm{E}-08$ & B2M,CTSS,Ifi47,IRF1,IRF8,TAP1,TAPBP & $28(11)$ \\
\hline EIF4E & 0.15 & translation regulator & Activated & 2.795 & bias & $8.89 \mathrm{E}-08$ & B2M,Bst2,CYBB, HLA-A,HLA-DQB1, LGALS3BP,LYZ,TAPBP & \\
\hline IRF8 & 2.169 & transcription regulator & & 1.911 & & 0.000000115 & B2M, CCL5,CD74,CTSS, Cxc19,CYBB,IRF8 & $32(14)$ \\
\hline pembrolizumab & & biologic drug & Activated & 2.236 & bias & 0.000000117 & B2M,CCL5,HLA-A,HLA-DQA1,IRF1 & \\
\hline PARP9 & 0.59 & enzyme & & 0.762 & bias & 0.000000139 & CD74,HLA-DQA1,HLA-DQB1,IRF1 & \\
\hline vinorelbine & & chemical drug & & -1.718 & & 0.000000139 & B2M,CCL5,CD74,RAC2 & \\
\hline TCL1A & & transcription regulator & & & & 0.000000141 & C1QA,C1QB,CTSS,CYBB,FABP7,MPEG1 & \\
\hline $\lg G$ & & complex & & 0.475 & & 0.000000157 & B2M,CCL5,Cxc19,GFAP,IFITM3,IRF1,NPPA,TAP1,TAPBP & $30(16)$ \\
\hline PTGER4 & -0.566 & $\begin{array}{l}\text { G-protein coupled } \\
\text { receptor }\end{array}$ & Inhibited & -2.621 & & 0.000000208 & Cxc19,CYBB, GBP2,Ifi47,Igtp, IRF1,PARP14 & $32(7)$ \\
\hline HRG & & other & Activated & 2 & bias & 0.000000219 & C1QA,C1QB,CD74,HLA-DQA1 & \\
\hline PNPT1 & 0.524 & enzyme & Inhibited & -2 & bias & 0.000000226 & Bst2,CCL5,GBP2,LGALS3BP,PARP14 & \\
\hline lactosylceramide & & $\begin{array}{c}\text { chemical - endogenous } \\
\text { mammalian }\end{array}$ & & & & 0.00000033 & CCL5,CxC19,GFAP,HLA-DQA1 & $25(4)$ \\
\hline TNF & & cytokine & Activated & 3.761 & & 0.000000378 & $\begin{array}{l}\text { B2M,C4A/C4B,CCL5,CD74,CTSS,CXC19,CYBB,GBP2,GFAP,HLA- } \\
\text { A,IGF1,IRF1,IRF8,NPPA,PARP14,PENK,SERPINA3,TAP1,TAPBP }\end{array}$ & $34(17)$ \\
\hline IL10 & & cytokine & & -1.916 & & 0.000000407 & CCL5,CD74,CTSS, Cxcl9, HLA-DQB1, HLA-DRB5, Igtp, ligp1, IRF1, TAP1 & $34(14)$ \\
\hline ITPR2 & 0.207 & ion channel & Activated & 2 & bias & 0.000000477 & Bst2,Ifi47,Igtp,ligp1 & \\
\hline IGF1 & -1.406 & growth factor & & 1.603 & & 0.000000491 & C1QA,C4A/C4B,CCL5,CD74,CYBB,GFAP,IFITM3,IGF1,NPPA,PENK,TAP1 & $34(16)$ \\
\hline rosiglitazone & & chemical drug & & 0.937 & & 0.000000645 & C1QA,C1QB, C4A/C4B,CCL5,Cxc19, GBP2, IGF1,IRF1, NPPA, PENK & $30(12)$ \\
\hline beta-estradiol & & $\begin{array}{l}\text { chemical - endogenous } \\
\text { mammalian }\end{array}$ & & -1.415 & & 0.000000815 & $\begin{array}{l}\text { BRINP2,C4A/C4B,CCL5,CD74,CYBB,,ERBB4,GBP2,GFAP,HLA-A,HLA- } \\
\text { DQA1, HLA- } \\
\text { DRB5,IFITM3,IGF1,IRF1,LGALS3BP,LYZ,MPEG1,NPPA,PENK,RAC2,SERPINA3 }\end{array}$ & $33(11)$ \\
\hline RNA polymerase II & & complex & & & & 0.000000816 & \begin{tabular}{|l|} 
B2M,CCL5,GBP2,HLA-DQA1, Ifi47,IGF1,TAP1,TAPBP \\
\end{tabular} & \\
\hline EGFR & 0.84 & kinase & & -0.432 & & 0.000000818 & CCL5, ERBB4,FABP7, GFAP, HNRNPH1,IGF1,IRF1,NPPA,PCDH1,SERPINA3 & $24(5)$ \\
\hline TLR2 & 2.269 & transmembrane receptor & & 0.448 & bias & 0.000000868 & CCL5,Cxcl9,CYBB, HLA-DQA1,HLA-DRB5,IRF1,NPPA & $31(14)$ \\
\hline methylprednisolone & & chemical drug & & 0.728 & & 0.00000097 & B2M,C1QB,CD74,CTSS, CYBB,FABP7, GBP2,IGF1,IRF1,SERPINA3, TAPBP & \\
\hline CREBBP & 0.162 & transcription regulator & & 1.718 & bias & 0.00000104 & B2M, CCL5, CxcI9, CYBB B,IRF1, LGALS3BP,NPPA, SERPINA3, TAPBP & $27(12)$ \\
\hline NFkB (complex) & & complex & Activated & 2.58 & bias & 0.00000111 & CCL5, CD74,CXCl9,CYBB, GBP2, GFAP, HLA-A,IRF1,NPPA,SERPINA3, TAP1 & $31(14)$ \\
\hline IFNB1 & & cytokine & Activated & 2.405 & & 0.0000013 & Bst2, CCL5, GBP2,HLA-A,Ifi47,Igtp,IRF1, PARP14 & $33(13)$ \\
\hline TGFB1 & 0.071 & growth factor & & 0.919 & & 0.0000015 & $\begin{array}{l}\text { B2M,C1QA,C1QB,CCL5,CD74,CTSS,CYBB,GBP2,GFAP,HLA-DQA1,HLA- } \\
\text { DQB1,HLA-DRB5,HNRNPH1,IGF1,IRF1,NPPA,S100A5,SERPINA3 }\end{array}$ & $35(16)$ \\
\hline IL2 & 2.116 & cytokine & Activated & 2.104 & bias & 0.00000158 & $\begin{array}{l}\text { CCL5,CD74,CxC19,GFAP,HLA-DQA1,HLA-DQB1,HLA- } \\
\text { DRB5,IRF1,NPTX2,Nrgn,PENK }\end{array}$ & $35(13)$ \\
\hline $\mathrm{ZC} 3 \mathrm{H} 12 \mathrm{C}$ & -0.19 & other & Inhibited & -2 & bias & 0.00000159 & GBP2,Igtp,ligp1,MPEG1 & \\
\hline ERK1/2 & & group & & -1.222 & bias & 0.00000166 & B2M,CCL5,CYBB,HLA-A,NPPA,PTN,TAP1,TAPBP & $28(10)$ \\
\hline CX3CL1 & 0.594 & cytokine & & 1.067 & & 0.0000018 & BRINP2, FABP7, GFAP,IGF1, LGALS3BP, LYZ & \\
\hline IL10RA & 2.135 & transmembrane receptor & Inhibited & $\frac{1.001}{-2.813}$ & & 0.00000183 & CCL5,Cxc19,GBP2, HLA-A, Ifi47, ligp1,IRF1,TAP1 & $27(10)$ \\
\hline ETV6-RUNX1 & & fusion gene/product & Inhibited & -2.03 & bias & 0.00000201 & APOLD1, Bst2,CCL5,CYBB, GBP2,IRF1,IRF8,RAC2 & \\
\hline AGN194204 & & chemical drug & Activated & 2.646 & bias & 0.0000024 & GBP2, Ifi47,IFITM3, Igtp, IRF1, PENK,TAP1 & \\
\hline JUND & 0.106 & transcription regulator & & & & 0.00000257 & C1QB,CCL5,Cxcl9,CYBB,PENK & $9(3)$ \\
\hline IFN alpha/beta & & group & Activated & 2 & bias & 0.00000273 & CCL5, Cxc19,HLA-A,IRF1,IRF8 & $27(10)$ \\
\hline MEF2A & -0.036 & transcription regulator & & 0.907 & bias & 0.00000273 & Cxcl9, GBP2, Ifi47, IRF1,NPPA & \\
\hline CpG ODN 1826 & & chemical reagent & Activated & 2.194 & & 0.0000029 & CCL5,Cxc19,CYBB,HLA-DQB1,PARP14 & \\
\hline IL6R & 0.299 & transmembrane receptor & & 0.528 & bias & 0.00000345 & CCL5,IGF1,IRF1,PENK,SERPINA3 & $28(8)$ \\
\hline JAK2 & 0.591 & kinase & Activated & 2.423 & bias & 0.00000369 & CCL5,CYBB,GBP2,GFAP,IRF1,TAP1 & $30(12)$ \\
\hline SSB & -0.031 & enzyme & Inhibited & $\frac{2.425}{-2.236}$ & & 0.00000387 & \begin{tabular}{|l|} 
C4A/C4B,CD74,CYBB,HLA-DQA1,HLA-DQB1 \\
\end{tabular} & \\
\hline 17-alpha-ethinylestradiol & & chemical drug & & -0.896 & & 0.00000398 & C1 QB,CCL5,CD74,CTSS,FABP7,IGF1 & $7(2)$ \\
\hline
\end{tabular}




\begin{tabular}{|c|c|c|c|c|c|c|c|c|}
\hline cyclophosphamide & & chemical drug & & -1.432 & & 0.00000409 & B2M,C4A/C4B,CCL5,CD74,RAC2 & \\
\hline kainic acid & & chemical toxicant & & 1.188 & bias & 0.0000046 & APOLD1,CCL5,ERBB4,GFAP,NPTX2,PENK & \\
\hline B4GALNT1 & 0.563 & enzyme & & & & 0.00000515 & $\mathrm{C} 1 \mathrm{QA}, \mathrm{C} 1 \mathrm{QB}, \mathrm{C} 4 \mathrm{~A} / \mathrm{C} 4 \mathrm{~B}$ & \\
\hline ACKR2 & & $\begin{array}{l}\text { G-protein coupled } \\
\text { receptor }\end{array}$ & Inhibited & -2 & bias & 0.00000534 & CCL5,Cxc19, Ifi47, ligp1 & \\
\hline BMP10 & & growth factor & & -1.342 & & 0.00000536 & CD74,HLA-A,NPPA,PTN,SERPINA3 & $25(4)$ \\
\hline ZNF106 & -0.029 & other & Inhibited & -2 & & 0.00000586 & C4A/C4B,IFITM3,LYZ,SERPINA3 & \\
\hline E. coli B5 lipopolysaccharide & & $\begin{array}{c}\text { chemical - endogenous } \\
\text { non-mammalian }\end{array}$ & Activated & 2.586 & & 0.00000635 & B2M,CCL5,CYBB,GBP2,HLA-A, Igtp,IRF1 & $32(15)$ \\
\hline CSF1 & 0.589 & cytokine & & 0.184 & bias & 0.00000651 & CCL5,CD74,CYBB,HLA-A,IGF1, ligp1,IRF8 & $32(15)$ \\
\hline fluticasone propionate & & chemical drug & & -1.747 & & 0.00000695 & C1QB,CCL5,CD74,HLA-DQA1,IRF8,TAP1 & \\
\hline SENP3 & 0.472 & peptidase & & 1.982 & bias & 0.00000702 & Bst2,Cxc19,HLA-A,TAP1 & \\
\hline $\mathrm{Hbb}-\mathrm{b} 2$ & & other & Activated & 2 & bias & 0.00000702 & C1QA,CD74,Cxc19,CYBB & \\
\hline Pam3-Cys-Ser-Lys4 & & chemical reagent & & 1.026 & bias & 0.00000743 & CCL5,Cxcl9,HLA-A,HLA-DRB5,IRF1,PARP14 & $29(13)$ \\
\hline tretinoin & & $\begin{array}{l}\text { chemical - endogenous } \\
\text { mammalian }\end{array}$ & Activated & 3.639 & & 0.00000744 & $\begin{array}{l}\text { C1QA,CD74,Clca3a1/Clca3a2,CTSS,CYBB,GFAP,HLA- } \\
\text { A,IGF1,IRF1,IRF8,LGALS3BP,NPPA,Nrgn,PARP14,PENK,TAP1 }\end{array}$ & $36(17)$ \\
\hline F2RL1 & & $\begin{array}{l}\text { G-protein coupled } \\
\text { receptor }\end{array}$ & & & & 0.00000762 & GBP2, ligp1,IRF8,NPTX2,SERPINA3 & \\
\hline aldesleukin & & biologic drug & Activated & 2 & bias & 0.00000765 & \begin{tabular}{|l|} 
B2M,IRF1,TAP1,TAPBP \\
\end{tabular} & \\
\hline CSF3 & & cytokine & & -0.277 & & 0.00000818 & CCL5,CYBB,GFAP,HLA-DQA1,IGF1,LYZ & $28(7)$ \\
\hline PSEN2 & 1.139 & peptidase & Inhibited & -2.211 & & 0.00000839 & C1QA,C1QB,CD74,CTSS,GFAP & \\
\hline HOXA9 & & transcription regulator & & & & 0.00000929 & CYBB,IGF1,LYZ,NPPA,Nrgn,PCDH1 & \\
\hline PSEN1 & 0.555 & peptidase & Inhibited & -2.205 & & 0.0000105 & C1QA,C1QB,CCL5,CD74,CTSS, GFAP,IGF1,TUBB2B & \\
\hline IFN type 1 & & group & & 1.972 & bias & 0.0000106 & Bst2,CCL5,Cxcl9,IRF1 & $27(12)$ \\
\hline TARDBP & 0.555 & transcription regulator & Inhibited & -2 & & 0.0000106 & C1QA,C1QB,GBP2,HLA-A & \\
\hline PRL & & cytokine & Activated & 2.593 & bias & 0.0000107 & B2M,CTSS, ERBB4,IRF1,PARP 14,PENK,SERPINA3 & \\
\hline mir-21 & & microRNA & & -1.709 & bias & 0.0000112 & Cxc19,GBP2, GFAP, Ifi47, ligp1,IRF1,TAP1 & $34(12)$ \\
\hline MYD88 & 1.446 & other & & 0.292 & bias & 0.0000115 & CCL5,Cxcl9,HLA-A,IGF1,IRF1,IRF8,NPPA & $30(14)$ \\
\hline pyrrolidine dithiocarbamate & & chemical reagent & & -0.492 & bias & 0.0000126 & CCL5,Cxc19,IGF1,IRF1,NPPA & $31(14)$ \\
\hline CCR2 & & $\begin{array}{l}\text { G-protein coupled } \\
\text { receptor }\end{array}$ & & 1.206 & bias & 0.0000132 & C1QA,C1QB,CCL5,Cxc19,IGF1 & \\
\hline AR & 0.227 & $\begin{array}{l}\text { ligand-dependent } \\
\text { nuclear receptor }\end{array}$ & & -0.294 & & 0.0000144 & ACBD7,C4A/C4B,CCL5,FABP7, GFAP,HLA-A,IGF1,Nrgn,PENK,SERPINA3 & \\
\hline SAFB & 0.192 & other & Inhibited & -2 & bias & 0.0000144 & B2M,CCL5,CD74,IGF1 & \\
\hline BIRC5 & 3.253 & other & & & & 0.0000155 & CD74,HLA-DQA1,HLA-DQB1,LYZ & \\
\hline PS-1145 & & chemical drug & & & & 0.0000172 & CCL5,IRF1,SERPINA3 & $22(6)$ \\
\hline PSMB11 & -3.84 & peptidase & & -0.447 & bias & 0.0000199 & CCL5,CTSS,Cxc19,GFAP,GNG13 & \\
\hline IL1R1 & 1.744 & transmembrane receptor & & 0.686 & bias & 0.0000204 & \begin{tabular}{|l|l|} 
CCL5, Cxcl9, GFAP,IGF1 \\
\end{tabular} & $28(10)$ \\
\hline STAT2 & 0.432 & transcription regulator & & & & 0.0000204 & CCL5, Ifi47, ligp1, IRF1 & $19(3)$ \\
\hline IFI30 & 2.817 & enzyme & & & & 0.0000212 & CTSS, HLA-A & \\
\hline valsartan & & chemical drug & & -1 & bias & 0.0000218 & CTSS,CYBB,GFAP,NPPA & \\
\hline filgrastim & & biologic drug & Inhibited & -2.157 & & 0.0000223 & B2M,CCL5,CD74,CYBB,HLA-DQB1,HLA-DRB5,MPEG1,PARP14 & \\
\hline NLRC5 & 2.976 & transcription regulator & & & & 0.0000236 & B2M,HLA-A,TAP1 & \\
\hline ADORA3 & & $\begin{array}{l}\text { G-protein coupled } \\
\text { receptor }\end{array}$ & & & & 0.0000236 & CCL5,IRF1,NPPA & $22(6)$ \\
\hline ST8SIA1 & 0.38 & enzyme & & & & 0.0000236 & C1QA,C1QB,C4A/C4B & \\
\hline OSMR & 1.902 & transmembrane receptor & & & & 0.0000248 & Cxcl9, GBP2, Ifi47, Igtp & \\
\hline $\mathrm{BCL3}$ & 2.5 & \begin{tabular}{|l|} 
transcription regulator \\
\end{tabular} & Inhibited & -2 & & 0.0000248 & CCL5,Cxc19,HLA-DQB1,IRF1 & $18(5)$ \\
\hline LIF & & cytokine & & 1.346 & & 0.0000252 & GFAP,IGF1,IRF1,NPPA,OMP,SERPINA3 & $26(7)$ \\
\hline CD40 & & transmembrane receptor & & 1.402 & bias & 0.0000301 & CCL5,Cxc19,HLA-DQB1,IRF1, TAP1, TAPBP & $29(14)$ \\
\hline NFKBIA & 0.37 & \begin{tabular}{|l|} 
transcription regulator \\
\end{tabular} & & 0.553 & & 0.0000307 & CCL5,CD74,GBP2,HLA-A,HLA-DQA1,IRF1,LYZ,NPPA & $29(11)$ \\
\hline cuprizone & & chemical toxicant & & & & 0.0000313 & CCL5,GFAP,IGF1 & \\
\hline RHO & & $\begin{array}{l}\text { G-protein coupled } \\
\text { receptor }\end{array}$ & Inhibited & -2 & & 0.0000316 & B2M,C1QA,CD74,CTSS & \\
\hline trovafloxacin & & chemical drug & Activated & 2 & & 0.0000335 & B2M,HLA-A,Igtp,IRF1 & \\
\hline gentamicin & & chemical drug & & 0.816 & & 0.000041 & C1QA,C1QB,C4A/C4B,IRF1,PTN,SEZ6L,TAP1 & \\
\hline ADCYAP1 & -1.482 & other & & -0.293 & & 0.0000432 & CCL5,GFAP,IRF1,SERPINA3,SEZ6L,TUBB2B & $15(5)$ \\
\hline Iosartan potassium & & chemical drug & & 0.447 & & 0.0000438 & CYBB, GBP2, Ifi47,IGF1,NPPA & $26(7)$ \\
\hline RXRB & 0.428 & $\begin{array}{l}\text { ligand-dependent } \\
\text { nuclear receptor }\end{array}$ & & & & 0.0000443 & C1QA,CTSS,IGF1,LYZ & $4(2)$ \\
\hline PLK2 & 0.294 & kinase & & & & 0.0000457 & Cxc19, Iigp 1,IRF1 & \\
\hline immethridine & & chemical reagent & & & & 0.0000457 & C4A/C4B,CTSS,SERPINA3 & \\
\hline REL & 0.644 & transcription regulator & & & & 0.0000463 & B2M,Cxcl9,HLA-A, ligp1,IRF8,PARP14 & \\
\hline APOE & 0.129 & transporter & & -1.964 & bias & 0.0000465 & C1QA,C1QB,CCL5,CTSS,CYBB,IGF1,SERPINA3 & $11(3)$ \\
\hline
\end{tabular}




\begin{tabular}{|c|c|c|c|c|c|c|c|c|}
\hline NR3C2 & 2.237 & $\begin{array}{l}\text { ligand-dependent } \\
\text { nuclear receptor }\end{array}$ & & 1.091 & & 0.0000468 & CCL5,HLA-DQB1,IGF1,NPPA,SERPINA3 & $27(7)$ \\
\hline KRAS & -0.316 & enzyme & & -0.378 & & 0.0000504 & B2M,CD74,CYBB,GFAP,IFITM3,IRF1,LYZ,PCDH1,SERPINA3,TAP1 & $30(9)$ \\
\hline PROCR & 0.94 & other & & & & 0.0000513 & GBP2,ligp1,IRF8 & \\
\hline PLK4 & 1.739 & kinase & & & & 0.0000513 & Cxc19, ligp 1,IRF1 & \\
\hline THRA & 0.388 & $\begin{array}{l}\text { ligand-dependent } \\
\text { nuclear receptor }\end{array}$ & & -1.067 & & 0.0000531 & IGF1,IRF1,NPPA,Nrgn,PENK & \\
\hline prostaglandin E2 & & $\begin{array}{c}\text { chemical - endogenous } \\
\text { mammalian }\end{array}$ & & -1.52 & & 0.0000572 & CCL5,Cxcl9,GFAP,IGF1, ligp1,IRF1,PENK & $34(18)$ \\
\hline DUSP1 & -0.176 & phosphatase & & -0.528 & & 0.0000602 & CYBB, IFITM3, Iigp1,IRF1,IRF8 & $20(4)$ \\
\hline MAP3K7 & & kinase & & 0.063 & & 0.0000605 & CCL5,GBP2,IRF1,NPPA & $26(10)$ \\
\hline IFNAR1 & 0.654 & transmembrane receptor & Activated & 2.2 & bias & 0.000062 & B2M,CCL5,Cxc19,HLA-A,IRF1 & $32(17)$ \\
\hline dehydroisoandrosterone & & \begin{tabular}{|c|}
$\begin{array}{c}\text { chemical - endogenous } \\
\text { mammalian }\end{array}$ \\
\end{tabular} & & & & 0.0000667 & B2M,GFAP,IGF1,NPPA & $17(6)$ \\
\hline NCOA2 & 0.137 & transcription regulator & & 1.96 & & 0.0000679 & CCL5,CXC19,HLA-A,IRF1,LYZ & \\
\hline fingolimod & & chemical drug & & -1.969 & bias & 0.00007 & CCL5,Cxc19,HLA-DQA1,HLA-DQB1 & \\
\hline atenolol & & chemical drug & & & & 0.0000704 & B2M,NPPA & \\
\hline RPSA & 0.035 & translation regulator & & & & 0.0000708 & CCL5,Ifi47,TAP1 & \\
\hline CNTF & -2.154 & cytokine & & & & 0.0000734 & GFAP,IRF1,PENK,SERPINA3 & $19(5)$ \\
\hline TLR3 & 0.655 & transmembrane receptor & & 1.941 & bias & 0.0000734 & CCL5,Cxc19,GBP2,Ifi47,ligp1,IRF1 & $29(18)$ \\
\hline Nuclear factor 1 & & group & & & & 0.0000782 & FABP 7, GFAP,SERPINA 3 & \\
\hline USP18 & 2.796 & peptidase & & & & 0.0000782 & CCL5,IFITM3,IRF1 & \\
\hline CNOT7 & 0.147 & transcription regulator & & & & 0.0000782 & B2M,LGALS3BP,TAP1 & \\
\hline MAPK1 & 0.472 & kinase & Inhibited & -2.449 & & 0.0000797 & CCL5,GBP2,IFITM3,LGALS3BP,NPPA,NPTX2,TAP1 & $15(4)$ \\
\hline NPC1 & -0.015 & transporter & & & & 0.0000922 & CD74,HLA-DQB1,HLA-DRB5,LYZ & \\
\hline MARK2 & 0.161 & kinase & & & & 0.0000945 & IGF1, ligp1,IRF1 & \\
\hline IL21 & & cytokine & Activated & 2 & bias & 0.000113 & CCL5,Cxc19,HLA-DRB5,Igtp,TAP1 & $27(7)$ \\
\hline RARB & -0.468 & $\begin{array}{l}\text { ligand-dependent } \\
\text { nuclear receptor }\end{array}$ & Activated & 2.236 & & 0.000113 & GBP2, Ifi47, Igtp,ligp 1,LYZ & \\
\hline ACE2 & 0.52 & peptidase & & & & 0.000113 & CCL5,Cxcl9,CYBB & \\
\hline Hbb-b1 & & transporter & Activated & 2 & bias & 0.000114 & C1QA,CD74,Cxc19,CYBB & \\
\hline 6-hydroxydopamine & & chemical toxicant & & & & 0.000114 & CCL5,CYBB,GFAP,PENK & $28(7)$ \\
\hline dextran sulfate & & chemical drug & & & & 0.000125 & C4A/C4B,CCL5,CD74,Cxc19,IFITM3,PTN & $25(4)$ \\
\hline OSM & & cytokine & Activated & 2.767 & & 0.000127 & B2M,CCL5,GBP2,HLA-A,IRF1,SERPINA3,TAP1,TAPBP & $26(13)$ \\
\hline hemin & & $\begin{array}{c}\text { chemical - endogenous } \\
\text { mammalian }\end{array}$ & & & & 0.000129 & CYBB,GFAP,IGF1,NPPA & \\
\hline IKBKB & 0.151 & kinase & & 1.186 & bias & 0.00013 & CCL5,Cxc19,GBP2,HLA-A,IRF1,NPPA & $28(13)$ \\
\hline CTF1 & & cytokine & & & & 0.000134 & IRF1,NPPA,SERPINA3 & $22(7)$ \\
\hline Ifn gamma & & complex & & & & 0.000135 & CCL5,CxC19,CYBB,IRF8 & $13(3)$ \\
\hline $\begin{array}{l}\text { E. coli serotype } 0127 \mathrm{~B} 8 \\
\text { lipopolysaccharide }\end{array}$ & & \begin{tabular}{|c|}
$\begin{array}{c}\text { chemical - endogenous } \\
\text { non-mammalian }\end{array}$ \\
\end{tabular} & Activated & 2.219 & & 0.000135 & CCL5,Cxc19,Ifi47,IGF1,IRF1 & $30(14)$ \\
\hline NR3C1 & 0.437 & $\begin{array}{c}\text { ligand-dependent } \\
\text { nuclear receptor }\end{array}$ & & -1.446 & & 0.000136 & B2M,C4A/C4B,CCL5,Cxc19,GBP2,IGF1,IRF1,IRF8,NPPA & $34(15)$ \\
\hline IL17A & & cytokine & & 0.849 & bias & 0.000138 & B2M,CCL5,Cxcl9,GBP2,IGF1,IRF1 & $31(16)$ \\
\hline GATA1 & & transcription regulator & & 0.152 & & 0.000138 & CCL5,Clca3a1/Clca3a2,CYBB,IRF8,LYZ,NPPA & \\
\hline STAT & & group & & & & 0.000145 & IRF1,NPPA,SERPINA3 & \\
\hline lisinopril & & biologic drug & & & & 0.000145 & CYBB,GBP2,Ifi47 & \\
\hline $\begin{array}{c}\text { 1-methyl-4-phenyl-1,2,3,6- } \\
\text { tetrahydropyridine }\end{array}$ & & chemical toxicant & & 1.868 & & 0.000146 & CCL5,CYBB,GFAP,PENK & $28(7)$ \\
\hline Histone $\mathrm{H} 2 \mathrm{~b}$ & & group & & & & 0.000147 & Ifii47,IRF1 & \\
\hline PIK3C3 & 0.216 & kinase & & & & 0.000147 & HLA-A,HLA-DQB1 & \\
\hline tyrphostin AG490 & & chemical drug & & -1.177 & bias & 0.000151 & CCL5,GFAP,IGF1,IRF1 & $32(12)$ \\
\hline $\mathrm{N}$-cor & & group & & & & 0.000163 & C1QA,CCL5,CTSS,IGF1 & \\
\hline IL13 & & cytokine & & 0.521 & & 0.000166 & CCL5,Clca3a1/Clca3a2,CTSS,CYBB,ERBB4,HLA-DRB5,IGF1 & $16(2)$ \\
\hline ethanol & & \begin{tabular}{|c|} 
chemical - endogenous \\
mammalian
\end{tabular} & & 0.342 & & 0.000168 & CCL5,Cxc19,GFAP,HLA-A, Ifi47,NPPA,Nrgn & $29(14)$ \\
\hline RNASEH2A & 1.63 & enzyme & & & & 0.000182 & GBP2,IFITM3,IRF1 & \\
\hline CYP19A1 & & enzyme & & 0.762 & & 0.000183 & GBP2,GFAP,HLA-A,IGF1 & \\
\hline sildenafil & & chemical drug & & & & 0.000196 & CYBB,GFAP,NPPA & \\
\hline ibuprofen & & chemical drug & & & & 0.000196 & CYBB,GFAP,SERPINA3 & $22(6)$ \\
\hline S-nitrosoglutathione & & chemical toxicant & & & & 0.000196 & CCL5,GFAP,IGF1 & \\
\hline doxorubicin & & chemical drug & & 1.655 & & 0.000196 & C4A/C4B,CYBB,IRF1,LGALS3BP,NPPA,RAC2,TAP1 & \\
\hline GSK0660 & & chemical reagent & & & & 0.000196 & C1QA,C1QB & \\
\hline CLTC & -0.008 & other & & & & 0.000196 & CD74,HLA-A & \\
\hline
\end{tabular}




\begin{tabular}{|c|c|c|c|c|c|c|c|c|}
\hline TAPBP & 1.268 & transporter & & & & 0.000196 & HLA-A,TAP1 & \\
\hline dihydrotestosterone & & $\begin{array}{c}\text { chemical - endogenous } \\
\text { mammalian }\end{array}$ & & -0.047 & & 0.000201 & B2M,C4A/C4B,CD74,CYBB,GFAP,HLA-A,IGF1,LYZ & $32(9)$ \\
\hline ARHGAP21 & 0.552 & other & & & & 0.00021 & Cxc19, ligp 1,IRF1 & \\
\hline Cdc42 & -0.016 & enzyme & & & & 0.00021 & CTSS,GFAP,NPPA & \\
\hline VIP & -0.691 & other & & -0.815 & & 0.000211 & CCL5,IGF1,IRF1,LYZ & $30(12)$ \\
\hline CEBPB & -0.102 & transcription regulator & & 0.277 & bias & 0.000214 & C1QA,CCL5,CD74,GFAP,HLA-A,IFITM3,IGF1,RAC2 & $29(7)$ \\
\hline SoX4 & 0.138 & transcription regulator & & 1.342 & bias & 0.000234 & CD74,HLA-DQB1,IGF1,LYZ,TUBB2B & \\
\hline IL12 (complex) & & complex & & & & 0.000244 & CCL5, Cxc19, ligp1,IRF1,IRF8 & $30(15)$ \\
\hline PSMB9 & 5.28 & peptidase & & & & 0.000252 & HLA-A,TAP1 & \\
\hline RFXAP & 0.649 & transcription regulator & & & & 0.000252 & B2M,HLA-DQA1 & $6(2)$ \\
\hline HA900 & & chemical reagent & & & & 0.000252 & CCL5,PTN & \\
\hline KIT & 0.332 & transmembrane receptor & & & & 0.000259 & Cxcl9,Ifi47,Igtp,IRF1 & \\
\hline IFNGR1 & 0.328 & transmembrane receptor & & & & 0.000274 & CCL5,Cxcl9,IRF1 & $26(11)$ \\
\hline ZFTA-RELA & & fusion gene/product & & & & 0.000274 & IRF1,TAP1,TAPBP & \\
\hline RELA & 0.457 & transcription regulator & & 1.13 & bias & 0.000276 & B2M,CCL5,CYBB,IGF1,IRF1, TAP1,TAPBP & $29(12)$ \\
\hline SMARCA4 & -0.088 & transcription regulator & & 1.913 & bias & 0.000281 & \begin{tabular}{|l} 
CD74,CTSS,IFITM3,IGF1,IRF1,PCDH1,RAC2,TAP1 \\
\end{tabular} & $15(3)$ \\
\hline $\mathrm{DMD}$ & -0.099 & other & & & & 0.000303 & C1QB,CTSS,IGF1,LYZ,MPEG1 & \\
\hline B4GALT6 & -0.263 & enzyme & & & & 0.000314 & CCL5,GFAP & \\
\hline ganetespib & & chemical drug & & & & 0.000314 & \begin{tabular}{|l|} 
HLA-A,HLA-DQA1 \\
\end{tabular} & \\
\hline cortistatin A & & chemical reagent & & & & 0.000314 & IRF1,IRF8 & \\
\hline $\begin{array}{c}\text { salmonella minnesota R595 } \\
\text { lipopolysaccharides }\end{array}$ & & $\begin{array}{c}\text { chemical - endogenous } \\
\text { non-mammalian }\end{array}$ & & 1.964 & bias & 0.000314 & CCL5,HLA-DQA1,IRF1,IRF8 & $27(9)$ \\
\hline mimosine & & chemical drug & & & & 0.000383 & HLA-DQA1,HLA-DQB1 & \\
\hline JUN & 0.137 & transcription regulator & & -0.669 & bias & 0.000385 & C1QB,Clca3a1/Clca3a2,Cxc19,FABP7,IGF1,NPPA,PENK & \\
\hline BAX & 0.341 & transporter & & & & 0.000391 & CCL5,CTSS,HLA-A & \\
\hline NR1H3 & 0.841 & $\begin{array}{l}\text { ligand-dependent } \\
\text { nuclear receptor }\end{array}$ & & & & 0.000395 & Bst2,C1QA,CCL5,LYZ,TAP1 & \\
\hline epigallocatechin-gallate & & chemical drug & Inhibited & -2.204 & & 0.000419 & CCL5,Ifi47,IRF1,PTN,TAP1 & $28(10)$ \\
\hline IL1RN & & cytokine & Inhibited & -2 & bias & 0.000425 & CTSS, HLA-DQB1,IGF1,IRF1 & $21(4)$ \\
\hline MOG & 0.554 & other & & & & 0.000436 & CCL5,Cxc19,IGF1 & $22(6)$ \\
\hline CDK9 & 1.441 & kinase & & & & 0.000436 & CCL5,HLA-DQA1,HNRNPH1 & \\
\hline FCGR2A & 0.857 & transmembrane receptor & & & & 0.000436 & CCL5,GBP2,IFITM3 & $9(3)$ \\
\hline RAS & & group & & & & 0.000438 & GBP2,Ifi47,IGF1,IRF1 & \\
\hline diaminopimelic acid & & $\begin{array}{c}\text { chemical - endogenous } \\
\text { non-mammalian }\end{array}$ & & & & 0.000459 & CCL5,Cxc19 & \\
\hline 15-deoxy-delta-12,14 -PGJ 2 & & $\begin{array}{c}\text { chemical - endogenous } \\
\text { mammalian }\end{array}$ & & -0.714 & & 0.000461 & CCL5,CYBB,GFAP,IRF1,NPPA & $29(12)$ \\
\hline CTCF & 0.179 & transcription regulator & & & & 0.000476 & HLA-DQA1,HLA-DQB1,HLA-DRB5,LYZ & \\
\hline LDLR & 0.624 & transporter & & & & 0.000479 & Bst2,C1QA,CCL5,LYZ,TAP1 & \\
\hline Growth hormone & & group & & 0.615 & & 0.000497 & CCL5, GFAP,IGF1,IRF1,NPPA & $29(13)$ \\
\hline ADAM10 & -0.016 & peptidase & & & & 0.000532 & CD74,FABP7,OMP,TUBB2B & \\
\hline IKBKG & 1.928 & kinase & & 1.934 & bias & 0.000532 & CCL5,GBP2,HLA-A,NPPA & $27(13)$ \\
\hline mibolerone & & chemical drug & Inhibited & -2 & & 0.000532 & C4A/C4B,CD74,HLA-DQA1,IGF1 & \\
\hline cardiotoxin & & chemical - other & & 1 & bias & 0.000535 & B2M,CCL5,Cxc19,IGF1,PTN & \\
\hline NCOR2 & 0.274 & transcription regulator & & & & 0.000536 & \begin{tabular}{|l|} 
C1QA,CTSS,IGF1 \\
\end{tabular} & $5(2)$ \\
\hline $\mathrm{Ccl} 2$ & & cytokine & & & & 0.000536 & CCL5,CYBB,IGF1 & $17(6)$ \\
\hline heme & & $\begin{array}{c}\text { chemical - endogenous } \\
\text { mammalian }\end{array}$ & & & & 0.000536 & CCL5,CxCl9,CYBB & $22(7)$ \\
\hline CCL3L3 & 1.626 & cytokine & & & & 0.000542 & CCL5,Cxc19 & \\
\hline tacrolimus & & chemical drug & & & & 0.000545 & CCL5,CD74,CYBB,NPPA,PENK & $33(13)$ \\
\hline ciglitazone & & chemical drug & & -1 & & 0.000561 & CCL5,CYBB,GFAP,NPPA & $24(9)$ \\
\hline CSF2 & & cytokine & & 1.218 & bias & 0.000562 & C4A/C4B,CD74,Cxc19,CYBB,HLA-DQB1,IFITM3,IGF1 & $37(9)$ \\
\hline IL11 & & cytokine & & & & 0.000563 & IGF1,IRF1,SERPINA3 & $4(2)$ \\
\hline IL1A & 2.089 & cytokine & & 1.319 & bias & 0.000565 & C4A/C4B,CCL5,IGF1,IRF1,SERPINA3 & $27(11)$ \\
\hline Socs1 & 3.005 & other & & -1.934 & bias & 0.000576 & Cxc19, Ifi47, ligp 1, IRF1 & $20(6)$ \\
\hline LY294002 & & chemical drug & & -1.132 & bias & 0.000587 & CCL5,CD74,Cxc19,GFAP,IGF1,IRF1,PTN & $33(16)$ \\
\hline ACOX1 & -0.224 & enzyme & Inhibited & -2 & & 0.000623 & HLA-DQA1, HLA-DRB5,IGF1, LGALS3BP & \\
\hline HTT & 0.224 & transcription regulator & & & & 0.00063 & B2M,CCL5,CD74,FABP7,GFAP,MPEG1,PENK,SERPINA3 & \\
\hline TRPV1 & & ion channel & & & & 0.000631 & GFAP,HLA-DQB1 & \\
\hline trichostatin $\mathrm{A}$ & & chemical drug & & 1.238 & & 0.000631 & B2M,CYBB,HLA-DQB1,IGSF9,IRF1,IRF8,NPPA,PENK,SEZ6L & \\
\hline TICAM1 & -0.623 & other & & 1.943 & bias & 0.00064 & CCL5, Ifi47,Igtp,IRF1 & $26(9)$ \\
\hline PRDM1 & -0.528 & transcription regulator & & -1.406 & & 0.000651 & CD74,HLA-DQA1,IRF8,SERPINA3,TAPBP & \\
\hline morphine & & chemical drug & & -0.83 & & 0.000656 & CYBB,GFAP,NPPA,PENK & $12(3)$ \\
\hline
\end{tabular}




\begin{tabular}{|c|c|c|c|c|c|c|c|c|}
\hline AGT & -0.795 & growth factor & & 1.379 & & 0.000657 & C4A/C4B,CCL5,CTSS,CYBB,IGF1,NPPA,NPTX2,PTN,SERPINA3 & $29(14)$ \\
\hline CD40LG & & cytokine & & & & 0.000689 & B2M,CCL5,HLA-DQA1,HLA-DQB1,IRF1,TAP1 & $30(14)$ \\
\hline U0126 & & chemical drug & & -0.025 & bias & 0.000705 & CCL5,CYBB, GFAP, HLA-DQA1,IRF1,NPPA,RAC2 & $23(6)$ \\
\hline Iovastatin & & chemical drug & & -1 & & 0.000708 & CCL5,GFAP,IGF1,IRF1 & $31(9)$ \\
\hline CUX1 & & transcription regulator & & & & 0.000712 & CCL5,CYBB,NPPA & \\
\hline GFI1 & & transcription regulator & & & & 0.000726 & ligp1,IRF1,LYZ,SERPINA3 & \\
\hline SMC3 & 0.227 & other & & & & 0.000727 & HLA-DQA1,HLA-DQB1 & \\
\hline CRKL & -0.033 & kinase & & & & 0.000727 & Cxc19,ligp1 & \\
\hline PIAS4 & 0.196 & transcription regulator & & & & 0.000727 & Cxc19,IRF1 & $19(7)$ \\
\hline RFX5 & & transcription regulator & & & & 0.000727 & $\mathrm{~B} 2 \mathrm{M}, \mathrm{CD} 74$ & \\
\hline vadimezan & & chemical drug & & & & 0.000727 & CCL5,IRF1 & $18(6)$ \\
\hline PPARD & -0.121 & $\begin{array}{l}\text { ligand-dependent } \\
\text { nuclear receptor }\end{array}$ & & 0.537 & & 0.000734 & C1QA,C1QB,FABP7,MPEG1,NPPA & $8(2)$ \\
\hline monocrotaline & & chemical toxicant & & & & 0.000745 & CCL5,CYBB,NPPA & $16(5)$ \\
\hline Go 6976 & & chemical drug & & & & 0.000778 & CCL5,CYBB,NPPA & $26(12)$ \\
\hline AZD8055 & & chemical drug & & & & 0.000829 & $\mathrm{CCL5, \textrm {CxCl9 }}$ & \\
\hline VIPR1 & -0.217 & $\begin{array}{l}\text { G-protein coupled } \\
\text { receptor }\end{array}$ & & & & 0.000829 & CCL5,IRF1 & $13(4)$ \\
\hline pyridostigmine & & chemical drug & & & & 0.000829 & Cxc19,NPPA & \\
\hline forskolin & & chemical toxicant & & -1.281 & & 0.000837 & CCL5,GFAP,HLA-DQA1,HLA-DQB1,IGF1,NPPA,NPTX2,PENK & $25(9)$ \\
\hline DOCK8 & 0.019 & other & & & & 0.000848 & Cxcl9, ligp1,IRF1 & \\
\hline STING1 & 1.402 & other & & & & 0.000848 & CCL5,Cxc19,IFITM3 & $28(8)$ \\
\hline TNFSF13B & & cytokine & & & & 0.000848 & CD74,CTSS,HLA-DQA1 & $4(2)$ \\
\hline CREB1 & 0.202 & transcription regulator & & -0.174 & & 0.000867 & APOLD1,BRINP2,HLA-A,HLA-DQB1,NPTX2,Nrgn,PENK & \\
\hline GATA2 & 1.036 & transcription regulator & & -0.577 & & 0.000867 & C110rf97,CCL5,CYBB, GBP2,NPPA,S100A5 & \\
\hline ERBB2 & 0.583 & kinase & & -1.133 & & 0.00088 & CCL5,CXC19,ERBB4,NPTX2,PCDH1,PENK,SERPINA3,TAP1,TAPBP & $15(4)$ \\
\hline SP1 & 0.563 & transcription regulator & & & & 0.000893 & CCL5,IFITM3,IGF1,IRF1,NPPA,PENK,PTN & \\
\hline JAK1 & 0.172 & kinase & & & & 0.000921 & HLA-A,IRF1,TAP1 & $26(8)$ \\
\hline PLAU & & peptidase & & & & 0.000921 & CCL5,IGF1,PTN & $7(2)$ \\
\hline $\mathrm{RC} 3 \mathrm{H} 1$ & 0.575 & enzyme & & & & 0.00096 & CCL5,IFITM3,IRF1 & \\
\hline vorinostat & & chemical drug & Inhibited & -2.236 & & 0.000968 & CD74,HLA-DQB1,HLA-DRB5,IRF1,LYZ & $25(4)$ \\
\hline geldanamycin & & chemical drug & & -1.342 & & 0.00103 & HLA-DQA1,IRF1,NPPA,PCDH1,TAP1 & \\
\hline Endothelin & & group & & & & 0.00105 & CD74,NPPA & \\
\hline ADORA1 & -0.341 & $\begin{array}{l}\text { G-protein coupled } \\
\text { receptor }\end{array}$ & & & & 0.00105 & NPPA,PENK & \\
\hline ATXN7 & -0.541 & other & & & & 0.00105 & GNG13,PENK & \\
\hline TGAL copolymer & & biologic drug & & & & 0.00105 & CCL5,IGF1 & \\
\hline VCAN & 1.011 & other & & 1 & & 0.00106 & C4A/C4B,IRF8,PARP14,PENK & \\
\hline levothyroxine & & $\begin{array}{l}\text { chemical - endogenous } \\
\text { mammalian }\end{array}$ & & & & 0.00108 & NPPA,Nrgn,PENK & $5(2)$ \\
\hline STK40 & -0.705 & kinase & & & & 0.00112 & C1QA,C1QB,HLA-DQA1 & \\
\hline NFKB1 & -0.398 & transcription regulator & & & & 0.00116 & B2M,CCL5,Cxcl9, CYBB,IRF1 & $28(12)$ \\
\hline SMURF1 & -0.455 & enzyme & & & & 0.00118 & \begin{tabular}{|l|l|} 
Cxcl9,IRF1 \\
\end{tabular} & \\
\hline Cux1 & 0.209 & transcription regulator & & & & 0.00118 & CCL5,Cxc19 & \\
\hline triflusal & & chemical drug & & & & 0.00118 & \begin{tabular}{|l|l|} 
CD74,GFAP \\
\end{tabular} & \\
\hline L-carnitine & & $\begin{array}{c}\text { chemical - endogenous } \\
\text { mammalian }\end{array}$ & & & & 0.00118 & GFAP,NPPA & $8(3)$ \\
\hline ESR1 & 2.206 & $\begin{array}{l}\text { ligand-dependent } \\
\text { nuclear receptor }\end{array}$ & Inhibited & -2.012 & & 0.00121 & CD74,CTSS,ERBB4,GFAP,IFITM3,IGF1, ligp1,IRF1,KCNH3,LGALS3BP, TAPBP & $12(2)$ \\
\hline DDX58 & -0.154 & enzyme & & & & 0.00121 & CCL5,IRF1,IRF8 & $11(3)$ \\
\hline SPI1 & 2.598 & transcription regulator & Activated & 2.184 & & 0.00125 & CTSS,Cxc19,CYBB,IFITM3,LYZ & \\
\hline MAPK9 & -0.037 & kinase & & 1.091 & & 0.00125 & CCL5, ligp1,LGALS3BP,PARP14 & $25(6)$ \\
\hline enterotoxin B & & biologic drug & & & & 0.0013 & CCL5,CxCl9,SERPINA3 & \\
\hline prazosin & & chemical drug & & & & 0.0013 & GFAP,NPPA & \\
\hline AIRE & & transcription regulator & & & & 0.0014 & C4A/C4B,CCL5,PARP14 & \\
\hline RXRA & 0.631 & $\begin{array}{l}\text { ligand-dependent } \\
\text { nuclear receptor }\end{array}$ & & -0.277 & & 0.00145 & C1QA,CTSS,IGF1,LYZ,NPPA & $5(2)$ \\
\hline HOXA10 & & transcription regulator & & -1.964 & & 0.00148 & CYBB,HLA-DQA1,HLA-DQB1,LYZ & \\
\hline $\mathrm{CD} 3$ & & complex & & 0.928 & bias & 0.00156 & CCL5,CD74,HLA-DQB1,IGF1,IRF1,IRF8,RAC2 & $38(12)$ \\
\hline probucol & & chemical drug & & & & 0.00158 & CYBB,NPPA & \\
\hline NKX2-1 & & transcription regulator & & & & 0.0016 & CD74,HLA-A,LYZ,RAC2 & \\
\hline sodium chloride & & $\begin{array}{c}\text { chemical - endogenous } \\
\text { mammalian }\end{array}$ & & & & 0.0016 & CCL5,CYBB,NPPA & $16(5)$ \\
\hline NFYA & 0.162 & transcription regulator & & & & 0.00166 & HLA-DQB1,IGF1,IRF1 & \\
\hline
\end{tabular}




\begin{tabular}{|c|c|c|c|c|c|c|c|c|}
\hline NOS2 & & enzyme & & 1.387 & & 0.00166 & Cxc19,LGALS3BP,NPPA,SERPINA3 & \\
\hline CG & & complex & Activated & 2.213 & bias & 0.00167 & B2M,C4A/C4B,HLA-A,HLA-DQA1,IGF1,LGALS3BP & \\
\hline PPARA & -0.957 & $\begin{array}{l}\text { ligand-dependent } \\
\text { nuclear receptor }\end{array}$ & & -0.577 & & 0.00167 & C1QA,C1QB,CYBB,HLA-DQA1,IFITM3,NPPA & \\
\hline CCK & -0.93 & other & & & & 0.00173 & GFAP,PENK & \\
\hline lipoarabinomannan & & $\begin{array}{c}\text { chemical - endogenous } \\
\text { non-mammalian }\end{array}$ & & & & 0.00173 & HLA-DRB5,IRF1 & \\
\hline ilomastat & & chemical drug & & & & 0.00173 & CCL5,ERBB4 & \\
\hline LCN2 & 2.773 & transporter & & & & 0.00177 & CCL5,Cxc19,GFAP & $22(6)$ \\
\hline IL18 & -0.581 & cytokine & & -0.33 & bias & 0.0018 & CCL5,IRF1,NPPA,PENK & $31(13)$ \\
\hline $\mathrm{ZFHX3}$ & -0.416 & transcription regulator & & & & 0.00183 & HLA-A,IFITM3,TUBB2B & \\
\hline SB203580 & & chemical drug & & -1 & bias & 0.00184 & C4A/C4B,CCL5,GBP2,IRF1,NPPA,PENK & $30(17)$ \\
\hline HOXA5 & & transcription regulator & & & & 0.00188 & \begin{tabular}{|l|l|} 
IGF1,PTN \\
\end{tabular} & \\
\hline mifepristone & & chemical drug & & -1.342 & & 0.00188 & C1QB,CD74,CYBB,HLA-DQB1,PTN & $27(7)$ \\
\hline SAMSN1 & 0.001 & other & & & & 0.00189 & \begin{tabular}{|l|} 
Cxcl9,ligp1,IRF1 \\
\end{tabular} & \\
\hline SLC13A1 & & transporter & & & & 0.00195 & GBP2,IGF1,Igtp & \\
\hline IKBKE & 0.565 & kinase & & & & 0.00195 & CCL5,Cxcl9,HLA-A & $25(8)$ \\
\hline ZFP36 & 2.028 & transcription regulator & & & & 0.00201 & CTSS, CYBB,IRF1 & \\
\hline PPIF & -0.21 & enzyme & & & & 0.00201 & CCL5,Cxcl9,PTN & \\
\hline LEP & & growth factor & & 0.93 & & 0.00201 & CCL5,CYBB,GFAP,IGF1,IRF1,NPPA & $34(14)$ \\
\hline SLPI & & other & & & & 0.00204 & CCL5,CTSS & \\
\hline imatinib & & chemical drug & & -1.387 & & 0.00209 & Cxc19,CYBB,Ifi47,Igtp,IRF1 & $21(4)$ \\
\hline levodopa & & $\begin{array}{c}\text { chemical - endogenous } \\
\text { mammalian }\end{array}$ & & -0.964 & & 0.00213 & C1QA, C4A/C4B,GFAP,HLA-A,NPTX2,PENK,RBAK & \\
\hline daidzein & & chemical drug & & & & 0.0022 & GFAP,HLA-A,HLA-DQA1 & \\
\hline HRAS & -0.02 & enzyme & & & & 0.0022 & B2M,CCL5,CTSS,LYZ,NPPA,SERPINA3,TAP1 & $22(7)$ \\
\hline PDGF-AA & & complex & & & & 0.00221 & GFAP,IGF1 & \\
\hline $\mathrm{CDC73}$ & 0.388 & other & & & & 0.00221 & \begin{tabular}{|l|l|} 
IGF1,IRF1 \\
\end{tabular} & \\
\hline TICAM2 & & other & & & & 0.00221 & CCL5,IRF1 & $11(4)$ \\
\hline Saa3 & 2.556 & other & & & & 0.00221 & \begin{tabular}{|l|} 
CCL5,IGF1 \\
\end{tabular} & \\
\hline SPRY1 & 0.259 & other & & & & 0.00221 & FABP7,IGF1 & \\
\hline Fus & 0.315 & transcription regulator & & & & 0.00221 & HNRNPH1,KCNIP1 & \\
\hline bee venom & & $\begin{array}{l}\text { chemical - endogenous } \\
\text { non-mammalian }\end{array}$ & & & & 0.00233 & CCL5,CYBB,IRF1 & $27(10)$ \\
\hline NFATC2 & -0.024 & transcription regulator & & & & 0.00236 & CCL5,Cxcl9, ligp 1,IRF1 & $28(11)$ \\
\hline NFIX & 0.211 & transcription regulator & & & & 0.00238 & GFAP,SERPINA3 & \\
\hline wortmannin & & chemical drug & & -0.577 & & 0.00244 & CCL5,IGF1,IRF1,IRF8 & $26(12)$ \\
\hline vancomycin & & biologic drug & & -0.243 & & 0.00248 & C1QA,C1QB,C4A/C4B,SEZ6L & \\
\hline ZNF503 & -1.487 & other & & & & 0.00256 & \begin{tabular}{|l|} 
GFAP,PENK \\
\end{tabular} & \\
\hline dimethyl itaconate & & chemical reagent & & & & 0.00256 & IFITM3,IRF1 & \\
\hline CCR1 & & $\begin{array}{l}\text { G-protein coupled } \\
\text { receptor }\end{array}$ & & & & 0.00256 & CCL5,CTSS & \\
\hline IL1 & & group & & 1.807 & bias & 0.00259 & CCL5,GFAP,IGF1,IRF1,LYZ & $32(13)$ \\
\hline N-nitro-L-arginine methyl ester & & chemical drug & & & & 0.00261 & CYBB,GFAP,NPPA & $22(6)$ \\
\hline $\mathrm{gm} 26504$ & & other & & & & 0.00268 & IGF1 & \\
\hline CAMTA2 & 0.218 & transcription regulator & & & & 0.00268 & NPPA & \\
\hline CAMTA1 & 0.378 & other & & & & 0.00268 & NPPA & \\
\hline SNORD21 & & other & & & & 0.00268 & HLA-A & \\
\hline CYTL1 & & cytokine & & & & 0.00268 & IGF1 & \\
\hline TPH2 & & enzyme & & & & 0.00268 & IGF1 & \\
\hline ENDOG & -0.026 & enzyme & & & & 0.00268 & NPPA & \\
\hline SGTA & -0.03 & other & & & & 0.00268 & IGF1 & \\
\hline GPLD1 & 0.739 & enzyme & & & & 0.00268 & LGALS3BP & \\
\hline CORIN & & peptidase & & & & 0.00268 & NPPA & \\
\hline PRPF4 & 0.002 & other & & & & 0.00268 & CCL5 & \\
\hline Raet1d/Raet1e & & other & & & & 0.00268 & HLA-A & \\
\hline GAN & 0.524 & other & & & & 0.00268 & GFAP & \\
\hline PTS & 0.403 & enzyme & & & & 0.00268 & IGF1 & \\
\hline TONSL & -0.132 & other & & & & 0.00268 & CCL5 & \\
\hline ZNF260 & 0.245 & transcription regulator & & & & 0.00268 & NPPA & \\
\hline Adora3/LOC100911796 & & $\begin{array}{l}\text { G-protein coupled } \\
\text { receptor }\end{array}$ & & & & 0.00268 & NPPA & \\
\hline HSP-990 & & chemical drug & & & & 0.00268 & HLA-A & \\
\hline anthraquinone & & chemical toxicant & & & & 0.00268 & $\mathrm{CCL} 5$ & \\
\hline
\end{tabular}




\begin{tabular}{|c|c|c|c|c|c|c|c|c|}
\hline SCH 39370 & & $\begin{array}{c}\text { chemical - protease } \\
\text { inhibitor }\end{array}$ & & & & 0.00268 & NPPA & \\
\hline 10-hydroxydecanoic acid & & $\begin{array}{c}\text { chemical - endogenous } \\
\text { non-mammalian }\end{array}$ & & & & 0.00268 & IRF1 & \\
\hline thiorphan & & $\begin{array}{c}\text { chemical - protease } \\
\text { inhibitor }\end{array}$ & & & & 0.00268 & NPPA & \\
\hline $\begin{array}{c}\text { deoxycorticosterone } \\
\text { acetate/potassium } \\
\text { chloride/sodium chloride }\end{array}$ & & chemical reagent & & & & 0.00274 & CCL5,CYBB & \\
\hline TBK1 & 0.522 & kinase & & & & 0.00291 & \begin{tabular}{|l|} 
CCL5,Cxcl9, ligp1 \\
\end{tabular} & $11(3)$ \\
\hline FTO & 0.048 & enzyme & & & & 0.00293 & IGF1,NPPA & \\
\hline BAK1 & 0.562 & other & & & & 0.00293 & CCL5,HLA-A & \\
\hline NKX2-3 & & transcription regulator & Inhibited & -2 & & 0.00293 & GBP2,PARP14,TAP1,UNC93B1 & \\
\hline RARA & 0.348 & $\begin{array}{l}\text { ligand-dependent } \\
\text { nuclear receptor }\end{array}$ & & -0.108 & & 0.00295 & CTSS,IRF1,LGALS3BP,PENK,TAPBP & \\
\hline HAVCR1 & & other & & & & 0.00307 & B2M,IRF1,TAP1 & \\
\hline STAT4 & & transcription regulator & & 1.981 & bias & 0.00308 & Cxc19,HLA-DQB1,IRF1,TUBB2B & \\
\hline CARD9 & & other & & & & 0.00313 & CCL5,Cxc19 & \\
\hline CXCL10 & 2.616 & cytokine & & & & 0.00313 & $\mathrm{CCL} 5, \mathrm{Cxc19}$ & \\
\hline PTX3 & & other & & & & 0.00313 & \begin{tabular}{|l|l|} 
CCL5,IGF1 \\
\end{tabular} & \\
\hline colistin & & biologic drug & & & & 0.00315 & C1QA,C1QB,SEZ6L & \\
\hline INSIG1 & -0.009 & other & & & & 0.00315 & CCL5,HLA-DQA1,IRF8 & \\
\hline kanamycin A & & chemical drug & & & & 0.00331 & C1QA,C1QB,SEZ6L & \\
\hline TIRAP & -3.413 & other & & & & 0.00333 & \begin{tabular}{|l|l|} 
CCL5,IRF1 \\
\end{tabular} & $11(3)$ \\
\hline CFB & & peptidase & & & & 0.00333 & C4A/C4B,NPPA & \\
\hline mir-23 & & microRNA & & & & 0.00333 & IGF1,IRF1 & \\
\hline FAS & 1.333 & transmembrane receptor & & & & 0.00339 & CCL5,Cxc19,GBP2,HLA-DQB1,IRF1 & $28(12)$ \\
\hline NCF1 & 1.123 & enzyme & & & & 0.00354 & CCL5,IGF1 & $22(7)$ \\
\hline CGAS & 4.151 & enzyme & & & & 0.00354 & $\mathrm{CCL} 5, \mathrm{Cxc19}$ & \\
\hline KDM6B & 0.264 & enzyme & & & & 0.00354 & CCL5,Igtp & \\
\hline C1QA & 1.876 & other & & & & 0.00354 & C4A/C4B,SERPINA3 & \\
\hline BECN1 & -0.037 & other & & & & 0.00354 & CCL5,NPPA & \\
\hline NFIC & 0.108 & transcription regulator & & & & 0.00354 & FABP7,GFAP & \\
\hline TAB1 & -0.236 & enzyme & & & & 0.00354 & $\mathrm{CCL} 5, \mathrm{GBP} 2$ & $23(10)$ \\
\hline Rxr & & group & & & & 0.00357 & C1QA,CTSS,IGF1 & \\
\hline SYK & 1.298 & kinase & & & & 0.00366 & \begin{tabular}{|l} 
CCL5,Cxc19,IRF1 \\
\end{tabular} & $27(10)$ \\
\hline INSR & -0.193 & kinase & & & & 0.00369 & C1QA,IGF1,ligp1,LYZ,MPEG1,NPPA & \\
\hline cholesterol & & $\begin{array}{c}\text { chemical - endogenous } \\
\text { mammalian }\end{array}$ & & 1.982 & & 0.00371 & CYBB,HLA-DRB5,LYZ,MPEG1 & \\
\hline metronidazole & & chemical drug & & & & 0.00375 & C1QA,C1QB,SEZ6L & \\
\hline TNFSF14 & & cytokine & & & & 0.00376 & CCL5,Cxc19 & $20(4)$ \\
\hline SUMO1 & 0.231 & enzyme & & & & 0.00376 & \begin{tabular}{|l|} 
NPPA,TAP1 \\
\end{tabular} & \\
\hline PBX1 & 0.225 & transcription regulator & & & & 0.00376 & CYBB,FABP7 & \\
\hline TIr & & group & & & & 0.00384 & CCL5,HLA-A,IRF1 & $29(11)$ \\
\hline TERC & & other & & & & 0.00398 & \begin{tabular}{|l|}
$\mathrm{CCL} 5, \mathrm{GFAP}$ \\
\end{tabular} & \\
\hline PTP4A1 & -0.523 & phosphatase & & & & 0.00403 & CCL5,HNRNPH1, RBAK & \\
\hline PRDM16 & 0.568 & transcription regulator & & & & 0.0042 & CCL5,Cxcl9 & \\
\hline CYBB & 4.896 & enzyme & & & & 0.0042 & CCL5,CYBB & \\
\hline HSPG2 & 0.901 & enzyme & & & & 0.0042 & \begin{tabular}{|l|} 
CTSS,IGF1 \\
\end{tabular} & \\
\hline KIrk1 & & \begin{tabular}{|l} 
transmembrane receptor \\
\end{tabular} & & & & 0.0042 & CCL5,IRF8 & \\
\hline vinblastine & & chemical drug & & & & 0.0042 & CCL5,HLA-A & $22(7)$ \\
\hline Alpha catenin & & group & & & & 0.00422 & IGF1,IRF1,LYZ & \\
\hline indomethacin & & chemical drug & & 1.91 & & 0.0043 & C4A/C4B,IFITM3,IGF1,NPPA & $18(5)$ \\
\hline mir-130 & & microRNA & & & & 0.00444 & CCL5,IRF8 & \\
\hline UBE2I & 0.78 & enzyme & & & & 0.00444 & \begin{tabular}{|l|} 
IRF1,TAP1 \\
\end{tabular} & \\
\hline RAD21 & 0.185 & transcription regulator & & & & 0.00444 & HLA-DQA1,HLA-DQB1 & \\
\hline FOS & -0.184 & transcription regulator & & -0.581 & & 0.00461 & CCL5,Cxc19,LGALS3BP,NPPA,NPTX2,PENK & $23(8)$ \\
\hline tetradecanoylphorbol acetate & & chemical drug & & 0.669 & & 0.00462 & CCL5,CYBB, ERBB4,IGF1,IRF1,IRF8,LYZ,NPPA,SERPINA3 & $33(13)$ \\
\hline PRKCA & 0.17 & kinase & & & & 0.00462 & CYBB,GFAP,NPPA & $22(6)$ \\
\hline SUMO3 & 0.464 & other & & & & 0.00468 & \begin{tabular}{|l|} 
Bst2,TAP1 \\
\end{tabular} & \\
\hline IGFBP3 & -0.084 & other & & & & 0.00468 & \begin{tabular}{|l|} 
CCL5,IGF1 \\
\end{tabular} & $8(3)$ \\
\hline steroid & & $\begin{array}{c}\text { chemical - endogenous } \\
\text { mammalian }\end{array}$ & & & & 0.00468 & CCL5,IGF1 & $5(2)$ \\
\hline genistein & & chemical drug & & -1.3 & & 0.00468 & CCL5,CD74,HLA-A,HLA-DQA1,IGF1 & $32(9)$ \\
\hline
\end{tabular}




\begin{tabular}{|c|c|c|c|c|c|c|}
\hline thioacetamide & & chemical toxicant & & 0.00481 & C4A/C4B,GFAP,IGF1,LGALS3BP & \\
\hline bortezomib & & chemical drug & 0.849 & 0.00488 & CCL5,Cxc19,IGF1,SERPINA3 & $29(9)$ \\
\hline SERPINE2 & -0.202 & other & & 0.00492 & CCL5,Cxc19 & \\
\hline SMARCA5 & 0.368 & transcription regulator & & 0.00505 & B2M,HLA-A,UNC93B1 & \\
\hline PLAUR & & transmembrane receptor & & 0.00517 & CCL5,CYBB & $19(5)$ \\
\hline $\begin{array}{c}\text { 15-keto-13,14- } \\
\text { dihydroprostaglandin E2 }\end{array}$ & & $\begin{array}{c}\text { chemical - endogenous } \\
\text { mammalian }\end{array}$ & & 0.00536 & GFAP & \\
\hline MEX3C & 0.34 & enzyme & & 0.00536 & IGF1 & \\
\hline ARL16 & -0.099 & other & & 0.00536 & $\mathrm{CCL} 5$ & \\
\hline ADGRG1 & -0.16 & $\begin{array}{l}\text { G-protein coupled } \\
\text { receptor }\end{array}$ & & 0.00536 & IGF1 & \\
\hline ADH1C & -0.975 & enzyme & & 0.00536 & NPPA & \\
\hline Raet1a & & other & & 0.00536 & HLA-A & \\
\hline CBP-ICSBP-IRF-1-PU.1 & & complex & & 0.00536 & CYBB & \\
\hline HLA-B27 & & complex & & 0.00536 & \begin{tabular}{|l|} 
HLA-DQA1 \\
\end{tabular} & \\
\hline SEMA5A & 0.079 & transmembrane receptor & & 0.00536 & GFAP & \\
\hline SPR & 0.007 & enzyme & & 0.00536 & \begin{tabular}{|l|} 
IGF1 \\
\end{tabular} & \\
\hline Raet1b & & other & & 0.00536 & HLA-A & \\
\hline AP1M1 & 0.228 & transporter & & 0.00536 & HLA-A & \\
\hline OAS1 & & enzyme & & 0.00536 & IRF1 & \\
\hline CELA1 & -0.838 & peptidase & & 0.00536 & HLA-A & \\
\hline RIMS2 & 0.291 & other & & 0.00536 & IGF1 & \\
\hline IGFALS & & other & & 0.00536 & IGF1 & \\
\hline $\begin{array}{c}\text { miR-1195 (miRNAs w/seed } \\
\text { GAGUUCG) }\end{array}$ & & mature microRNA & & 0.00536 & IGF1 & \\
\hline $\mathrm{H} 60 \mathrm{a}$ & & other & & 0.00536 & HLA-A & \\
\hline apilimod & & chemical drug & & 0.00536 & RAC2 & \\
\hline LTK & 2.91 & kinase & & 0.00536 & NPPA & \\
\hline DCTN4 & 0.202 & other & & 0.00536 & CCL5 & \\
\hline $\begin{array}{l}\text { poly-L-glutamic acid-peptoid } 1 \\
\text { conjugate QM56 }\end{array}$ & & chemical reagent & & 0.00536 & CCL5 & \\
\hline NAGLU & 0.77 & enzyme & & 0.00536 & LYZ & \\
\hline SLC25A12 & 0.033 & transporter & & 0.00536 & CCL5 & \\
\hline TNNT2 & -1.685 & other & & 0.00536 & NPPA & \\
\hline AGXT & & enzyme & & 0.00536 & NPPA & \\
\hline ST8SIA2 & 1.466 & enzyme & & 0.00536 & GFAP & \\
\hline $\mathrm{CDO1}$ & 0.159 & enzyme & & 0.00536 & IGF1 & \\
\hline GBP2 & 5.235 & enzyme & & 0.00536 & HLA-A & \\
\hline Kcnip2 & & ion channel & & 0.00536 & KCNIP1 & \\
\hline $\begin{array}{l}\text { 1,5-bis-(dihexyl-N-nitrosoamino)- } \\
\text { 2,4-dinitrobenzene }\end{array}$ & & chemical reagent & & 0.00536 & CYBB & \\
\hline GTPL714 & & chemical reagent & & 0.00536 & NPPA & \\
\hline RPS19 & 0.362 & other & & 0.00536 & CD74 & \\
\hline selonsertib & & chemical drug & & 0.00536 & NPPA & \\
\hline paraoxon & & chemical toxicant & & 0.00536 & GFAP & \\
\hline fenfluramine & & chemical drug & & 0.00536 & PENK & \\
\hline mavacamten & & chemical drug & & 0.00536 & NPPA & \\
\hline fascaplysin & & chemical drug & & 0.00536 & PTN & \\
\hline lanreotide & & biologic drug & & 0.00536 & IGF1 & \\
\hline 5 -aminovaleric acid & & $\begin{array}{c}\text { chemical - endogenous } \\
\text { mammalian }\end{array}$ & & 0.00536 & GFAP & \\
\hline fluorocitric acid & & chemical reagent & & 0.00536 & GFAP & \\
\hline barium & & chemical reagent & & 0.00536 & \begin{tabular}{|l|} 
PENK \\
\end{tabular} & \\
\hline NONO & 0.256 & transcription regulator & & 0.00538 & CCL5,LGALS3BP,PARP14 & \\
\hline memantine & & chemical drug & & 0.00543 & GFAP,TAP1 & \\
\hline DRD2 & & $\begin{array}{l}\text { G-protein coupled } \\
\text { receptor }\end{array}$ & & 0.00569 & IGF1,PENK & \\
\hline IL17F & & cytokine & & 0.00569 & \begin{tabular}{|l|} 
Cxc19,IGF1 \\
\end{tabular} & $22(6)$ \\
\hline CGS 21680 & & chemical reagent & & 0.00569 & CCL5,NPPA & $11(3)$ \\
\hline pentoxifylline & & chemical drug & & 0.00569 & CCL5,CYBB & \\
\hline ribavirin & & chemical drug & & 0.00569 & Cxc19,IRF1 & $20(4)$ \\
\hline camptothecin & & chemical drug & & 0.00573 & GBP2, HLA-A,HLA-DQA1,HLA-DQB1,IRF1, TAP1 & $26(5)$ \\
\hline semaxinib & & chemical drug & & 0.00584 & $\mathrm{C} 1 \mathrm{QA}, \mathrm{C} 1 \mathrm{QB}, \mathrm{Cxc} 19$ & $5(2)$ \\
\hline NOTCH1 & 0.099 & transcription regulator & -1 & 0.00589 & FABP7,GFAP,IRF1,IRF8 & \\
\hline
\end{tabular}




\begin{tabular}{|c|c|c|c|c|c|c|c|c|}
\hline JAK & & group & & & & 0.00595 & IFITM3,IGF1 & \\
\hline USP22 & 0.459 & peptidase & & & & 0.00595 & CCL5,CYBB & \\
\hline pristane & & chemical toxicant & & & & 0.00595 & \begin{tabular}{|l|} 
CCL5,IRF8 \\
\end{tabular} & \\
\hline ATF3 & -0.157 & transcription regulator & & & & 0.00596 & CCL5,GBP2,PENK & \\
\hline IL22 & & cytokine & & & & 0.00621 & CCL5,CXC19,SERPINA3 & \\
\hline DPP4 & -1.215 & peptidase & & & & 0.00623 & CCL5,Cxc19 & \\
\hline FLT3 & 0.591 & kinase & & & & 0.00651 & \begin{tabular}{|l|} 
CYBB, LYZ \\
\end{tabular} & \\
\hline $\mathrm{HBB}$ & 2.726 & transporter & & & & 0.00651 & CCL5,Cxc19 & \\
\hline SOD1 & 0.103 & enzyme & & & & 0.0066 & B2M,C1QA, GFAP,IGF1 & \\
\hline Pka & & complex & & & & 0.00671 & IGF1,IRF1,PENK & \\
\hline sox11 & 0.733 & transcription regulator & & & & 0.00671 & CCL5,ERBB4,HLA-DRB5 & \\
\hline PRKACA & -0.138 & kinase & & & & 0.00679 & IGF1,PENK & \\
\hline temozolomide & & chemical drug & & & & 0.00679 & CCL5,Cxcl9 & \\
\hline fulvestrant & & chemical drug & & 1.869 & & 0.00685 & CCL5,CD74,IGF1,IRF1 & $21(6)$ \\
\hline AHR & 0.59 & $\begin{array}{l}\text { ligand-dependent } \\
\text { nuclear receptor }\end{array}$ & Activated & 2.19 & & 0.00704 & C1QA,C1QB,CCL5,Cxc19,IRF1 & \\
\hline SMAD1 & -0.628 & transcription regulator & & & & 0.00708 & \begin{tabular}{|l|} 
GFAP,IRF1 \\
\end{tabular} & $4(2)$ \\
\hline C3AR1 & 2.789 & $\begin{array}{l}\text { G-protein coupled } \\
\text { receptor }\end{array}$ & & & & 0.00708 & CCL5,IGF1 & \\
\hline $\mathrm{IFIH} 1$ & 0.687 & enzyme & & & & 0.00708 & \begin{tabular}{|l} 
Bst2,CCL5 \\
\end{tabular} & \\
\hline vincristine & & chemical drug & & & & 0.00708 & \begin{tabular}{|l|} 
CCL5,IGF1 \\
\end{tabular} & \\
\hline $\begin{array}{ll}\text { calcitriol } \\
\end{array}$ & & chemical drug & & & & 0.00709 & CCL5,Cxc19,CYBB,IGF1,NPPA,TAP1 & $28(13)$ \\
\hline quinolinic acid & & $\begin{array}{c}\text { chemical - endogenous } \\
\text { mammalian }\end{array}$ & & & & 0.00737 & GFAP,PENK & \\
\hline N-formyl-Met-Leu-Phe & & chemical reagent & & & & 0.00737 & CYBB, RAC2 & \\
\hline IL12 (family) & & group & & & & 0.00751 & CCL5,IRF1,IRF8 & \\
\hline NFKB2 & 1.414 & transcription regulator & & & & 0.00751 & CCL5,CTSS,HLA-DQA1 & \\
\hline resiquimod & & chemical drug & & & & 0.00755 & C4A/C4B,CCL5,Cxc19,IFITM3 & \\
\hline EBF1 & -0.765 & transcription regulator & & & & 0.00765 & CCL5,Cxcl9,IRF1 & \\
\hline PAF1 & 0.332 & other & & & & 0.00767 & CCL5,IFITM3 & \\
\hline halofuginone & & chemical drug & & & & 0.00779 & C4A/C4B,CTSS,LGALS3BP & \\
\hline estrogen & & chemical drug & & 0.255 & bias & 0.00782 & CYBB,IGF1,PENK,SERPINA3 & $29(11)$ \\
\hline IL15 & -1.64 & cytokine & & & & 0.00791 & CCL5,CD74,IRF1,NPTX2,RAC2 & \\
\hline KAT2B & 0.198 & transcription regulator & & & & 0.00798 & B2M,NPPA & \\
\hline istradefylline & & chemical drug & & & & 0.00803 & PENK & \\
\hline HS-243 & & chemical - kinase inhibitor & & & & 0.00803 & CCL5 & \\
\hline SXN101959 & & chemical reagent & & & & 0.00803 & IGF1 & \\
\hline drotrecogin alfa & & biologic drug & & & & 0.00803 & NPPA & \\
\hline Ga12/13 & & group & & & & 0.00803 & IGF1 & \\
\hline propentofylline & & chemical drug & & & & 0.00803 & GFAP & \\
\hline SLC4A5 & & transporter & & & & 0.00803 & NPPA & \\
\hline DPP10 & 0.481 & peptidase & & & & 0.00803 & KCNIP1 & \\
\hline LRRC8E & & ion channel & & & & 0.00803 & CCL5 & \\
\hline AGPAT1 & 0.102 & enzyme & & & & 0.00803 & IGF1 & \\
\hline HP1BP3 & 0.348 & other & & & & 0.00803 & IGF1 & \\
\hline $\mathrm{ABRA}$ & & other & & & & 0.00803 & NPPA & \\
\hline SRFBP1 & 0.915 & other & & & & 0.00803 & NPPA & \\
\hline PCDH17 & -0.209 & other & & & & 0.00803 & NPPA & \\
\hline Ap1 gamma & & group & & & & 0.00803 & HLA-A & \\
\hline GLO1 & 0.222 & enzyme & & & & 0.00803 & GFAP & \\
\hline GNLY & & other & & & & 0.00803 & CCL5 & \\
\hline INPP1 & -1.374 & phosphatase & & & & 0.00803 & NPPA & \\
\hline Tardbp & & transcription regulator & & & & 0.00803 & ERBB4 & \\
\hline ostarine & & chemical drug & & & & 0.00803 & IGF1 & \\
\hline ZNRD1ASP & & other & & & & 0.00803 & HLA-A & \\
\hline S100A1 & -0.082 & other & & & & 0.00803 & NPPA & \\
\hline IFNGR2 & 0.973 & transmembrane receptor & & & & 0.00803 & IRF1 & \\
\hline MBD5 & -0.14 & $\begin{array}{c}\text { other } \\
\end{array}$ & & & & 0.00803 & IGF1 & \\
\hline MYOZ2 & & other & & & & 0.00803 & NPPA & \\
\hline DDX4 & 1.602 & enzyme & & & & 0.00803 & IFITM3 & \\
\hline Lycium barbarum polysaccharides & & $\begin{array}{c}\begin{array}{c}\text { chemical - endogenous } \\
\text { non-mammalian }\end{array} \\
\end{array}$ & & & & 0.00803 & IGF1 & \\
\hline LIFR & -0.03 & transmembrane receptor & & & & 0.00803 & GFAP & \\
\hline
\end{tabular}




\begin{tabular}{|c|c|c|c|c|c|c|c|}
\hline HERC5 & & enzyme & & & 0.00803 & CCL5 & \\
\hline fomepizole & & chemical drug & & & 0.00803 & CCL5 & \\
\hline dexrazoxane & & chemical drug & & & 0.00803 & NPPA & \\
\hline chlorisondamine & & chemical drug & & & 0.00803 & PENK & \\
\hline CRTC1-MAML2 & & fusion gene/product & & & 0.00803 & IGF1 & \\
\hline nexinhib20 & & chemical reagent & & & 0.00803 & CYBB & \\
\hline (-)-gallocatechin gallate & & $\begin{array}{c}\text { chemical - protease } \\
\text { inhibitor }\end{array}$ & & & 0.00803 & IRF1 & \\
\hline 2',5'-dideoxyadenosine & & chemical reagent & & & 0.00803 & IGF1 & \\
\hline protamine zinc insulin & & biologic drug & & & 0.00803 & IGF1 & \\
\hline $\begin{array}{l}\text { 2R,4R-4-aminopyrolidine-2,4- } \\
\text { dicarboxylic acid }\end{array}$ & & chemical reagent & & & 0.00803 & GFAP & \\
\hline aflatoxin B1 & & $\begin{array}{c}\text { chemical - endogenous } \\
\text { non-mammalian }\end{array}$ & 1 & bias & 0.0082 & HLA-A,HLA-DQA1,HLA-DQB1,LGALS3BP & \\
\hline IFNA4 & & cytokine & & & 0.00829 & Bst2,GBP2 & \\
\hline JUNB & 1.227 & transcription regulator & & & 0.00837 & $\mathrm{C} 1 \mathrm{QB}, \mathrm{Cx} \mathrm{Cl} 9, \mathrm{PENK}$ & $9(3)$ \\
\hline cytokine & & group & & & 0.00837 & CCL5,GFAP,IRF1 & $22(7)$ \\
\hline carrageenan & & chemical drug & & & 0.00861 & CCL5,GFAP & $19(5)$ \\
\hline $\mathrm{DIO} 2$ & -0.134 & enzyme & & & 0.00882 & NPPA,PENK,ZNF804A & $6(3)$ \\
\hline IRGM & 3.578 & enzyme & & & 0.00893 & B2M,IFITM3 & \\
\hline glucocorticoid & & chemical drug & -1.982 & & 0.00908 & CCL5,CD74,IRF8,SERPINA3 & $9(2)$ \\
\hline budesonide & & chemical drug & 1.732 & & 0.00939 & B2M,CCL5,IFITM3,PTN & \\
\hline TSC2 & 0.123 & other & & & 0.00944 & GFAP, Ifi47,IFITM3 & \\
\hline $\mathrm{HDL}$ & & complex & & & 0.00959 & CCL5,GFAP & $11(3)$ \\
\hline APLN & 0.503 & other & & & 0.00959 & GFAP,NPPA & $17(6)$ \\
\hline $\mathrm{DCN}$ & 0.422 & other & & & 0.00959 & HLA-DQA1, HLA-DQB1 & \\
\hline TNFRSF1A & 0.505 & transmembrane receptor & & & 0.00976 & CCL5,GFAP,IGF1 & $12(4)$ \\
\hline galactosylceramide-alpha & & chemical reagent & & & 0.00993 & Cxcl9,IRF1 & $22(7)$ \\
\hline SMPD1 & 0.103 & enzyme & & & 0.00993 & CCL5,GFAP & $17(3)$ \\
\hline PTPN6 & 1.712 & phosphatase & & & 0.00993 & \begin{tabular}{|l|} 
CYBB,IRF1 \\
\end{tabular} & $24(8)$ \\
\hline nitrofurantoin & & chemical drug & & & 0.0101 & C4A/C4B,CTSS,IGF1 & \\
\hline SP600125 & & chemical drug & -0.152 & & 0.0101 & CCL5,GBP2,IGF1,NPPA & \\
\hline Insulin & & group & -1.732 & & 0.0102 & CCL5,CYBB,GFAP,IGF1,LGALS3BP,NPPA & \\
\hline progesterone & & $\begin{array}{l}\text { chemical - endogenous } \\
\text { mammalian }\end{array}$ & -1.091 & & 0.0102 & CCL5,GFAP,HLA-A,HLA-DQB1,IGF1, PCDH1 & \\
\hline MAP2K7 & 0.831 & kinase & & & 0.0103 & CCL5,NPPA & \\
\hline APOA1 & & transporter & & & 0.0103 & CYBB,GFAP & \\
\hline MAP2K4 & -0.014 & kinase & & & 0.0106 & CCL5,NPPA & \\
\hline Ro $25-6760$ & & chemical toxicant & & & 0.0107 & NPPA & \\
\hline sargramostim & & biologic drug & & & 0.0107 & CYBB & \\
\hline chitinase & & group & & & 0.0107 & \begin{tabular}{|l|l|l|l} 
CCL5 \\
\end{tabular} & \\
\hline CACTIN & 0.965 & other & & & 0.0107 & CCL5 & \\
\hline ROBO3 & 0.191 & transmembrane receptor & & & 0.0107 & IRF8 & \\
\hline C10orf71 & 1.224 & other & & & 0.0107 & NPPA & \\
\hline SLCO1C1 & -0.406 & transporter & & & 0.0107 & Nrgn & \\
\hline endothelin receptor & & group & & & 0.0107 & NPPA & \\
\hline ITPRID2 & -0.074 & other & & & 0.0107 & IGF1 & \\
\hline LRIG3 & -1.051 & other & & & 0.0107 & ERBB4 & \\
\hline ALX3 & -1.162 & transcription regulator & & & 0.0107 & GFAP & \\
\hline cathepsin $\mathrm{L}$ inhibitor & & chemical drug & & & 0.0107 & NPPA & \\
\hline TRIL & 0.429 & other & & & 0.0107 & CCL5 & \\
\hline GALNS & 0.755 & enzyme & & & 0.0107 & GFAP & \\
\hline KCND3 & 0.034 & ion channel & & & 0.0107 & KCNIP1 & \\
\hline PKIA & 0.361 & other & & & 0.0107 & IGF1 & \\
\hline UFD1 & 0.28 & peptidase & & & 0.0107 & CCL5 & \\
\hline RGL2 & 0.523 & other & & & 0.0107 & NPPA & \\
\hline mir-384 & & microRNA & & & 0.0107 & NPPA & \\
\hline K-604 & & chemical drug & & & 0.0107 & CCL5 & \\
\hline TAF12 & 0.229 & transcription regulator & & & 0.0107 & \begin{tabular}{|l|} 
IRF1 \\
\end{tabular} & \\
\hline NPLOC4 & 0.195 & other & & & 0.0107 & CCL5 & \\
\hline A4GALT & & enzyme & & & 0.0107 & IRF1 & \\
\hline CITED1 & -1.565 & transcription regulator & & & 0.0107 & IGF1 & \\
\hline CSTB & 1.037 & peptidase & & & 0.0107 & GFAP & \\
\hline SCIN & & other & & & 0.0107 & RAC2 & \\
\hline
\end{tabular}




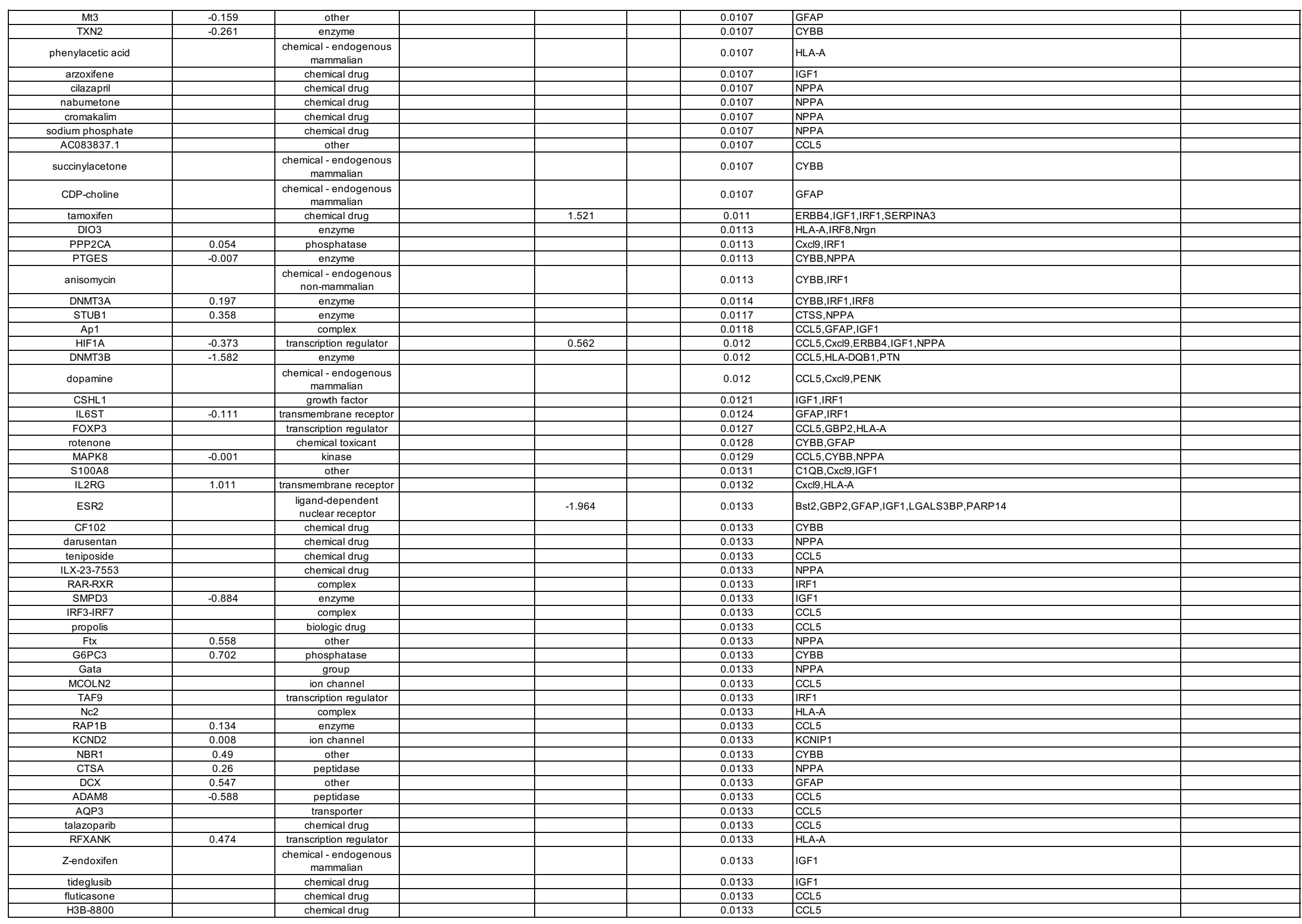




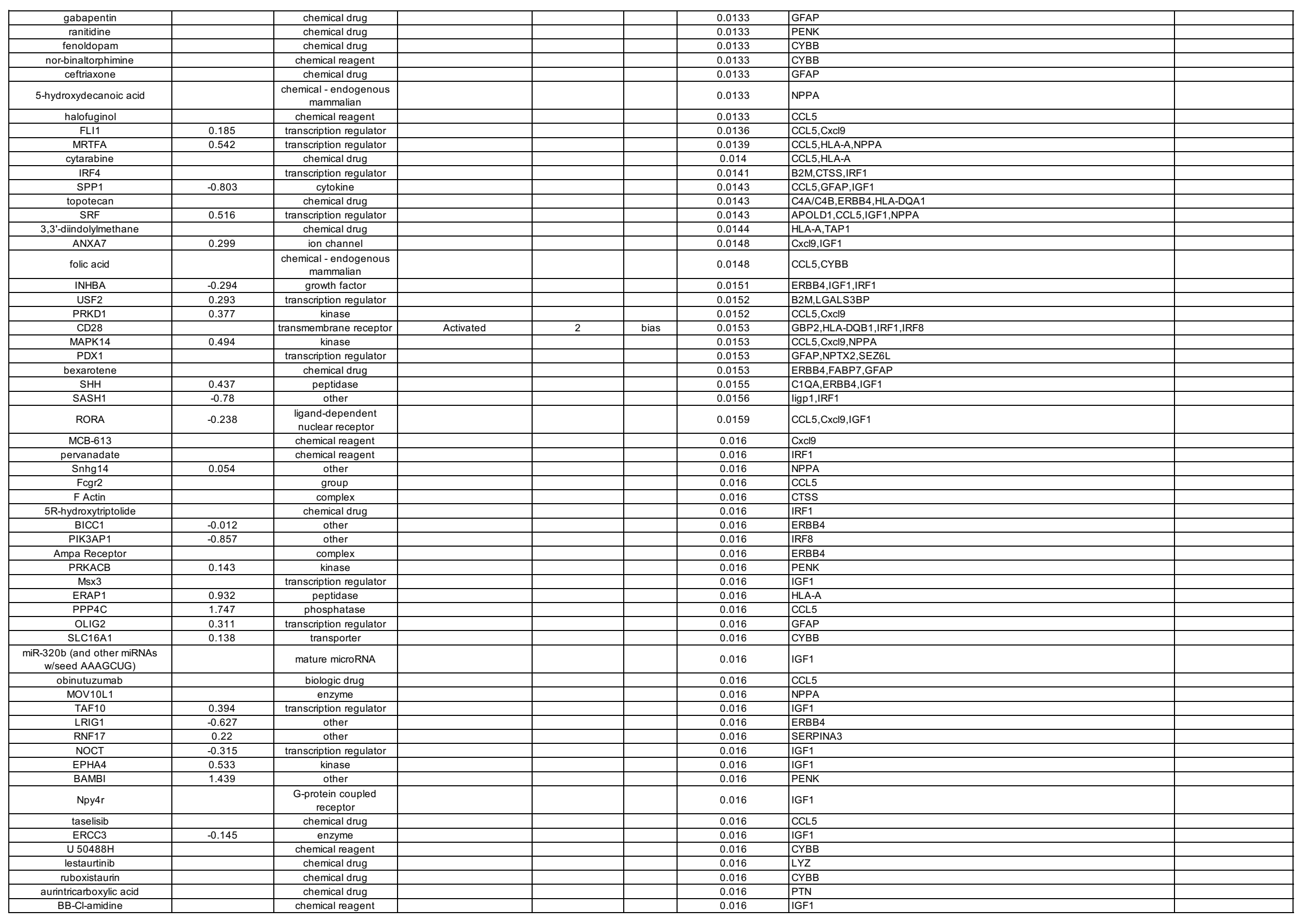




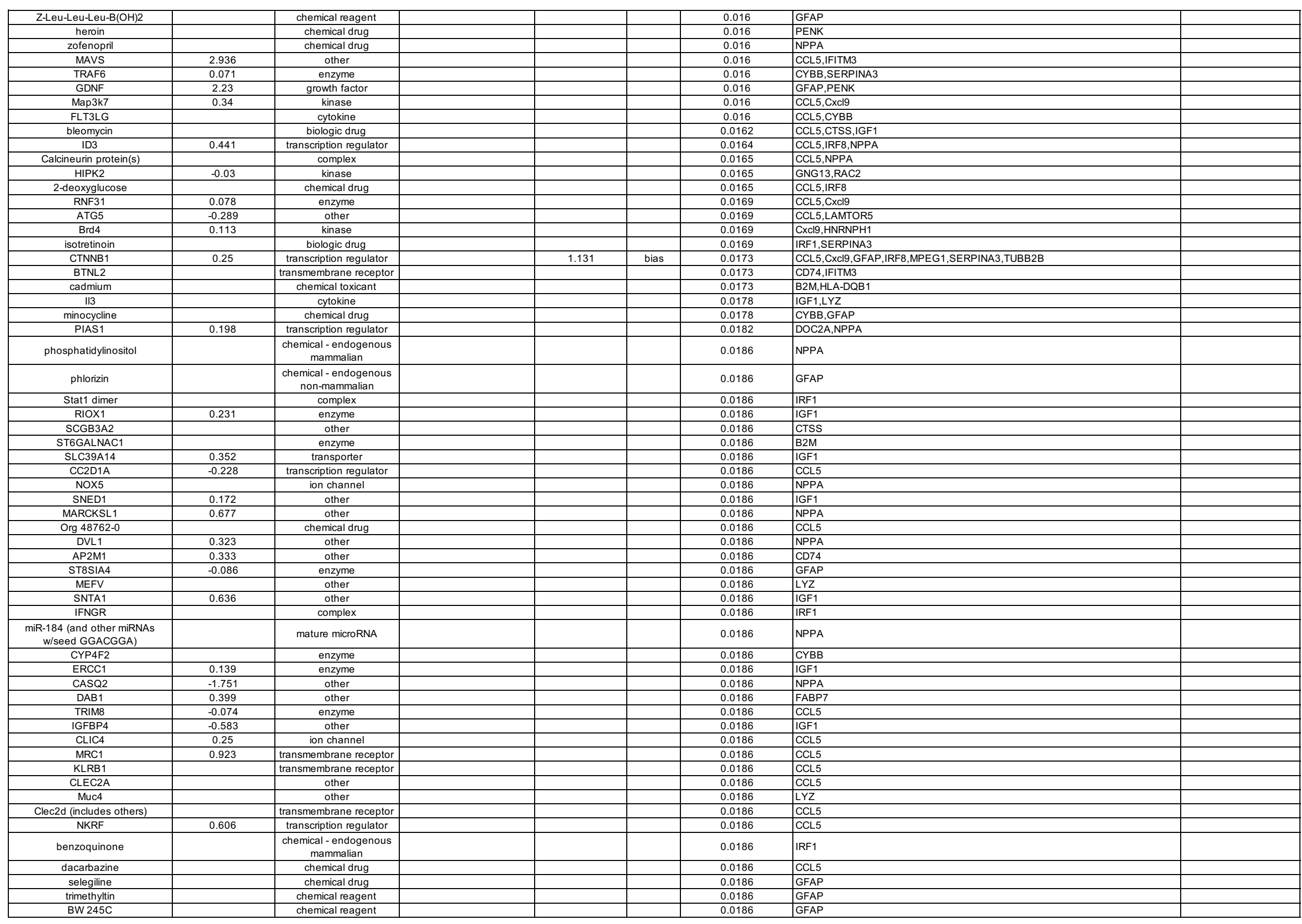




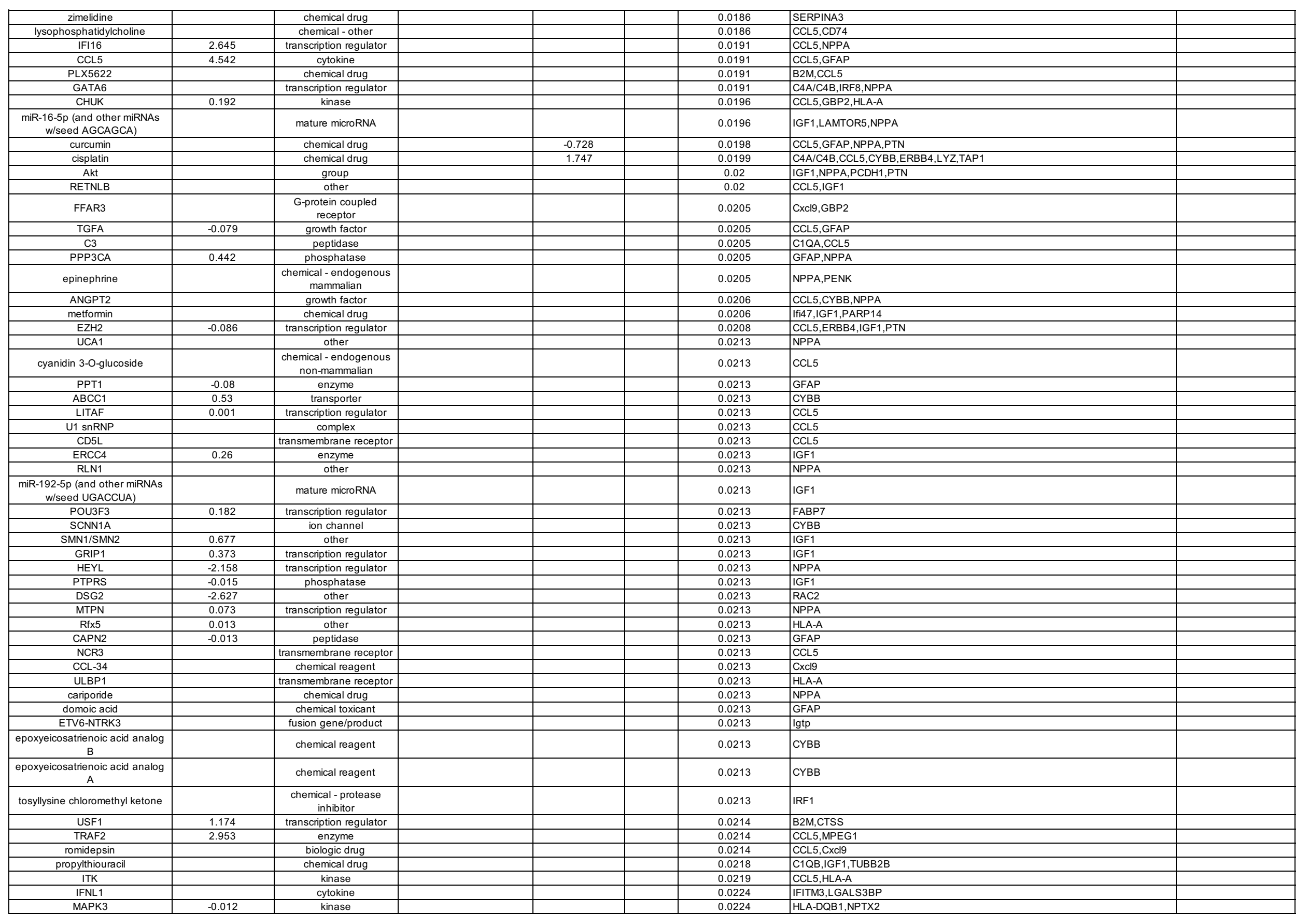




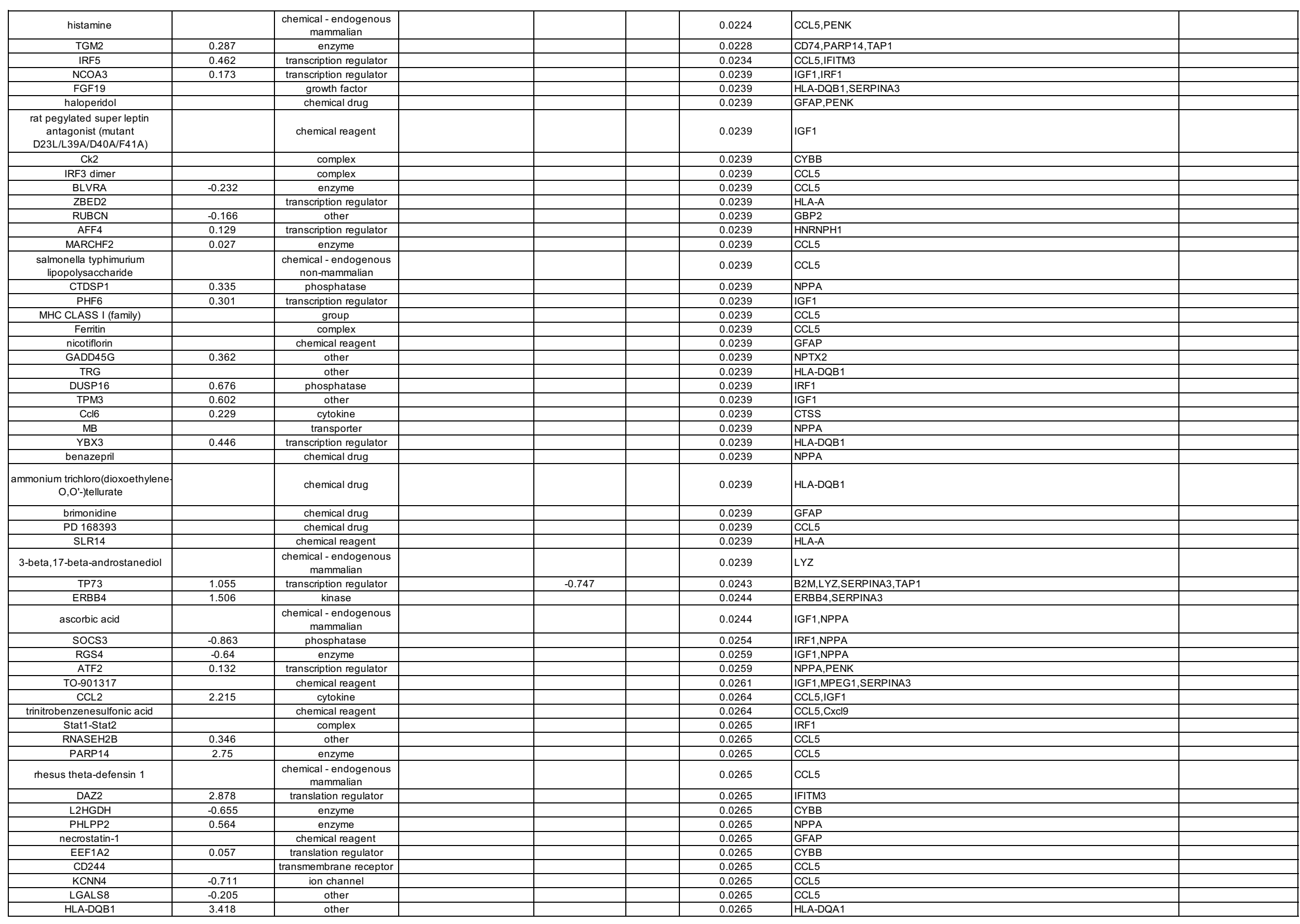




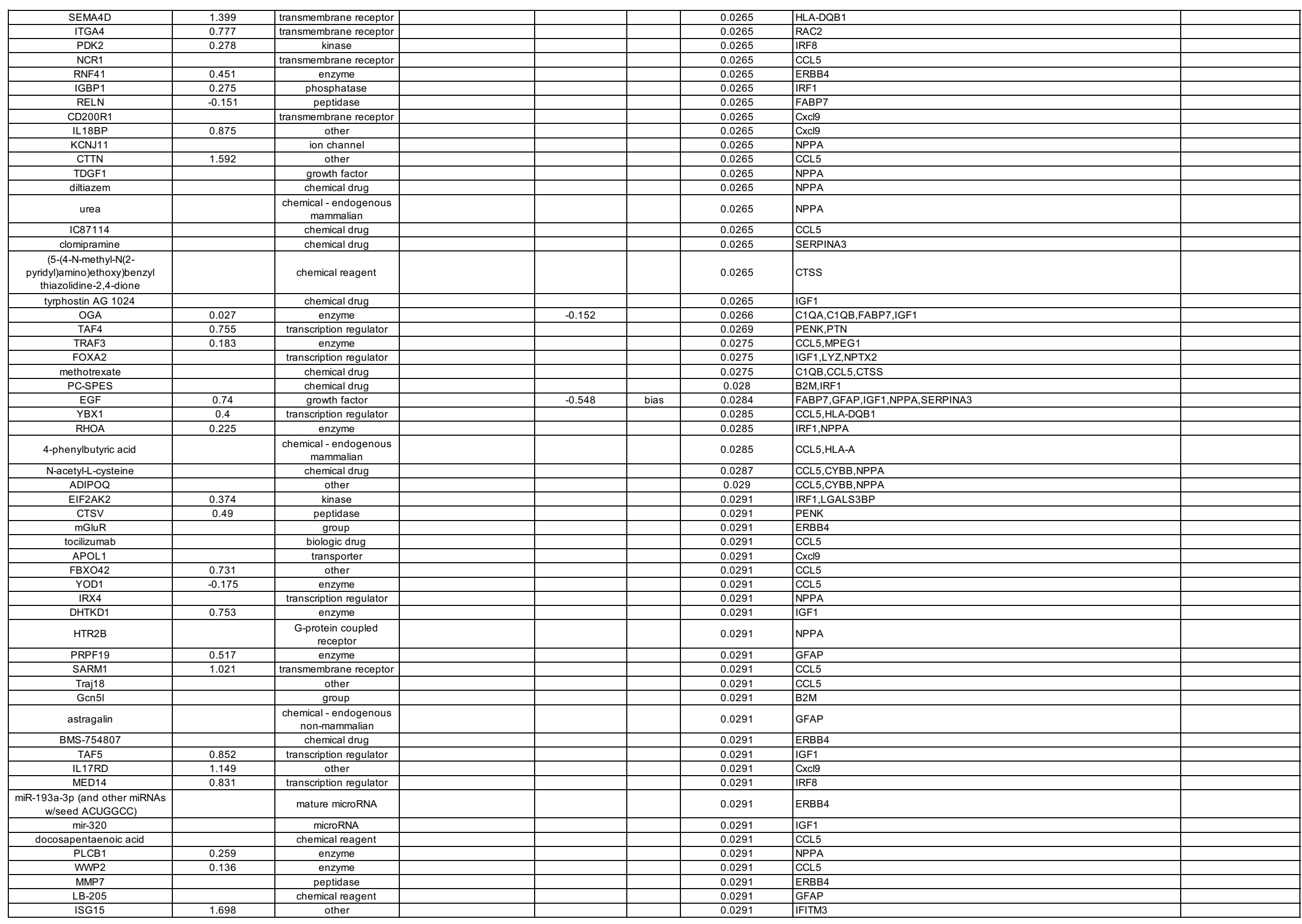




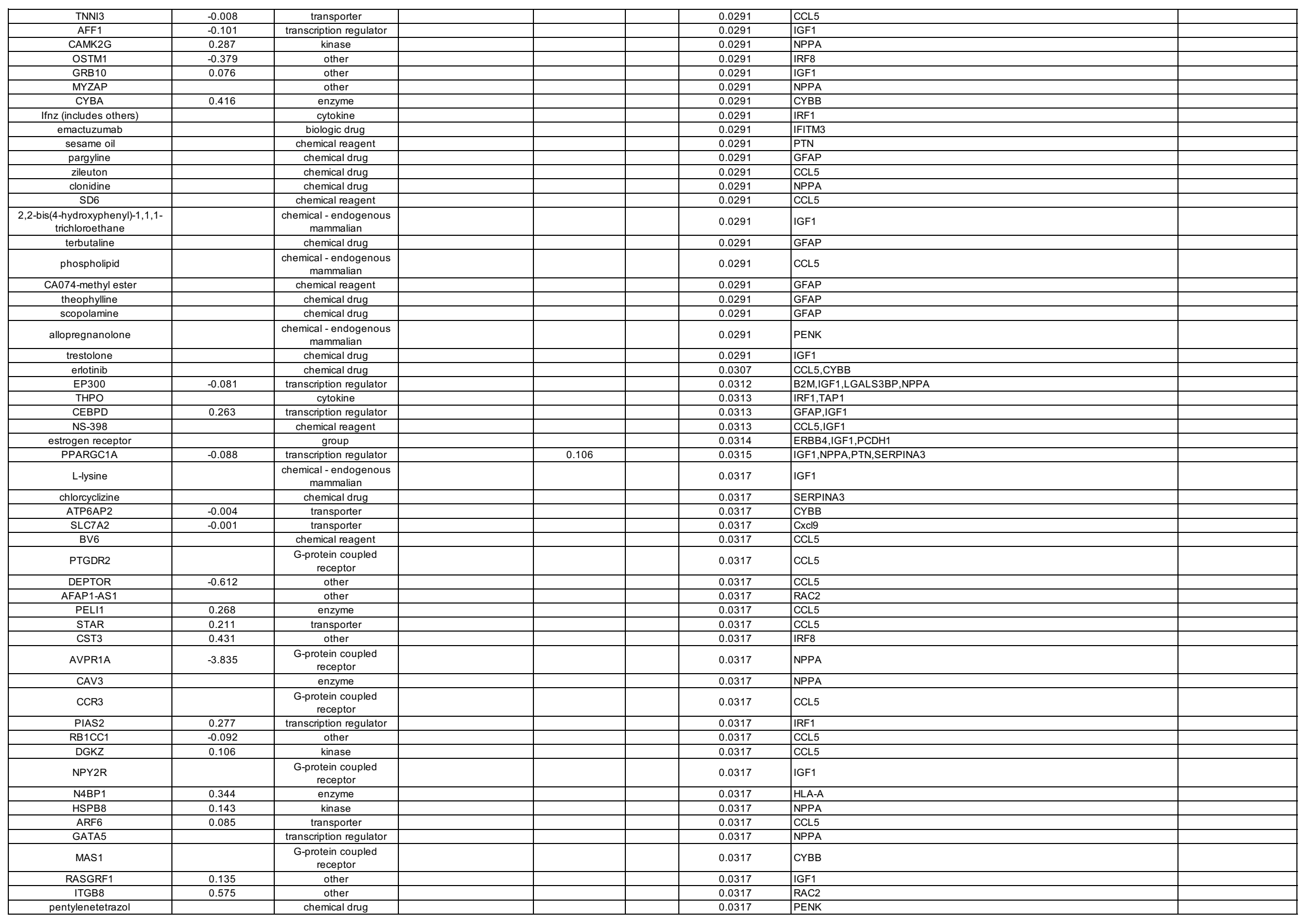




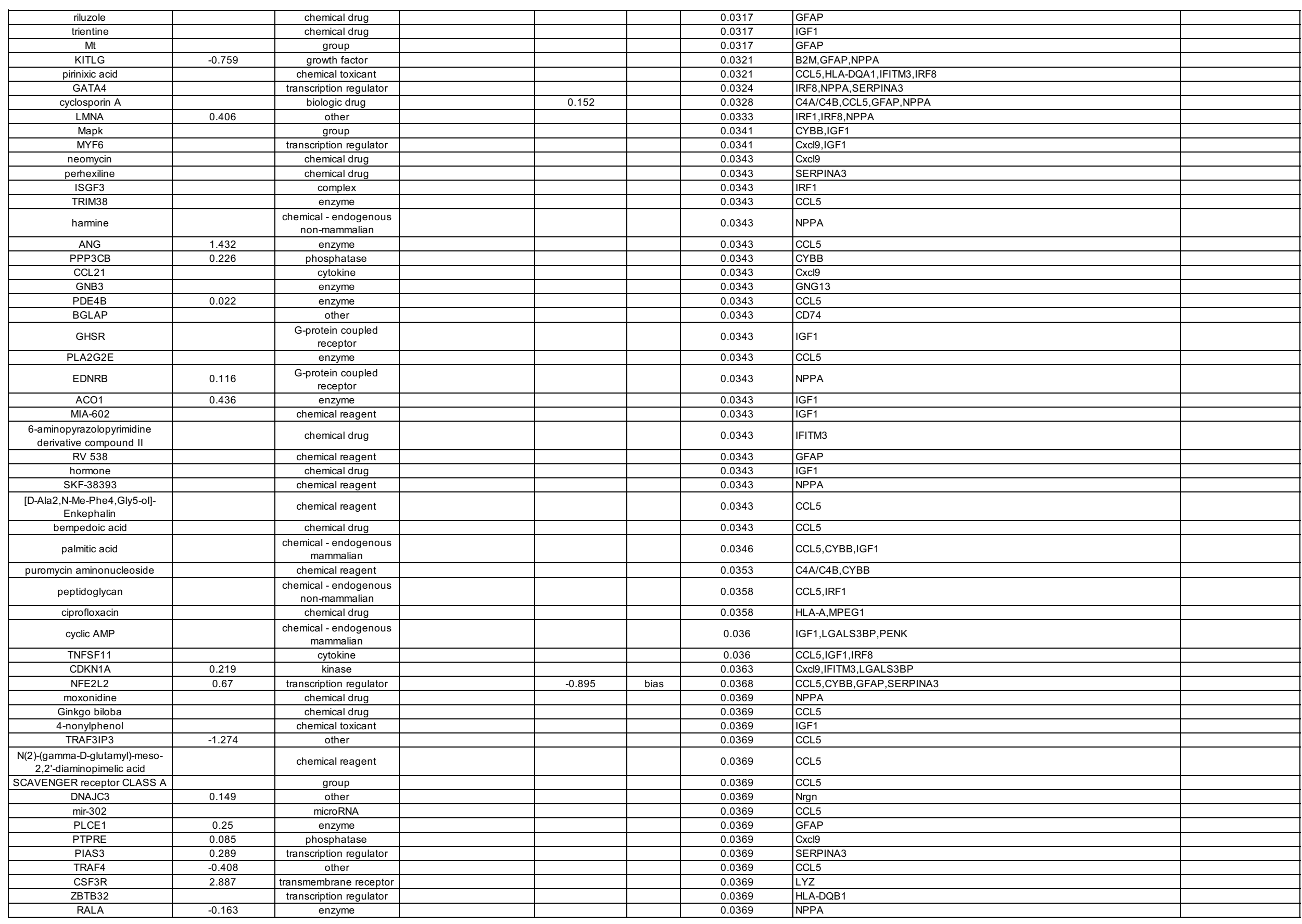




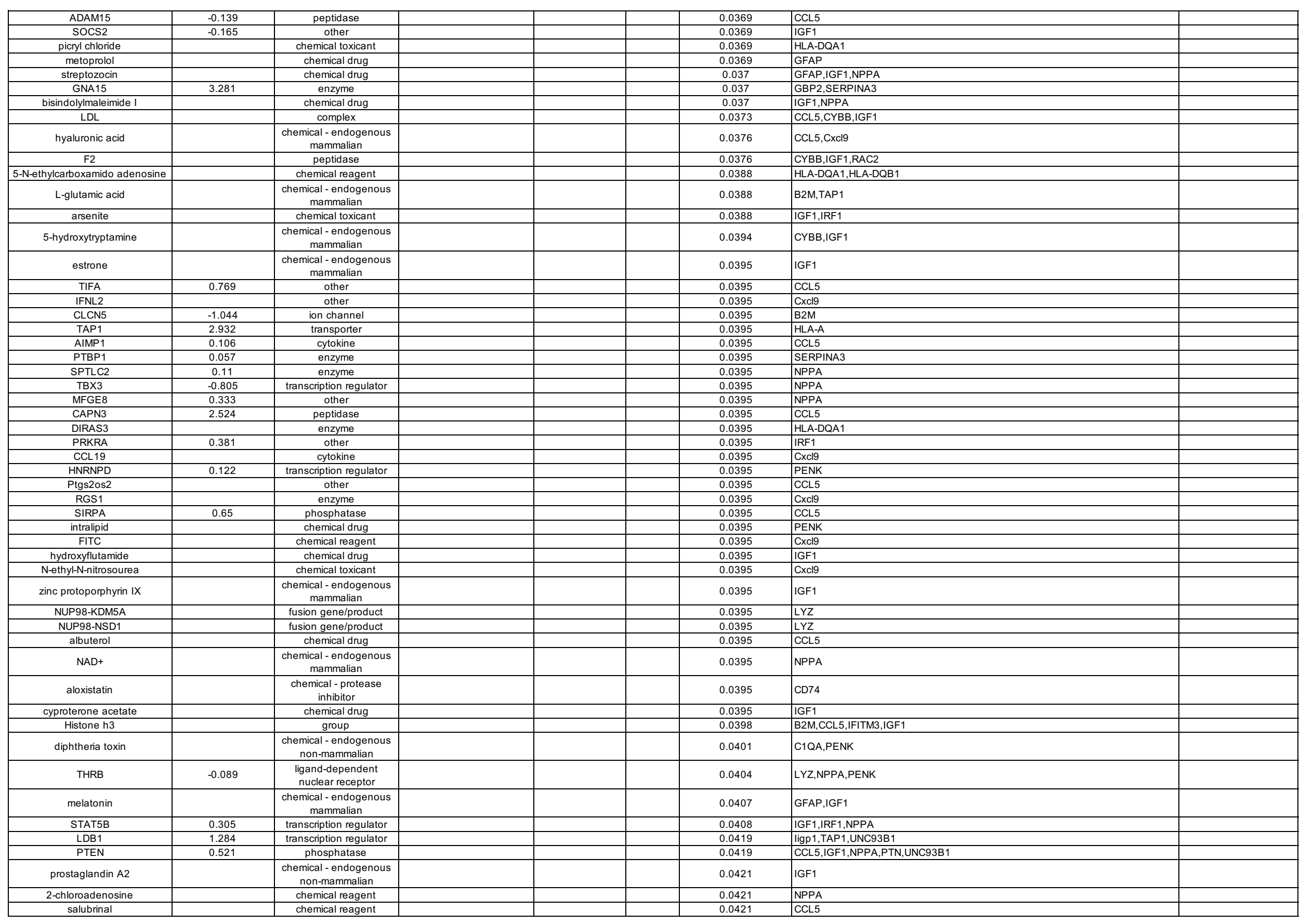




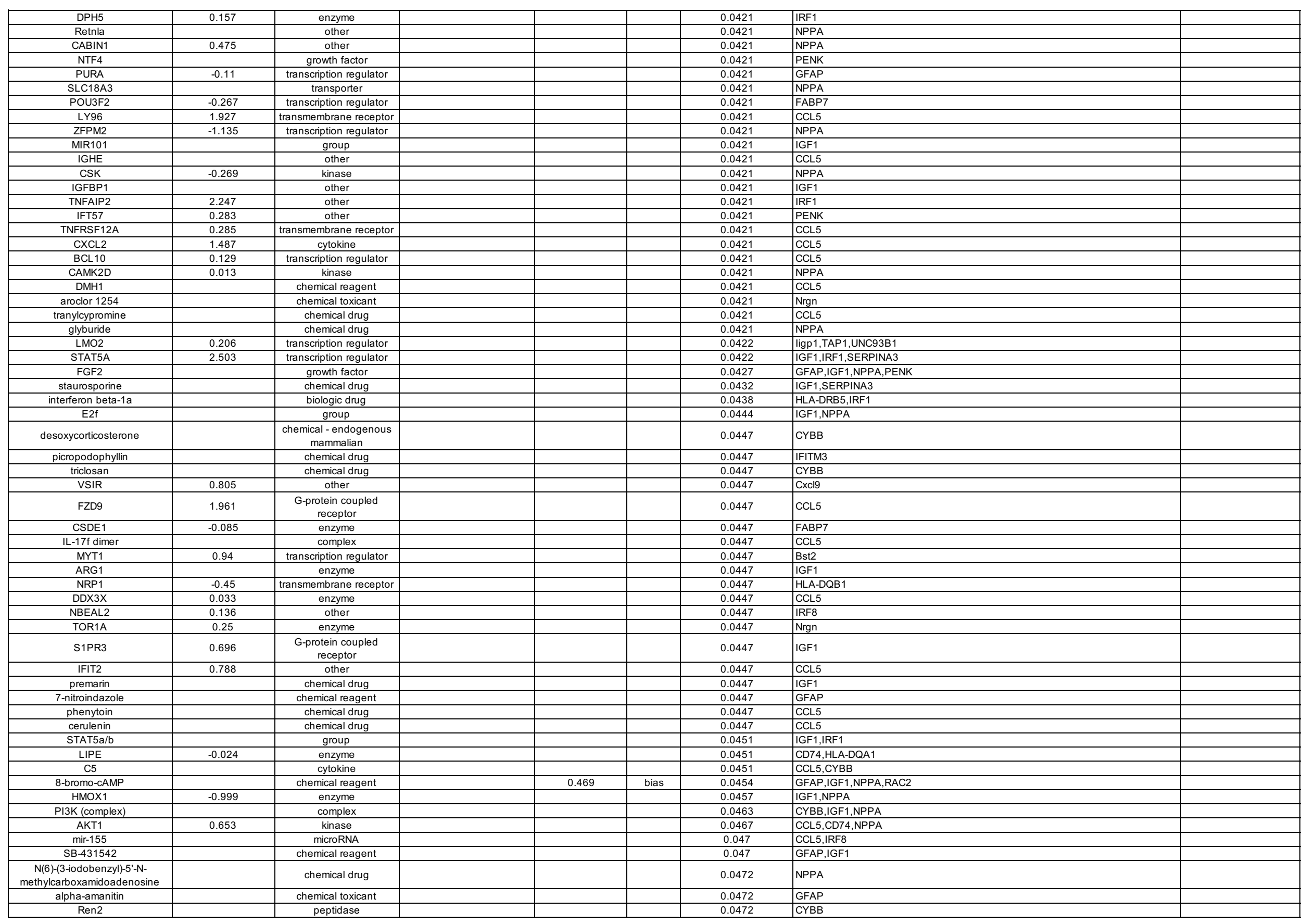




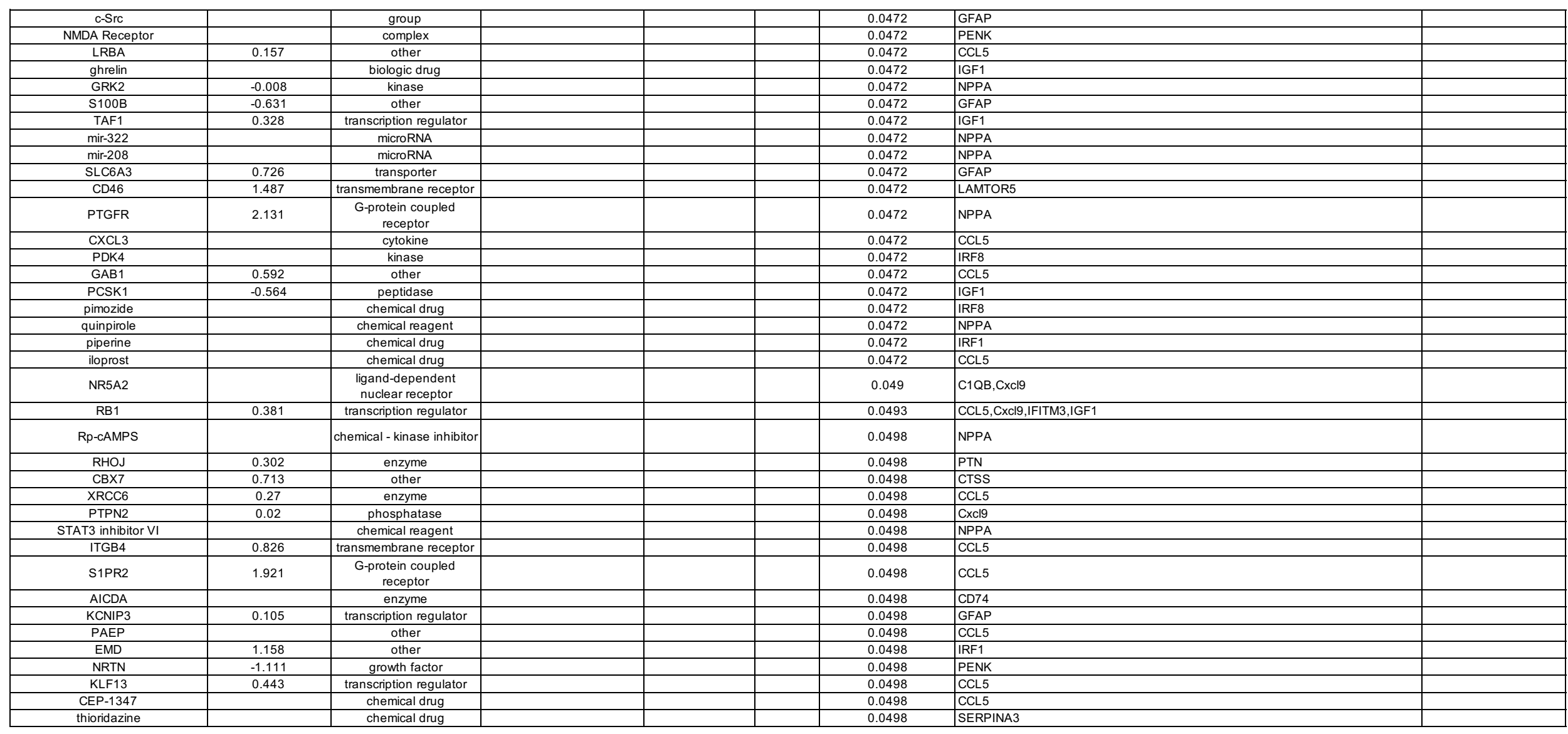

๑ 2000-2021 QIAGEN. All rights reserved. 